\title{
Modelling the fate of oxidisable organic contaminants in groundwater
}

\author{
D.A. Barry ${ }^{a, *}$, H. Prommer ${ }^{\text {a }}$, C.T. Miller ${ }^{\text {b }}$, P. Engesgaard ${ }^{\text {c }}$, A. Brun ${ }^{\text {d }}$, C. Zheng ${ }^{\text {e }}$ \\ "Institute for Infrastructure and Enxironment, Contaminated Land Assessment and Remediation Research Centre. \\ School of Engineering and Electronics, Crew Building. The King's Buildings. The Unitersity of Edinburgh, \\ Edinburgh $E H 93 \mathrm{JN}$. United Kingdom \\ 'Department of Enxironmental Sciences and Engineering. Center for the Adtanced Study of the Environment. University of North Carolina, \\ Chapel Hill, NC 27599-743I. USA \\ ' Entironment and Resources DTU. Technical Unitersity of Denmark, Bygningstortet, Building 115, DK-2800 Kongens Lyngby. Denmark \\ ${ }^{d}$ DHI Water and Enxironment. Monitoring and Information Technology Department, Gustav Wieds Vej 10. 8000 Arhus C. Denmark \\ 'Department of Geological Sciences, The Unitersity of Alabama. Tuscaloosa, AL 35487, USA
}

Received 30 December 2001; received in revised form 10 February 2002; accepted 13 February 2002

\begin{abstract}
Subsurface contamination by organic chemicals is a pervasive environmental problem, susceptible to remediation by natural or enhanced attenuation approaches or more highly engineered methods such as pump-and-treat, amongst others. Such remediation approaches, along with risk assessment or the pressing need to address complex scientific questions, have driven the development of integrated modelling tools that incorporate physical, biological and geochemical processes.

We provide a comprehensive modelling framework, including geochemical reactions and interphase mass transfer processes such as sorption/desorption, non-aqueous phase liquid dissolution and mineral precipitatation/dissolution, all of which can be in equilibrium or kinetically controlled. This framework is used to simulate microbially mediated transformation/degradation processes and the attendant microbial population growth and decay. Solution algorithms, particularly the split-operator (SO) approach, are described, along with a brief résumé of numerical solution methods. Some of the available numerical models are described, mainly those constructed using available flow, transport and geochemical reaction packages. The general modelling framework is illustrated by pertinent examples, showing the degradation of dissolved organics by microbial activity limited by the availability of nutrients or electron acceptors (i.e., changing redox states), as well as concomitant secondary reactions. Two field-scale modelling examples are discussed, the Vejen landfill (Denmark) and an example where metal contamination is remediated by redox changes wrought by injection of a dissolved organic compound. A summary is provided of current and likely future challenges to modelling of oxidisable organics in the subsurface.
\end{abstract}

(C) 2002 Elsevier Science Ltd. All rights reserved.

Keywords: BTEX; NAPL; Landfill; Kinetics; Equilibrium; Natural attenuation; Enhanced attenuation; Groundwater remediation; Redox; TEAP; Monod; Michaelis-Menten; Microbial degradation; PHREEQC-2; PHT3D; MT3DMS

\section{Introduction}

Organic liquids, such as solvents or petroleum products, are widespread, potentially carcinogenic contaminants of soil and groundwater [1,2]. Over the past 20

"Corresponding author. Tel.: +44-131-650-7204: fax: +44-131-6507276.

E-mail addresses: d.a.barry@a ed.ac.uk (D.A. Barry), henning.prommer@csiro.au (H. Prommer), casey_miller@unc.edu (C.T. Miller), pe(aer.dtu.dk (P. Engesgaard), adb $(a$ mit.dhi.dk (A. Brun), czheng@ua.edu (C. Zheng). years, numerous investigations into the fate of organic contaminants in the subsurface have been carried out, accompanied by remediation efforts aimed at, e.g., protecting valuable water supplies. While the pumpand-treat method has been widely used [3], it is not always successful. Being intrusive it incurs costs that may be high in comparison to other approaches, such as subsurface barriers [4] or biostimulation [5-7]. Methods that rely on biological approaches, where organic contaminants degrade to more benign forms, have become more widely employed. Natural, or intrinsic, attenuation refers to cases where in situ microbial species 


\section{Nomenclature}

\section{Roman}

$b \quad$ sorption energy coefficient $\left[\mathrm{L}^{3} \mathrm{M}^{-1}\right]$

C concentration $\left[\mathrm{M} \mathrm{L}^{-3}\right]$

$C_{\text {switch }}$ concentration switch value $\left[\mathrm{M} \mathrm{L}^{-3}\right]$

d dispersivity [L]

D, $D_{i j}$ hydrodynamic dispersion coefficient tensor $\left[\mathrm{L}^{2} \mathrm{~T}^{-1}\right]$

$D_{\text {eff }} \quad$ effective molecular diffusion coefficient $\left[\mathrm{L}^{2} \mathrm{~T}^{-1}\right]$

$f \quad$ real-valued function

$g$ magnitude of gravitational acceleration $\left[\mathrm{L} \mathrm{T}^{-2}\right]$

$\begin{array}{ll}\mathscr{H} & \text { Heaviside step function } \\ I_{\text {inh }} & \text { inhibition factor }\left[\mathrm{M} \mathrm{L}^{-3}\right]\end{array}$

f interphase mass exchange $\left[\mathrm{M} \mathrm{L}^{-3} \mathrm{~T}^{-1}\right]$

j non-advective transport vector $\left[\mathrm{M} \mathrm{L}^{-2} \mathrm{~T}^{-1}\right.$ ]

$k_{1} \quad$ first-order degradation rate $\left[\mathrm{T}^{-1}\right]$

$k_{2}$ second-order degradation rate $\left[\mathrm{L}^{-3} \mathrm{M}^{-1} \mathrm{~T}^{-1}\right]$

$k_{\mathrm{d}} \quad$ first-order biomass decay coefficient $\left[\mathrm{T}^{-1}\right]$

$k_{n}^{\mathrm{a}}$

k aqueous phase) $\left[\mathrm{T}^{-1}\right]$

k unit vector oriented opposite to gravitational acceleration

k permeability tensor $\left[\mathrm{L}^{2}\right]$

$\mathrm{K}$ hydraulic conductivity tensor $\left[\mathrm{L} \mathrm{T}^{-1}\right.$ ]

$K_{\text {bio }}$

$K_{\mathrm{f}}$

$K_{\text {inh }}$

half-saturation constant for inhibition of biomass growth $\left[\mathrm{M} \mathrm{L}^{-3}\right]$

Freundlich sorption capacity coefficient $\left[\mathrm{L}^{3 \mathrm{n}_{\mathrm{f}}} \mathrm{M}^{-\mathrm{n}_{\mathrm{f}}}\right]$

half-saturation constant for inhibition of the degradation rate of an organic chemical $\left[\mathrm{M} \mathrm{L}^{-3}\right]$

$K_{\mathrm{m}} \quad$ half-saturation constant $\left[\mathrm{M} \mathrm{L}^{-3}\right]$

$K_{\mathrm{p}} \quad$ partition coefficient $\left[\mathrm{L}^{-3} \mathrm{M}^{-1}\right]$

$K_{\mathrm{s}} \quad$ Monod half-saturation constant $\left[\mathrm{M} \mathrm{L}^{-3} \mathrm{~T}^{-1}\right]$

$l_{j} \quad j=1$ or 2, parameter in Freundlich-Langmuir interpolation

$L_{\mathrm{r}} \quad$ reaction operator $\left[\mathrm{M} \mathrm{L}^{-3} \mathrm{~T}^{-1}\right]$

$L_{1} \quad$ transport operator $\left[\mathrm{M} \mathrm{L}^{-3} \mathrm{~T}^{-1}\right]$

$m$ counter

$n_{\mathrm{dec}} \quad$ number of species produced during biomass decay

$n_{\mathrm{f}} \quad$ Freundlich sorption energy coefficient

$n_{i} \quad$ number of inhibiting species

$n_{\text {prod }}$ number of species used in the microbial degradation

$n_{\mathrm{s}} \quad$ number of degradable solutes

$n_{\mathrm{sn}} \quad$ number of NAPL-phase species

$n_{\mathrm{ss}} \quad$ number of sorbed-phase species

$p \quad$ pressure $\left[\mathrm{M} \mathrm{L}^{-1} \mathrm{~T}^{-2}\right]$

pe measure of electron activity in an aqueous solution
$\mathrm{pH}$ measure of hydrogen ion activity in an aqueous solution

q volumetric flux $\left[\mathrm{L} \mathrm{T}^{-1}\right]$

$Q \quad$ sorption monolayer capacity coefficient

$r \quad$ stoichiometric coefficient

$\mathscr{R}$ biological or chemical reaction source/sink term $\left[\mathrm{M} \mathrm{L}^{-3} \mathrm{~T}^{-1}\right]$

mass source term $\left[\mathrm{M} \mathrm{L}^{-3} \mathrm{~T}^{-1}\right]$

$\begin{array}{ll}\mathscr{S} & \text { mass source term }\left[\mathrm{ML}_{\mathrm{s}}\right. \\ S_{\mathrm{s}} & \text { specific storativity }\left[\mathrm{L}^{-1}\right]\end{array}$

$t \quad$ time [T]

$\mathbf{v}$ mean pore fluid flow velocity vector [ $\left.\mathrm{L} \mathrm{T}^{-1}\right]$

$V_{\mathrm{m}} \quad$ Michaelis-Menten maximum reaction rate $\left[\mathrm{M} \mathrm{L}^{-3} \mathrm{~T}^{-1}\right]$

$\mathbf{x} \quad$ Cartesian coordinate [L]

$Y^{i} \quad$ degrader mass yielded per mass of solute species $l$ degraded

$z \quad$ distance in the vertical direction $[\mathrm{L}]$

Greek

$\alpha \quad$ index indicating an arbitrary fluid phase

$\beta \quad$ Toth heterogeneity parameter

$\delta \quad$ Kronecker delta function

$\Delta t \quad$ numerical time step [T]

$\epsilon_{\mathrm{a}} \quad$ allowable error magnitude

$\epsilon_{\mathrm{s}} \quad$ splitting error magnitude

$\theta \quad$ volume fraction

$1 \quad$ index indicating an arbitrary species

$\mu \quad$ dynamic viscosity $\left[\mathrm{M} \mathrm{L}^{-1} \mathrm{~T}^{-1}\right]$

$\mu_{\mathrm{m}} \quad$ specific microbial population growth rate $\left[\mathrm{T}^{-1}\right]$

$\mu_{\max }$ maximum microbial population growth rate $\left[\mathrm{T}^{-1}\right]$

$\rho \quad$ density $\left[\mathrm{M} \mathrm{L}^{-3}\right]$

$\phi \quad$ piezometric head [L]

$\omega$ mass fraction

\section{Subscripts}

e equilibrium

$i \quad$ direction $1,2,3$ or $x, y, z$

$j \quad$ as for $i$

1 longitudinal

t transverse

\section{Superscripts}

a aqueous phase

$\mathrm{m}$ microbial population

n non-aqueous phase

s solid phase

\section{Abbreviations}

ASO alternating split operator

ATP adenosine triphosphate

BTEX benzene, toluene, ethylbenzene, xylenes

DOC dissolved organic carbon

ELLAM Eulerian-Lagrangian localised adjoint method 


$\begin{array}{ll}\text { EPS } & \text { extracellular polymer substances } \\ \text { FD finite difference } \\ \text { FE } & \text { finite element } \\ \text { GIM } & \text { global implicit method } \\ \text { ISO iterative split operator } \\ \text { LEA local equilibrium assumption } \\ \text { LNAPL less dense than water non-aqueous phase } \\ \text { MOC liquid method of characteristics }\end{array}$

NAPL non-aqueous phase liquid

ODE ordinary differential equation

SO split operator

SRB sulfate-reducing bacteria

SSO sequential split operator

TCE trichloroethylene

TEAP terminal electron acceptor process

TIC total inorganic carbon

TVD total variation diminishing naturally degrade the organic contaminants to innocuous compounds. Thus, monitored natural attenuation is often the remediation scheme of choice since it would normally be the cheapest approach. Enhanced natural attenuation, where natural processes are enabled or stimulated, may also prove relatively inexpensive in suitable circumstances. As such, it has become an acceptable option to regulatory bodies [8-10].

Due to the number of physical, chemical and biological processes that interact, sometimes subtly, during natural attenuation and aquifer cleanup by intrinsic or enhanced bioremediation, cleanup assessment calls for an integrated modelling approach. Whether microbial activity is responsible for breaking down organic contaminants such as dissolved petroleum products directly or whether it is employed more indirectly to alter geochemical conditions (e.g., such that metal precipitation occurs), predictions about the combined biogeochemical/hydrodynamic system become very difficult if isolated aspects of the total problem are considered separately. An exception to this is for highly engineered approaches, based on marked stimulation or modification of some specific aspect of the subsurface system. These can be analysed using targeted and more simplified modelling, analysis and optimisation. In other circumstances, integrated modelling might well be necessary. For example, techniques that promote bioremediation by stimulation of specific microbial populations would likely need to consider changes in redox state and nutrient availability due to changes in microbial mass and distribution. As a consequence of biostimulation, the microbial populations could grow enough to occupy a significant part of the pore space and cause bioclogging [11]. Ultimately, the hydrodynamic properties of the porous medium are altered, adding an extra degree of complexity to the integrated modelling approach. However, as of now, only very few attempts have incorporated bioclogging phenomena into integrated, mechanistic models [12-14], and none has been applied to a field-scale problem.

Simulating natural and engineered subsurface environments using mechanistic groundwater flow and contaminant transport models is a well-established practice $[15-25]$. The last few decades has seen a rise of easily accessible computational power and in the extent and frequency of reported groundwater contamination problems by organics. These circumstances have motivated the rapid development of mathematical modelling tools $[26,27]$ to assist in quantifying the transport and fate of these contaminants. Ideally, such modelling efforts should be capable of describing complex interacting processes, including those of a physical, chemical or biological nature $[28,29]$. Further, the availability of comprehensive models allows groundwater scientists and engineers to create rational frameworks in which to formulate and integrate knowledge that has been otherwise derived from theoretical work, laboratory investigations and field experiments.

Direct data acquisition in the subsurface is typically very expensive, so field data sets are usually sparse. Furthermore, important model parameters vary markedly in space [30-32], so field-scale models cannot be validated on strictly deterministic grounds - even if the process description is an excellent representation of reality [33]. On the other hand, subsurface biogeochemical systems are often so complex that they preclude heuristic description, and models must be used to improve understanding of them. Consequently, modelling helps predict the future state of such systems and aids in the design of remedial strategies which account for the operative transport and reaction processes.

The overall goal of this work is to provide a comprehensive, realistic framework for modelling complex subsurface systems that comprise multiple, interacting, physical, chemical and biological processes, with the main focus being on oxidisable organic contaminants. Our objectives are (a) to provide a general transport modelling framework; (b) to detail approaches for modelling physical, chemical and biological processes that are operative in the subsurface; (c) to discuss strategies used to solve the given model formulation; (d) to outline numerical methods that may be used to approximate the formulated models; (e) to summarise a few examples of complex biogeochemical models of subsurface systems; (f) to provide examples of biogeochemical modelling; and (g) to summarise some important open issues in the modelling of complex subsurface systems. 


\section{Theory}

Transport and fate of organics in the subsurface environment are affected by a wide range of physical, chemical and biological processes. We provide a conservation equation framework for describing these complex systems and outline sets of closure relations, including process submodels, needed to produce wellposed models of these complex systems. The process submodels are grouped into transport, interphase mass transfer, biological, and chemical processes. There are numerous process submodels available in the literature, so only a selection is provided. Nonetheless, many specific cases can be considered by using various subsets of the model formulations provided.

\subsection{Conservation equations}

Fundamental conservation equations for porous medium systems include conservation of mass, momentum and energy [34]. We focus on the saturated zone under isothermal conditions, and take Darcy's law as a suitable statement of momentum conservation, in which case only conservation of mass equations are required. The conservation of mass for a species $\iota$ in a phase $\alpha$ is $\frac{\partial}{\partial t}\left(\theta^{x} \rho^{x} \omega^{i x}\right)=-\nabla \cdot\left(\theta^{x} \rho^{x} \omega^{i z} \mathbf{v}^{x}\right)-\nabla \cdot \mathbf{j}^{1 x}+\mathscr{I}^{1 x}$

$$
+\mathscr{R}^{i x}+\mathscr{S}^{i x},
$$

where $t$ is time, $\theta$ is a volume fraction, $\rho$ is density, $\omega$ is a mass fraction, $\mathbf{v}$ is a mean pore fluid flow velocity vector, j represents non-advective transport, $\mathscr{I}$ represents interphase mass exchange, $\mathscr{R}$ represents biological or chemical reactions and $\mathscr{S}$ represents a mass source (e.g., direct injection of species $t$ ). The superscripts are species and phase indices.

The following identities apply to Eq. (1)

$$
\begin{array}{ll}
\sum_{\alpha} \theta^{\alpha}=1, & \sum_{\alpha} \mathscr{I}^{1 \alpha}=0, \quad \sum_{i} \omega^{i \alpha}=1, \\
\sum_{i} \mathbf{j}^{i \alpha}=0, & \sum_{i} \mathscr{R}^{1 \chi \alpha}=0 .
\end{array}
$$

Note that the final identity in Eq. (2) states that reactions all occur within a phase and that interphase mass transfer occurs as a separate process. Some models directly react a species within an organic phase with an aqueous phase species (i.e., direct degradation of the organic liquid), an approach that might be used for some microbially driven degradation reactions. Such an approach would need to be split into an interphase transfer and a reaction in the formalism presented here.

For convenience, we introduce the definitions

$\sum_{i} \mathscr{I}^{1 x}=\mathscr{I}^{x}, \quad \sum_{i} \mathscr{S}^{1 x}=\mathscr{S}^{x}$.

Summing Eq. (1) over all species $t$ and combining with Eqs. (2) and (3) yields the $\alpha$-phase mass-balance equation $\frac{\partial}{\partial t}\left(\theta^{\alpha} \rho^{\alpha}\right)=-\nabla \cdot\left(\theta^{\alpha} \rho^{\alpha} \mathbf{v}^{\alpha}\right)+\mathscr{I}^{\alpha}+\mathscr{S}^{\alpha}$.

As mentioned, Darcy's law [35] is used to approximate momentum conservation

$\theta^{\alpha} \mathbf{v}^{\alpha}=\mathbf{q}^{\alpha}=-\frac{\mathbf{k}^{\alpha}}{\mu^{\alpha}} \cdot\left(\nabla p^{\alpha}+\rho^{\alpha} g \nabla z\right)$,

where $\mathbf{q}$ is the Darcy flux vector, or volumetric flux; $\mathbf{k}$ is the effective permeability tensor; $\mu$ is the dynamic viscosity; $p$ is the fluid pressure; $g$ is the magnitude of gravitational acceleration, which is assumed to be oriented in the $-\mathbf{k}$ direction; and $z$ is a spatial coordinate aligned with $\mathbf{k}$.

\subsection{Flow and transport processes}

The complex geochemical systems of concern in this work cannot be described adequately without knowing the fluid velocity field. Non-aqueous phase liquids (NAPLs) are often the contaminants that prompt the development and application of such models. NAPLs typically originate at or near the ground surface (e.g., accidental spillage), and transport through the unsaturated zone affects their biogeochemical interactions. These conditions require multiple fluid systems to be considered. The modelling of the full dynamics of threefluid phases, multi-species biogeochemical systems at a field scale that is adequately resolved in space and time is a significant computational challenge with many open questions [34,36-40].

Three potential avenues could simplify the general multi-phase flow problem discussed above. First, the dynamics of NAPL release and fate are usually characterised by widely varying time scales. Thus, the relatively short-term flow and redistribution resulting from a short-duration NAPL release can be modelled separately using a multi-phase flow simulator run until the NAPL becomes essentially immobile, or measured. The immobile NAPL distribution can then be used as input into a model that uses it as a contaminant source and may include dynamic equations to represent changing fluid saturations with time. Second, the saturated zone concentration conditions immediately down-gradient of the NAPL source can be represented as boundary conditions in the model, which may be time dependent. Third, unsaturated zone transport processes, such as the diffusion of oxygen, can be approximated as a boundary condition in a saturated zone model. Obviously, these simplifications are not applicable in all circumstances. For instance, a pooled LNAPL floating above a seasonally varying water table undergoes a continual process of smearing and pooling, dynamic processes that clearly will affect dissolution of its constituent components [41-44]. Even so, they can be applied in a large number of practical cases. 
In order to focus on the geochemical complexities, we will restrict our considerations to cases in which we can apply some of the above simplifications. In these cases, we need resolve only the saturated zone flow and groundwater velocity. The classic groundwater flow equation, derived by combining Eqs. (4) and (5) along with a linear compressibility closure relation, is [45,46]

$$
S_{\mathrm{s}} \frac{\partial \phi}{\partial t}=\nabla \cdot(\mathbf{K} \cdot \nabla \phi)+\frac{\left(\mathscr{P}^{\mathrm{a}}+\mathscr{P}^{\mathrm{a}}\right)}{\rho^{\mathrm{a}}},
$$

where $S_{\mathrm{s}}$ is the specific storage coefficient representing the elastic storage of the system, the superscript a denotes the aqueous phase, $\phi$ is the hydraulic head and $\mathbf{K}$ is the effective hydraulic conductivity tensor, which will depend upon the fraction of static NAPL present if this is simulated as an internal source term. For dissolution of NAPL from the vadose zone, the NAPL source would be simulated via the boundary condition at the water table.

The volumetric fraction of an immobile NAPL, and hence that of the water phase, can be developed in time by noting that Eq. (4) reduces to

$$
\frac{\partial}{\partial t}\left(\theta^{n} \rho^{n}\right)=\mathscr{f}^{n},
$$

where $n$ is an index representing the NAPL phase [47]. Eq. (7) shows that NAPL saturation changes only as a result of interphase mass exchange under the simplified conditions outlined above. Closure of Eq. (7) requires explicit specification of the right-hand side; approaches for doing so are discussed below.

An important characteristic of this class of problems is that they involve multiple species. For example, different microbial consortia likely dominate degradation under different redox conditions. Even though multiple species are typically involved, the aqueous phase solution usually remains dilute due to the low solubility of organic components and relatively low concentrations of solutes in groundwater. Thus, non-dilute effects on such things as density and viscosity typically can be ignored. Under such conditions, Eq. (1) becomes

$$
\frac{\partial}{\partial t}\left(\theta^{\mathrm{a}} C^{\mathrm{a} a}\right)=-\nabla \cdot\left(\theta^{\mathrm{a}} C^{\mathrm{a} a} \mathbf{v}^{\mathrm{a}}\right)-\nabla \cdot \mathbf{j}^{\mathrm{a}}+\mathscr{I}^{\mathrm{a} a}+\mathscr{R}^{\mathrm{a} a}+\mathscr{S}^{\mathrm{a}},
$$

where $C^{t a}=\rho^{x} \omega^{t a}$, i.e. (mass of chemical species $\imath$ in the aqueous phase)/(volume of the aqueous phase).

Eq. (8) can be further developed by specifying the standard form of the hydrodynamic dispersion for a water-saturated porous media $[48,49]$ in place of $\mathbf{j}^{\text {ia }}$, giving

$$
\frac{\partial}{\partial t}
$$$$
\left.C^{\mathrm{ia}}\right)=-\nabla \cdot\left(\theta^{\mathrm{a}} C^{\mathrm{a}} \mathbf{v}\right)+\nabla \cdot\left(\theta^{\mathrm{a}} \mathbf{D}^{\mathrm{i}} \cdot \nabla C^{\mathrm{a}}\right)
$$

$$
+\mathscr{I}^{\mathrm{a}}+\mathscr{R}^{\mathrm{a}}+\mathscr{\mathscr { S }}^{\mathrm{a}} \text {, }
$$

where
$D_{i j}^{\prime}=\delta_{i j} d_{\mathrm{t}}|v|+\left(d_{1}-d_{\mathrm{t}}\right) \frac{v_{i} v_{j}}{|v|}+\delta_{i j} D_{\mathrm{eff}}^{\prime}$

and $\theta^{\mathrm{a}}$ is now the possibly spatially and temporally varying volumetric fraction of the aqueous phase. In Eq. (10), which employs the summation convention, $d_{1}$ is the longitudinal dispersivity, $d_{t}$ is the transverse dispersivity, and $D_{\text {eff }}^{t}$ is an effective molecular diffusivity for species $t$ that accounts for the effects of tortuosity. As we mention later in Section 5, careful selection of dispersivity values is required since biodegradation rates of dissolved organic contaminants are strongly dependent on redox conditions, which may vary markedly over short length scales.

\subsection{Interphase mass transfer}

In Eq. (1), we identify general terms for interphase mass transfer, $\mathscr{I}^{1 x}$, and biological/chemical reactions, $\mathscr{R}^{i x}$. The latter represents the conversion of one species into another while the former involves the movement of a species from one phase to another. One could model interphase mass transfer as reactions directly. However, we keep both categories, as interphase mass transfer is often modelled as a physical process rather than as a reaction. Or, if it is modelled as a reaction, it is done semi-empirically, e.g., a species is sorbed to a soil without specifying the surface reaction that binds the species to the soil. In this section, we discuss the first class of interphase mass transfer, i.e., no detailed biological or chemical reactions are considered. Next, in Section 2.4, a more detailed, reaction-based modelling approach is presented. The main difference between the approaches is that interphase transfer is usually modelled with a focus on physical processes and limitations, whereas for reactions biogeochemical processes and microbial activity are the primary concern.

Three types of interphase mass transfer can exist in the systems under consideration: NAPL-aqueous phase mass transfer (i.e., NAPL dissolution), sorption/ desorption and precipitation/dissolution of inorganic minerals. These mass transfer relationships have in common the need to specify two components: an equilibrium model and a rate model $[34,50]$.

\subsubsection{NAPL-aqueous phase}

The equilibrium model yields the aqueous phase concentration in equilibrium with a NAPL and can be written in a general form as

$C_{\mathrm{e}}^{\mathrm{a}}=f\left(C^{j n}, j=1, \ldots, n_{\mathrm{sn}}\right)$,

where $C_{\mathrm{e}}$ represents an equilibrium concentration and $n_{\mathrm{sn}}$ is the number of species in the NAPL phase. For single component NAPLs, the aqueous solubilities are readily available from tabulated sources and may be estimated. For multi-component NAPL systems, Raoult's law [51,52] is typically used, although it is limited. 
The standard, rate-limited NAPL dissolution model can be given as

$\mathscr{I}_{n}^{\mathrm{ra}}=\theta^{\mathrm{a}} k_{n}^{\mathrm{aa}}\left(C_{\mathrm{e}}^{\mathrm{a}}-C^{\mathrm{ia}}\right)$,

where $k_{n}^{\text {ta }}$ is a mass-transfer rate coefficient, which is the product of a mass transfer coefficient and the specific interfacial area between the two phases. Correlations for $k_{n}^{\text {ra }}$, cast in terms of a non-dimensional Sherwood number, as a function of system properties such as the Reynolds and Schmidt numbers, are available for certain well-characterised systems $[34,53-57]$. Since these correlations include only a relatively small fraction of the potential system dependencies, they should be viewed as rough approximations [34,57].

Note that Eqs. (11) and (12) are standard forms, applicable to dilute aqueous phases. For non-dilute aqueous phases, such as those with a chemical or biological surfactant, alternative models accounting for micelle formation and interchange across the NAPLaqueous phase interface are more appropriate [58]. Surfactant systems are slower to achieve equilibrium than non-surfactant systems [59].

NAPL dissolution is an extremely complex process because (a) many NAPLs are complex mixtures, which complicates the equilibrium model needed; (b) the common rate model used, while simple in basic form, has a coefficient that depends upon many additional parameters and space and time; (c) mass transfer occurs across the interfacial area between the two phases of concern, which is not an accessible quantity in standard multi-phase models; and (d) NAPL-aqueous phase mass transfer is an inherently unstable process, giving rise to the formation of complex dissolution fingering patterns in most natural systems $[47,54,58,60,61]$.

Lest one get caught in the substantial details of NAPL dissolution modelling, we can extract certain primary issues and thus simplify matters, at least conceptually. NAPL dissolution is primarily affected by the morphology of NAPL distribution, which evolves in space and time across a wide range of scales. An aqueous phase in contact with a NAPL phase approaches equilibrium relatively rapidly at typical groundwater velocities, say on the order of a centimetre of travel distance [57] - an insignificant distance for field-scale problems. Still, equilibrium concentrations are seldom observed in the field because of the complexity of NAPL distributions and the manner in which water samples are typically collected, which average over relatively large regions.

It would seem that modelling mass transfer at the field scale could be accomplished adequately by approximating the original morphology of the NAPL distribution and tracking it with time, assuming local equilibrium at local phase contacts. While a reasonable conclusion, NAPL-aqueous phase mass transfer under this conceptual model is a classical problem of scale, since the NAPL morphology must be resolved and developed over time at sub-grid-scale levels. Without such detailed descriptions, one uses correlations of dissolution, as determined from careful laboratory experiments. However, caution is urged in the use of such laboratory correlations. They are often collected under homogeneous conditions whereas they are applied to heterogeneous field-scale problems known to have strikingly different NAPL morphologies [34].

\subsubsection{Sorption/desorption}

Equilibrium models for sorption/desorption (hereafter simply sorption) are of the general form

$\omega_{\mathrm{e}}^{i s}=f\left(C_{\mathrm{e}}^{j a}, j=1, \ldots, n_{\mathrm{ss}}\right)$,

where the superscript s specifies the solid phase and $n_{\mathrm{ss}}$ is the number of sorbing species. For dilute systems, multicomponent effects are typically ignored and one of four standard equilibrium models is often used: linear, Freundlich, Langmuir or Toth. A summary of other sorption isotherms is available elsewhere [18]. [62])

The linear model is the simplest and of the form (e.g.,

$\omega_{\mathrm{e}}^{15}=K_{\mathrm{p}}^{\prime} C_{\mathrm{e}}^{\mathrm{a}}$,

where $K_{\mathrm{p}}^{\prime}$ is the partition coefficient, which depends upon solid and solute properties [63].

The Freundlich model is [64]

$\omega_{\mathrm{e}}^{t s}=K_{\mathrm{f}}^{t}\left(C_{\mathrm{e}}^{\mathrm{za}}\right)^{n_{\mathrm{f}}^{t}}$,

where $K_{f}^{1}$ is the Freundlich sorption capacity coefficient and $n_{\mathrm{f}}^{t}$ is the Freundlich sorption energy coefficient (e.g., $[65,66])$. Although the literature reports values of $n_{f}^{t}$ between 0.7 and 1.8 , typically it is less than and close to unity [67].

The Langmuir model is

$\omega_{\mathrm{e}}^{i \mathrm{~s}}=Q^{\prime} b^{\prime} C_{\mathrm{e}}^{\mathrm{ia}}\left(1+b^{i} C_{\mathrm{e}}^{\mathrm{ia}}\right)^{-1}$,

where $Q^{\prime}$ is the sorption monolayer capacity coefficient and $b^{\prime}$ is a sorption energy coefficient [64].

The Toth model is

$\omega_{\mathrm{e}}^{\prime \mathrm{s}}=Q^{\prime} b^{\prime} C_{\mathrm{e}}^{\mathrm{a}}\left[1+\left(b^{\prime} C_{\mathrm{e}}^{\mathrm{a}}\right)^{\beta^{c}}\right]^{-1 / \beta^{\prime}}$,

where $\beta$ is a Toth heterogeneity parameter $[68,69]$. Note that when $\beta^{t}=1$ the Toth model reduces to the Langmuir model.

Yet another model which generalises some of these is the Langmuir-Freundlich interpolation [18]

$\omega_{\mathrm{e}}^{1 \mathrm{~s}}=Q^{\prime}\left\{1-\left[1+\left(b^{i} C_{\mathrm{e}}^{2 a}\right)^{I_{4}}\right]^{I_{2}}\right\}$

where $l_{1}$ and $l_{2}$ are additional fitting parameters. For $l_{1}=1$ and $l_{2}=-1$, Eq. (18) reduces to Eq. (16) whereas taking $l_{1}=n_{\mathrm{f}}^{i}, l_{2}=1$ and then letting $K_{\mathrm{f}}^{\prime}=-Q^{\prime}\left(b^{i}\right)^{n_{\mathrm{f}}^{\prime}}$ gives Eq. (15). 
The linear sorption equilibrium model is the simplest and, perhaps, the most commonly used, particularly in analytical modelling. However, it has been found inadequate to describe many subsurface systems [70-73]. The Freundlich model is frequently used and adequately describes most systems. Its power-law form leads to selfsharpening fronts for the typical case of $n_{\mathrm{f}}^{i}<1$ (for a monotonically decreasing concentration oriented in the direction of flow) and to increased complexity in the solution methods needed compared to the linear case [74]. The Langmuir model is applicable to cases in which sorption is limited to a finite capacity represented by, for example, a monolayer of solute coverage on the solid phase. The Toth model is a flexible non-linear model that can represent some non-linear distributions that are not adequately represented by either of the simpler Freundlich or Langmuir models [34]. Some multi-solute sorption models exist as well [75], although they have received limited use for dilute subsurface systems $[76,77]$.

Besides the models presented above, there has been considerable work on sorption of organic compounds by sediments and soil organic matter [78,79]. We do not review these modelling efforts in any detail, except to note that several efforts have correlated organic sorption to relevant octanol-water partition coefficients and proportion of organic carbon in the soil, and have been based on the linear isotherm (Eq. (14)) $[63,80-87]$.

A variety of rate models exist to describe the rate at which sorption occurs. Two of the most common models are the local-equilibrium model $[70,88]$,

$\mathscr{I}_{\mathrm{s}}^{\mathrm{ra}}=-\theta^{\mathrm{s}} \rho^{\mathrm{s}}\left(\frac{\mathrm{d} \omega_{\mathrm{e}}^{\prime \mathrm{s}}}{\mathrm{d} C_{\mathrm{e}}^{\prime \mathrm{a}}}\right) \frac{\partial C^{i a}}{\partial t}$,

and the first-order model $[73,89]$

$\mathscr{I}_{\mathrm{s}}^{\mathrm{la}}=-\theta^{\mathrm{s}} \rho^{\mathrm{s}} k_{\mathrm{s}}^{\text {ta }}\left(\omega_{\mathrm{e}}^{\imath \mathrm{s}}-\omega^{\imath \mathrm{s}}\right)$,

where $k_{\mathrm{s}}^{\text {ta }}$ is a first-order mass transfer coefficient. A third typical model is the two-site model, which assumes two types of sites on the solid phase - one represented by the local-equilibrium model and the second represented by the first-order model [90-92].

While these three models are the commonly utilised and can be easily accommodated into the type of fieldscale simulators of interest in this work, they cannot simulate adequately many systems. Higher resolution models include two-scale surface and pore diffusion models, whereby the sorption process is represented by a diffusional process into a solid particle of specified, usually spherical, geometry [93-96]. Extensions to both first-order and diffusion models have been advanced by representation of the sorption process as the sum of a series of parallel processes, including cases in which model parameters are chosen from correlated or uncorrelated probability density functions $[69,97]$. These so-called parallel process models are computationally demanding and, to our knowledge, have seen little use at the field scale.

Finally, we mention that in some circumstances sorption/desorption can be modelled as an "ion-exchange process". In this case the geochemical modelling approach based on the law of mass action, as discussed in Section 2.4.1, can be used, with solid phase surface complexes treated as reaction products $[98,99]$. This modelling approach would not need to involve charged species. Rather, in a geochemical model one would define "reactions" wherein the exchange was quantified.

\subsubsection{Precipitation/dissolution}

Precipitation/dissolution, hereafter simply precipitation, is a common geochemical process that involves mass exchange between the aqueous phase and an inorganic solid mineral phase. For a simple single species model, it can be modelled in a simple manner by removing (adding) mass of a given species when concentrations exceed (reduce below) a given concentration (e.g., solubility of the species).

Precipitation reactions can involve [100] (a) simple salts, which tend not to undergo protolysis reactions or to form complexes; (b) oxides and hydroxides, which are common components of natural waters; and (c) carbonates, which are also a common and an important class of compound for natural waters. The chemistry of the latter two classes of solids is more complicated than that of the former because of the larger number of reactions in which these compounds can take part, such as complexation and interactions with a gas phase, and because of heterogeneous solid-phase characteristics. Because precipitation and associated geochemical reactions that influence precipitation in natural aquatic systems are common, comprehensive geochemical models include the full range of important processes, which vary from system to system. As a result, standard practice is to model precipitation within a comprehensive geochemical structure, as discussed below in Section 2.4.1.

Precipitation also influences directly physical flow through porosity changes. In the modelling examples presented in Sections 8 and 9, this possibility is ignored. However, in some circumstances, it will be a vital factor, e.g., self-sealing systems [101]. A practical application of this is clogging of in situ zero-valent iron walls used for remediation of halogenated organic compounds [102]. Since the evolution of the solid phase is formally represented in Eq. (1), this equation can be specialised to account for mineral precipitation. Indeed, with appropriate changes in notation, the volume fraction occupied by any given mineral satisfies an expression identical to Eq. (7). The precipitation rate may depend on aqueous phase chemistry, surface reactions and microbial activity. Changes in the solid phase volume fraction (and hence that occupied by the fluid phase) can be 
determined by variations in the sum of the total volume fraction occupied by all minerals. We remark, in passing, that a similar approach could be taken to model biofilm growth.

\subsection{Biogeochemical reaction modelling}

Interphase mass transfer can be either in equilibrium or modelled as time-dependent processes [103]. Similarly, a kinetic biochemical reaction requires some amount of time to reach completion. In a numerical model, the advective transport time scale for a solute to traverse a given computational cell can be compared with the mass transfer and kinetic reaction time scales. The dimensionless numbers that result are the ratio Sherwood number:Péclet number and the Damköhler 1 number [104-108]. For flow systems with negligible advection, such that diffusion is the dominant transport mechanism, the corresponding dimensionless numbers are the Sherwood and Damköhler II numbers, respectively. Interphase exchange and reaction processes that do not occur are characterised by an infinitely large characteristic time and dimensionless numbers of zero [109]. Large values of these numbers result when the characteristic time scale is small compared to the advective (or diffusive) transport time scale, in which case the mass transfer process is in equilibrium or the biochemical reaction has run to completion. In numerical models, dimensionless numbers can be used to evaluate the appropriate form of a process model that is needed and give guidance regarding effective numerical methods needed to resolve the reactions.

Organic chemicals can react with other chemical species directly, often as a result of microbial activity. Reactions affecting a given organic chemical are sometimes referred to as primary reactions. Note that this specification of "primary" reactants differs from that used in solving equilibrium geochemical equations [110]. Furthermore, as a result of degradation, aqueous phase chemical composition will change. Consequently, further reactions, also called secondary reactions, will take place. In either circumstance, computation of the evolving aqueous and solid phase chemical composition is a basic modelling task.

While it is reasonable in many cases to model aqueous speciation reactions as equilibrium reactions, kinetic approaches to microbially mediated reactions are the norm. The latter case is considered in detail in Sections 2.4.2 and 2.4.3, while the former case is discussed briefly below.

\subsubsection{Equilibrium and kinetic geochemistry}

Many thorough descriptions of equilibrium geochemistry are available $[18,100,110-114]$. Briefly, chemical species in natural waters are typically at dilute concentrations. As concentrations decrease, the activity of the species increases. Activity changes with ionic strength, as modelled by, e.g., the Davies equation [115]. For fixed temperature and for any given chemical reaction, the law of mass action states that the distribution between the activities of reactants and products is fixed and is described by a temperature-dependent equilibrium constant. The equilibrium constant is a simple function of the Gibb's free energy of formation and the temperature [116]. As concentrations increase beyond the solubility product, mineral precipitation can occur. On the other hand, mineral dissolution can take place in under-saturated solutions. The law of mass action also applies to precipitation/dissolution reactions by noting that activity of any mineral is identically unity. An alternative solution method for equilibrium geochemistry calculations is that based on minimising the Gibb's free energy. Both approaches give similar results under reasonable conditions [117].

Computer packages for equilibrium reaction calculations have been available for more than two decades [118-122]. They rely on databases containing the definition of the reactions among aqueous components/ species, mineral and gas phases and their reaction constants. It is worth remembering that these databases are not always consistent and should be checked in any given application [123,124]. Additionally, in applications, uncertainty arises from lack of knowledge of chemical and mineral constituents composing the soilwater system.

Reaction kinetics for abiotic systems (typical approaches for biological systems are discussed in the next section), including precipitation, rely on determination of reaction rate constants. Any given reaction (or sequence of reactions) can be characterised by rate expressions depending on forward and reverse reaction rates $[100,117,125]$. At equilibrium, the ratio of these reaction rates is equivalent to the reaction's equilibrium constant. Once the reaction rates are known, computation of the reaction evolution involves solution of first-order ordinary differential equations (ODEs) with general form as given by Eq. (7). For precipitation, a similar approach is followed although the situation is more complex as transport processes can affect the rate at with chemical species are transported from a mineral surface [126]. In that case, the reaction rate could be controlled by advection, so affecting the forward and reverse reaction rates. This kinetic modelling approach depends on the principal of microscopic reversibility $[100,117]$, a concept that relies on detailed knowledge of all elementary processes in an overall reaction [100].

For microbially mediated reactions, a range of rate models is available; these are discussed next.

\subsubsection{Microbially mediated chemical transformations}

Organic chemicals in aqueous systems are subject to both abiotic and biotic reactions and transformations. 
Often, however, biological activity will be the major factor in contaminant transformations as degradation rates could be accelerated by several orders of magnitude relative to non-mediated reactions (if they occur at all) and so this aspect of organic fate will be considered in some detail. Indeed, the existence of such reactions plays a central role in procedures such as (active) bioremediation, monitored natural attenuation, and contaminant source and product identification. Modelling of such systems requires an understanding of several factors: the set of reacting species, type of pathway for each - e.g., growth or decay; species reactants and products, redox conditions, existence of inhibitory compounds, and the presence and concentration of other potentially limiting species, such as nutrients and vitamins. Other factors, such as substrate availability and microbial movement can also affect the rate at which contaminants are degraded or transformed.

Clearly, when microbial populations are changing, the rate of contaminant removal and production of new reactants will vary according to the microbial mass, amongst other things. Fundamental to tractable modelling of microbial growth and decay is that the biological mass is conceptualised as a chemical species, composed of various elements such as carbon, hydrogen, oxygen, nitrogen, potassium, phosphorus, etc. Thus, the microbial mass reacts as a chemical species and is subject to chemical thermodynamic principles, as we shall discuss in Section 2.4.3. In this simplified approach, however, reaction kinetics are difficult to predict and normally would be determined by reference to experiments.

It is clear that many open issues remain regarding the construction of complete, realistic models of the biodegradation process for any given class of compound. However, an evolving set of models of varying complexity are now commonly used to approximate complex microbial degradation processes. We will summarise several of these, progressing from least sophisticated to more sophisticated.

A common model is the instantaneous reaction model [127-129], where, for example, a two-species reaction equation may be given as

$r_{1} C^{\mathrm{la}}+r_{2} C^{2 \mathrm{a}} \rightarrow r_{3} C^{3 \mathrm{a}}+r_{4} C^{4 \mathrm{a}}$.

In Eq. (21), $r$ is a stoichiometric constant, and the integers 1-4 are species qualifiers. The instantaneous reaction model assumes that the biochemical reaction takes place sufficiently quickly such that the actual rate is not important and, furthermore, that the limiting factor in the extent of the reaction is the availability of one of the reactants. Over a time step, $\Delta t$, equations for the reactants on the left-hand side are

$$
\mathscr{R}^{\mathrm{la}}= \begin{cases}-\theta^{\mathrm{a}} C^{\mathrm{la}} / \Delta t, & \text { if } C^{\mathrm{la}} \leqslant r_{1} C^{2 \mathrm{a}} / r_{2}, \\ -\theta^{\mathrm{a}} r_{1} C^{2 \mathrm{a}} /\left(r_{2} \Delta t\right), & \text { if } C^{\mathrm{la}}>r_{1} C^{2 \mathrm{a}} / r_{2},\end{cases}
$$

$\mathscr{R}^{2 a}= \begin{cases}-\theta^{\mathrm{a}} r_{2} C^{\mathrm{a} a} /\left(r_{1} \Delta t\right), & \text { if } C^{\mathrm{la}} \leqslant r_{1} C^{2 \mathrm{a}} / r_{2}, \\ -\theta^{\mathrm{a}} C^{2 \mathrm{a}} / \Delta t, & \text { if } C^{1 \mathrm{a}}>r_{1} C^{2 \mathrm{a}} / r_{2} .\end{cases}$

The case of more than two reactants with a single reactant limiting can be modelled by a trivial extension to this formulation. A key aspect of the instantaneous reaction model is that the concentration of at least one of the reacting species is zero for all times everywhere in the domain. Second, it is highly efficient due to the naturally decoupled nature of the solution procedure; such algorithm issues are discussed below (Section 3).

A host of kinetic reaction models of differing complexity can be built. For a selected organic chemical species, the simplest case is to assume that any dependency of the transformation rate of the organic substance between the substance and any other chemical or microbial population is neglected. A commonly applied microbial degradation kinetic model is the first-order model

$$
\mathscr{R}^{\mathrm{ia}}=-\theta^{\mathrm{u}} k_{1}^{\prime} C^{\mathrm{ia}} \text {, }
$$

where $k_{1}^{\prime}$ is a first-order biodegradation rate. This model assumes that the only factor affecting the biodegradation rate is the concentration of substrate present; this may be the case under some circumstances but often is not. The model in Eq. (24) formally applies to the situation where the microbial mass is constant (i.e., growth and decay rates are equal). Assuming that the carbon in the organic compound is used for cell growth, breakdown products from microbial decay, which are not explicitly modelled, are produced at a rate proportional to the loss in Eq. (24).

As concentrations increase, it is often expected that the degradation rate plateaus; this behaviour is not exhibited by Eq. (24). It is, however, a feature of the Michaelis-Menten model [130], which is routinely used to model enzyme-substrate reactions [131]

$$
\mathscr{R}^{\mathrm{ad}}=-\theta^{\mathrm{a}} \frac{V_{\mathrm{m}}^{\prime} C^{\text {a }}}{K_{\mathrm{m}}^{\prime}+C^{\prime a}},
$$

where $V_{\mathrm{m}}^{\prime}$ is a maximum reaction rate coefficient, and $K_{\mathrm{m}}$ is a half-saturation coefficient. The Michaelis-Menten equation is first order at relatively low substrate concentrations and zero order at relatively high substrate concentrations (e.g., [132]). The circumstances to which Eq. (25) pertain are the same as those above for Eq. (24).

The Michaelis-Menten model can be extended, again without recourse to specific microbial reactions, to account for circumstances where other organic or inorganic species also reduce the reaction rate for a particular species, e.g., electron acceptors might be limiting the degradation of an oxidisable contaminant. In that case, Eq. (25) is extended to

$$
\mathscr{R}^{\mathrm{a} a}=-\theta^{\mathrm{a}} \frac{V_{\mathrm{m}}^{\mathrm{i}} C^{\mathrm{ra}}}{K_{\mathrm{m}}^{\prime}+C^{r a}} \prod_{j=1}^{n_{j}} \frac{C^{j \mathrm{a}}}{K_{\mathrm{m}}^{j}+C^{j \mathrm{a}}},
$$

where $n_{i}$ is the number of inhibiting species. Once again, the microbial mass is assumed to be constant, and thus 
breakdown products from microbial decay are assumed to be different chemical species than those appearing in Eq. (26).

\subsubsection{Microbial population kinetics}

In this section we extend the foregoing models of organic degradation to include microbial population growth and decay. The key assumption is that microbial mass can be modelled as a chemical species, such that reactions can be specified for its growth and decay. If considered necessary, the microbial population can also be transported and undergo mass transfer to or from the solid phase, leading to a general transport equation being used for each distinct microbial population.

We note that, since our interest is in aquifers and soil profiles, the models considered here are macroscopic descriptions of microbial growth dynamics aimed at simulating laboratory- or field-scale processes. Thus, many of the complex interdependencies at the microscopic scale are commonly neglected and described by empirical formulations based on classical descriptions $[130,133]$. For instance, a simple approach is based on a conceptual extension to the first-order model, Eq. (24). A second-order model, in terms of substrate concentration and microbial biomass, respectively, can be written as,

$\mathscr{R}^{\mathrm{aa}}=-\theta^{\mathrm{a}} k_{2}^{\prime} C^{\mathrm{aa}} C^{\mathrm{ma}}$,

$\mathscr{R}^{\mathrm{ma}}=-Y^{i} \mathscr{R}^{\mathrm{a \textrm {a }}}-\theta^{\mathrm{a}} k_{\mathrm{d}} C^{\mathrm{ma}}$,

where $k_{2}^{\prime}$ is a second-order rate coefficient for species $l$, the superscript $\mathrm{m}$ is an index corresponding to the microbial degrader species, $Y^{\prime}$ is the degrader mass yielded per mass of solute species $\imath$ degraded, and $k_{\mathrm{d}}$ is a firstorder biomass decay coefficient, which represents degrader loss. The term decay refers to a unidirectional kinetic reaction involving the chemical species $C^{\text {ma }}$, wherein other chemical species are produced. In this instance, the reaction rate is characterised by the value of $k_{\mathrm{d}}$. It is assumed that the chemical species released as as result of degradation are different to $C^{\text {ma }}$, otherwise this would need to be included in Eq. (27). Note that $Y^{\prime}$ will change according to the mass units used. If, say, concentrations are measured in $\mathrm{moll}^{-1}$, then $Y^{t}$ will be a stoichiometric ratio, whereas if $\mathrm{g} \mathrm{l}^{-1}$ is used then $Y^{1}$ will additionally account for the molecular weights of $C^{\text {ta }}$ and $C^{\mathrm{ma}}$. Breakdown products are produced at a rate proportional to $\theta^{\mathrm{a}} k_{\mathrm{d}} C^{\mathrm{ma}}$. For the case where the degrader population is nearly constant $\left(Y^{\prime} k_{2}^{\prime} C^{\mathrm{a} a} \approx k_{\mathrm{d}}\right)$, the second-order model reduces to Eq. (24) by setting $k_{1}^{t}=k_{2}^{i} C^{\mathrm{ma}}$. Of course, in this case the degrader concentration need not be computed.

While many biological reaction rates are well represented by Eq. (25), it does not explicitly account for the growth and decay of a microbial degrader population. The Monod growth model is similar in form to the
Michaelis-Menten model [133], but it includes the growth and decay of a degrader population [134,135]. For a single chemical species and microbial population it can be written as

$$
\begin{aligned}
& \mathscr{R}^{\mathrm{ra}}=-\theta^{\mathrm{a}} \frac{\mu_{\mathrm{m}}^{\prime} C^{\mathrm{a}} C^{\mathrm{ma}}}{Y^{\mathrm{i}}\left(K_{\mathrm{s}}^{\prime}+C^{\mathrm{a}}\right)}, \\
& \mathscr{R}^{\mathrm{ma}}=-Y^{\prime} \mathscr{R}^{\mathrm{a} a}-\theta^{\mathrm{a}} k_{\mathrm{d}} C^{\mathrm{ma}},
\end{aligned}
$$

where $\mu_{\mathrm{m}}^{l}$ is a specific growth rate based on species $I$, and $K_{\mathrm{s}}^{\prime}$ is the corresponding Monod substrate half-saturation constant.

Eqs. (29) and (30) do not allow for limitations such as nutrients or other inorganic (e.g., electron acceptors) or organic species that might be needed for microbial growth. Similarly to Eqs. (27) and (28), they focus on a single (organic) species and do not explicitly account for the production of breakdown products. The standard Monod growth model has been extended $[136,137]$ to handle the case in which the rate of microbial growth is limited by the concentration of one or more species other than a single growth substrate. A formulation of this approach is

$$
\mathscr{R}^{\mathrm{a} a}=-\theta^{\mathrm{a}} \frac{\mu_{\mathrm{m}}^{l} C^{\mathrm{a} a} C^{\mathrm{ma}}}{Y^{\prime}\left(K_{\mathrm{s}}^{\prime}+C^{\imath \mathrm{a}}\right)} \prod_{k=1}^{n_{\imath}} \frac{C^{k \mathrm{a}}}{K_{\mathrm{s}}^{k}+C^{k \mathrm{at}}},
$$

$$
\mathscr{R}^{\mathrm{ma}}=-\sum_{1} Y^{\prime} \mathscr{R}^{\mathrm{aa}}-\theta^{\mathrm{a}} k_{\mathrm{d}} C^{\mathrm{ma}},
$$

$$
\mathscr{R}^{j \mathrm{a}}=r^{j} \theta^{\mathrm{a}} k_{\mathrm{d}} C^{\mathrm{ma}} \quad \text { for } j=1, \ldots, n_{\mathrm{dec}},
$$

$\mathscr{R}^{j a}=r^{j} \mathscr{R}^{\prime \mathrm{a}}$ for $j=1, \ldots, n_{\text {prod }}$,

where, again, $n_{i}$ is the number of potentially limiting species, $n_{\mathrm{dec}}$ is the number of species produced during degradation of the microbial population, $n_{\text {prod }}$ is the number of species used in the microbial degradation of the $\iota$ species and $r$ is a stoichiometric factor (or a ratio of factors). Eq. (32) models the entire biomass, both active and inactive. This model could easily be extended to account explicitly for living and decaying biomass, in which case two rate equations would be used. The summation in Eq. (32) assumes that the microbial population growth rate can be represented as the sum of growth rates due to the group of (organic) chemical compounds suspectable to breakdown by that microbial species, i.e., the summation is over all species $t$ of this type. Eq. (34) quantifies the loss of the $n_{\text {prod }}$ (usually inorganic) species that are included in the degradation reaction of the organic species 1 . In Eqs. (33) and (34) we assumed that species mass is measured in moles, in which case the rate of usage of any species is proportional to the stoichiometry of the reaction that produces or decays biomass. The coefficients on the right side of these equations should be adjusted by the appropriate 
molecular weight if mass is measured in grams. We note also that the second-order model given by Eqs. (27) and (28) could be extended to a multi-species version similar to Eqs. (31)-(34).

For multiple substrates - as accounted for in the summation in Eq. (32) expressions of the form given in Eqs. (31) and (34) are written, while Eq. (32) for the microbial population growth rate and Eq. (33) for the rate of species production from microbial decay are written once only.

While Eq. (32) presents the standard decay term $\left(k_{\mathrm{d}}\right)$ typically used by most models that quantify microbial growth and decay, an alternative is to use a Monod-type expression that creates a rate dependency of this term on electron acceptor availability (e.g., oxygen) [134], leading to

$$
\mathscr{R}^{\mathrm{ma}}=-\sum_{1} Y^{i} \mathscr{R}^{\mathrm{a}}-\theta^{\mathrm{a}} k_{\mathrm{d}} C^{\mathrm{ma}} \prod_{k=1}^{n_{i}}\left(\frac{C^{k \mathrm{a}}}{K_{\mathrm{s}}^{k}+C^{k \mathrm{a}}}\right) .
$$

This equation assumes that the set of species in Eq. (31) limiting the production of biomass also limit its decay. If this assumption does not apply then the appropriate set of species would be used in the product.

Another common extension to the Monod growth model is made to account for a reduction in a specific growth rate by two or more substrates competing for the same enzymatic system, which is expressed as [138]

$$
\mu_{\mathrm{m}}^{i}=\mu_{\max }^{i} \frac{C^{2 \mathrm{a}}}{C^{\mathrm{aa}}+K_{\mathrm{s}}^{i}\left(1+\sum_{\substack{\sum_{\mathrm{s}}=1 \\ i \neq i}}^{n_{k}} C^{\mathrm{ka}} / K_{\mathrm{s}}^{k}\right)},
$$

where $\mu_{\max }^{i}$ is the maximum growth rate for the microbial population on the $I$ solute species, and $n_{5}$ is the number of degradable solutes present. Other mathematical forms to represent competitive inhibition are possible, all of which relate inhibition of growth and/or substrate transformation to the concentration of the inhibitor species [139].

Biodegradation modelling can be extended further to consider multiple populations of microorganisms. It is possible that the chemical formulas (and thus stoichiometry) representing the various microbial populations would change, as would the parameters used to model the reaction rates. In general, this case can be modelled by writing expressions of the form in Eqs. (31) (34) for each microbial population.

A typical scenario in modelling biodegradation is that of a sequence of redox states, each of which involves a different microbial population. If, say, oxygen is present, then aerobic degradation would be expected to take place in preference to anaerobic degradation (Section 7). In such circumstances, an additional inhibition factor might be added to the right side of Eq. (36) to reduce the growth rate under appropriate circumstances. For instance, if oxygen is present, we could inhibit the growth of a microbial population relying on anaerobic condi- tions by forcing the specific growth rates due all pertinent organic chemical species to zero while oxygen is present. This is achieved by multiplying the right side of Eq. (36) by $1-\mathscr{H}\left(C^{\text {oxygen }}-C_{\text {switch }}^{\text {oxyen }}\right)$, where $\mathscr{H}$ is the Heaviside step function [140]. When the concentration of oxygen is above $C_{\text {switch }}^{\text {oxygen }}$, the specific growth rate is zero. This empirical approach is just one that could be used. For example, a thermodynamic/kinetic comparison procedure is available [141]. Another simple inhibition factor is discussed in Section 7.3 while switch values are employed in Section 8.

\section{Solution algorithms}

Organic chemical degradation characteristically has physical transport and reactive processes occurring simultaneously. The reactive processes routinely constitute complex biogeochemical problems involving many individual organic species. Determination of the concentration of each solute species generally requires solution for each phase in which they reside; a solution that requires the formulation and computation of a separate conservation equation for each unique speciesphase combination. The concentration of one or more microbial species in the aqueous phase, and usually on the solid phase as well, must also be determined through an appropriate set of conservation equations. The net result is that a large system of transport equations must be solved for most problems of interest.

A second feature of the geochemical problems of interest in this work is the complexity of the inorganic reactions typically considered, including precipitation, complexation, acid-base reactions and redox reactions, all of which affect speciation in subsurface waters [100]. Such considerations further increase the number of species that must be considered to represent subsurface systems accurately. While sophisticated geochemical models exist, they do not typically include efficient, high resolution, three-dimensional fluid flow and species transport solvers, nor the full range of interphase exchange and biological reaction models of interest.

The net result of these considerations is that state-ofthe-art modelling of complex biogeochemical processes in the subsurface environment is out of necessity most often accomplished by combining multiple models e.g., a flow model, a transport model, interphase mass transfer models, biological transformation and growth models, and geochemical models. Although a range of numerical schemes exists $[25,110,117,142,143]$, the need to combine models and simulate a large number of species under a variety of circumstances leads to the conclusion that (SO) algorithms are the most appropriate method to solve this challenging class of problems. Indeed, with few exceptions (e.g., [144]), the SO technique (e.g., $[16,25,106,117,145-155])$ has become the 
standard method for solving such combined physicobiogeochemical problems. It involves separating the processes (e.g., flow, transport of individual chemical components/species, chemical reactions, microbial activity) within the numerical model and solving each submodel independently. The technique enables use of available, well tested, transport, flow and reaction packages, as well as associated graphical user interfaces for setting up problems and interpreting results. The effort involved in developing such models is focussed mainly on interfacing between existing models and is much less than developing a model from scratch.

Three types of SO algorithm are commonly used, all of which uncouple the solution of the transport and the reaction (and mass transfer) operators [106,117,145, $146,148,150-153,156-166]$. This uncoupled nature allows for the straightforward combination of multiple models into a single simulator. However, SO approaches lead to an additional source of numerical error, usually proportional to $\Delta t$, the numerical time step of the discrete approximation.

The sequential SO (SSO) algorithm is summarised by

\section{SSO Algorithm}

For $t \in\left\{t_{0}, t_{0}+\Delta t\right\}$,

Step 1. Let $\hat{\theta}^{\mathrm{a}}\left(\mathbf{x}, t_{0}\right) \hat{C}^{\mathrm{a}}\left(\mathbf{x}, t_{0}\right)=\theta^{\mathrm{a}}\left(\mathbf{x}, t_{0}\right) C^{\mathrm{a} a}\left(\mathbf{x}, t_{0}\right)$,

Solve $\frac{\partial}{\partial t}\left(\hat{\theta}^{\mathrm{a}} \hat{C}^{\mathrm{a}}\right)=L_{\mathrm{t}}$.

Step 2. Let $\theta^{\mathrm{a}}\left(\mathbf{x}, t_{0}\right) C^{\text {ta }}\left(\mathbf{x}, t_{0}\right)=\hat{\theta}^{\mathrm{a}}\left(\mathbf{x}, t_{0}+\Delta t\right)$

$\hat{C}^{\mathrm{la}}\left(\mathbf{x}, t_{0}+\Delta t\right)$,

Solve $\frac{\partial}{\partial t}\left(\theta^{\mathrm{a}} C^{\mathrm{a}}\right)=L_{\mathrm{r}}$,

where $L_{\mathrm{t}}$ is a transport operator, and $L_{\mathrm{r}}$ is a reaction operator. The SSO algorithm is common and easy to implement but has a splitting error $\epsilon_{\mathrm{s}}=\mathrm{O}(\Delta t)$ [148].

The alternating SO (ASO) algorithm, also known as Strang splitting [167], is summarised by

\section{ASO Algorithm}

Step 1. For $t \in\left\{t_{0}, t_{0}+\Delta t / 2\right\}$, Let $\hat{\theta}^{\mathrm{a}}\left(\mathbf{x}, t_{0}\right) \hat{C}^{\mathrm{a}}\left(\mathbf{x}, t_{0}\right)=\theta^{\mathrm{a}}\left(\mathbf{x}, t_{0}\right) C^{\mathrm{a}}\left(\mathbf{x}, t_{0}\right)$,

Solve $\frac{\partial}{\partial t}\left(\hat{\theta}^{\mathrm{a}} \hat{C}^{i \mathrm{a}}\right)=L_{\mathrm{t}}$.

Step 2. For $t \in\left\{t_{0}, t_{0}+\Delta t\right\}$,

Let $\tilde{\theta}^{\mathrm{a}}\left(\mathbf{x}, t_{0}\right) \tilde{C}^{\mathrm{a} a}\left(\mathbf{x}, t_{0}\right)=\hat{\theta}^{\mathrm{a}}\left(\mathbf{x}, t_{0}+\Delta t / 2\right) \hat{C}^{1 a}\left(\mathbf{x}, t_{0}+\Delta t / 2\right)$,

Solve $\frac{\partial}{\partial t}\left(\tilde{\theta}^{\alpha} \tilde{C}^{i \alpha}\right)=L_{\mathrm{r}}$.

Step 3. For $t \in\left\{t_{0}+\Delta t / 2, t_{0}+\Delta t\right\}$,

Let $\theta^{\mathrm{a}}\left(\mathbf{x}, t_{0}+\Delta t / 2\right) C^{\mathrm{a}}\left(\mathbf{x}, t_{0}+\Delta t / 2\right)=\tilde{\theta}^{\mathrm{a}}\left(\mathbf{x}, t_{0}+\Delta t\right)$ $\tilde{C}^{t \mathrm{a}}\left(\mathbf{x}, t_{0}+\Delta t\right)$,

Solve $\frac{\partial}{\partial t}\left(\theta^{\alpha} C^{i x}\right)=L_{\mathrm{t}}$.
The ASO algorithm requires more computational effort than the SSO algorithm, but the splitting error, $\epsilon_{\mathrm{s}}$, is $\mathrm{O}\left(\Delta t^{2}\right)$ [148], at least for linear reactions [106,153].

The iterative SO (ISO) algorithm decouples the transport and reaction operators as is the case with other SO algorithms, but unlike the other algorithms it iterates through the steps until some error tolerance is reached [168]. The ISO algorithm is

\section{ISO Algorithm}

For $t \in\left\{t_{0}, t_{0}+\Delta t\right\}$,

Let $m=1$,

While $\epsilon_{\mathrm{s}}>\epsilon_{\mathrm{a}}$, repeat,

Step 1. Let $\hat{\theta}_{m+1}^{\mathrm{a}}\left(\mathbf{x}, t_{0}\right) \hat{C}_{m+1}^{\mathrm{a} a}\left(\mathbf{x}, t_{0}\right)=\theta^{\mathrm{a}}\left(\mathbf{x}, t_{0}\right) C^{\mathrm{a} a}\left(\mathbf{x}, t_{0}\right)$,

$$
\text { Solve } \frac{\partial}{\partial t}\left(\hat{\theta}_{m+1}^{\mathrm{a}} \hat{C}_{m+1}^{\mathrm{aa}}\right)=L_{\mathrm{t}}+\hat{L}_{\mathrm{r}} \text {. }
$$

Step 2. Let $\theta_{m+1}^{\mathrm{a}}\left(\mathbf{x}, t_{0}\right) C_{m+1}^{\mathrm{a}}\left(\mathbf{x}, t_{0}\right)=\theta^{\mathrm{a}}\left(\mathbf{x}, t_{0}\right) C^{\mathrm{a}}\left(\mathbf{x}, t_{0}\right)$,

$$
\text { Solve } \frac{\partial}{\partial t}\left(\theta_{m+1}^{\mathrm{a}} C_{m+1}^{\mathrm{a}}\right)=\hat{L}_{\mathrm{t}}+L_{\mathrm{r}}
$$

Step 3. Let $m=m+1$,

where $\hat{L}_{\mathrm{t}}$ and $\hat{L}_{\mathrm{r}}$ approximate the transport and reaction operators that uncouple the solution procedures, while limiting the splitting error. Given $\epsilon_{\mathrm{a}}>0$, the stopping criterion is based on computation of $\epsilon_{\mathrm{s}}$, a suitable norm of the difference between computed concentrations for successive iterations. The iterative nature of the algorithm can further reduce the splitting error to whatever tolerance is needed. While the ISO algorithm is more accurate than either the SSO or ASO algorithms, the increased accuracy comes at the expense of additional computational effort per step.

A key aspect of all the SO methods presented here is that all the reaction computations $\left(L_{\mathrm{r}}\right)$ are carried out for each grid cell (in a spatially discretised domain) independently from the neighbouring grid cells, allowing for easy implementation on parallel computer architectures. However, obtaining good performance in a parallel processing environment is not trivial, nor is it the focus of this work. Load balancing and communication issues for all steps in the algorithm will in general require careful consideration. Note that, within this step, each grid cell is treated as a closed system. That is, the total concentration of each chemical component, consisting of the sum of aqueous, sorbed, precipitated and gas-phase concentrations, does not change, although the distribution within these phases and the concentration of species will vary.

$L_{\mathrm{r}}$ is used to represent both interphase mass transfer processes and biochemical reactions. As we have noted already, the rates at which mass transfer and reactions proceed in relation to the rate at which the chemicals are transported provide the criteria for choosing an appropriate (mathematical) solution technique to describe 
accurately the reactive processes. Under the assumption that all reactive processes proceed rapidly in comparison to groundwater flow and transport, interphase mass transfer processes can be represented using the local equilibrium assumption (LEA), and biochemical reactions proceed to completion. While the LEA can reduce the number of equations requiring solution, it can lead to modifications in the $\mathrm{SO}$ algorithms and complicate the use of well-established component models.

The SO algorithms outlined above, or variants of them, are important aspects of the solution of complex biogeochemical problems. While the algorithmic discussion above was presented in terms of two differential operators, it is necessary in some circumstances to extend these algorithms to more than two operators. This would be the case if, for example, separate codes were used for transport, interphase mass transfer, biological reactions and geochemical reactions. Subdividing $L_{\mathrm{r}}$ and $L_{\mathrm{t}}$ into component parts would extend the algorithms. General error analysis for all SO methods and convergence theory for ISO remains to be developed for a wide range of conditions of practical importance, although recently encouraging progress has been reported [169]. Splitting error, and thus the appropriate choice of algorithm, depends upon the relative magnitude of each operator in the overall system. In general, as the contrast in the magnitude of the operators grow, the splitting error decreases. Conversely, operators of a similar magnitude are expected to have the largest splitting errors. In such cases, the ASO or ISO algorithm would usually be a better choice than the simpler SSO algorithm. In certain cases, it may be advantageous to use a fully coupled approach [117].

\section{Numerical approximations}

The models of interest in this work require numerical approximations. These approximations involve discretisation in space and time. The purpose of this work is not to comment on the details of modern numerical methods, as several other efforts in this special issue are focused on this topic. However, it is worthwhile to annotate the features of any state-of-the-art simulator:

- the fluid flow solver should be able to handle heterogeneous conditions and the evolution of a trapped NAPL phase, be mass conservative, accommodate irregularly shaped domains and have locally conservative velocity fields;

- the transport solver should be able to resolve sharp fronts without excessive numerical dispersion or oscillations, be locally and globally mass conservative, and accommodate irregularly shaped domains;

- the interphase mass transfer and reaction solvers should be flexible in terms of the number and range of species handled and the processes accounted for, and use robust and accurate time-integration methods; and

- ideally, all components would include spatial and temporal error estimation and control through adaption of the solution discretisation and/or order of the approximation method, overall error control on the operator-splitting algorithm and be suitable for parallel processing.

Although most of the elements outlined have been accomplished individually we know of no single subsurface reactive biogeochemical flow and transport simulator that approaches this entire list of specifications. Indeed, this level of sophistication requires a considerable amount of additional work.

Correct modelling of physical processes is particularly important for natural attenuation, as predictions of the fate of organic contaminants often rely heavily on physical transport. Solving the advection-dispersion equation numerically, i.e., Eq. (8) without the reaction or source terms, is the first, essential step in modelling the fate and transport of multi-component organic contaminants in groundwater. Unfortunately, obtaining an accurate numerical solution for the advection-dispersion equation is difficult $[170,171]$. No single technique yet yields completely satisfactory solutions under all hydrogeological conditions. In the groundwater modelling community, most solution techniques fall into three categories, i.e., Eulerian, Lagrangian and mixed Eulerian-Lagrangian [172,173]. Here, we briefly summarise the evolution of these approaches and associated numerical methods - much fuller discussions of these issues are available elsewhere in this special issue [174].

- Finite difference or finite element (Eulerian) methods [106,175-178]. For advection-dominated problems, standard Eulerian methods are susceptible to excessive numerical dispersion and/or artificial oscillation. To mitigate these difficulties, very fine spatial and temporal discretisations may be required.

- Particle tracking-based (Lagrangian) methods [49, 179-185]. This approach, as typified by the randomwalk particle methods, is highly efficient and virtually free of numerical dispersion. However, it can lead to local mass balance errors [184] and to numerical instability in non-uniform media with multiple sinks/ sources and complex boundary conditions [186].

- Mixed Eulerian-Lagrangian methods [186-200]. These combine particle tracking for advection and finite-difference (FD) or finite-element (FE) methods for nonadvective terms. They suffer from some of the same numerical difficulties as the random-walk particle methods and, depending on the approach used, do not guarantee mass conservation. For this reason, 
more recent efforts have focused on developing massconservative Eulerian-Lagrangian schemes, such as the Eulerian-Lagrangian localised adjoint method [193,197,201].

- Total-variation-diminishing (TVD) methods (e.g., [171, 202-215]). TVD methods are essentially mass conservative higher order FD (or finite-volume) methods. They are typically implemented with a flux limiter to suppress spurious oscillations while preserving the sharp concentration fronts.

- Multi-grid methods [216-219]. These methods use a sequence of nested meshes with increasing fineness to attain convergence to a desired level of discretisation error [220,221]. Related families of methods include local grid refinement and domain decomposition [222-225].

\section{Scale issues}

Scale effects pervade the hydrological sciences. For example, a practical problem is to incorporate the effect of heterogeneity of medium properties into flow and transport simulations which, by necessity, operate on a discretisation length scale. Not surprisingly, scale issues are manifest under many titles, including upscaling, homogenisation, effective medium theory and stochastic transport theory.

One major thrust of dealing with the effect of hydraulic conductivity heterogeneity on solute transport has been to determine macroscopic dispersion coefficients analytically [226-228]. This approach, while appropriate for plumes dominated by physical flow processes, is not likely to be directly useful for numerical modelling of non-linear reactive transport given the sensitivity of microbial degradation of organic compounds to redox state. For contaminant plumes, redox state can vary markedly over short distances. As has been noted [229-232], mixing between contaminated and native groundwater largely controls the rate of degradation of the contaminant. For example, if aerobic biodegradation dominates, then the degradation rate will be controlled by availability of oxygen (and perhaps nitrate if facultative bacteria are involved). The flux into a plume thus depends on oxygen diffusion, geometrical factors such as the contaminant plume surface area, as well as geochemistry and oxygen recharge rate. In shallow aquifers, boundary conditions are likely to be changing and in enhanced remediation schemes the system will be subjected to relatively large changes. Upscaling of nonlinear processes under such conditions is a significant challenge. Nonetheless, investigators have reported studies of relatively simple biodegradation models [233235 ] where the effects of heterogeneity have been computed. It is unclear whether these approaches would be suitable for complex geochemical systems with many chemical constituents, mineral types and microbial species, such as those of concern in this work.

\section{Examples of available simulators}

As mentioned, we know of no single simulator which covers the complete range of the processes discussed above. For example, reactions included in many of the earlier [13,16,127,236-241] but also the more recent biodegradation models [242-246] are limited to a small number of aqueous species that are directly involved in the primary biodegradation reaction. Apart from the model of Malone et al. [247] and BIONAPL3D [246], both of which allow the simulation of equilibrium and/ or kinetic dissolution of organic compounds from multicomponent NAPL mixtures, biodegradation models typically do not include the option of mass transfer processes. Previously, most comprehensive geochemical codes had no transport capabilities [118-122] or were lacking the option to simulate kinetic reactions [248253]. However, in the recent past numerous models and applications have combined biodegradation reactions and the resulting secondary geochemical reactions [254 258]. For instance, the RT3D model [243], which has become a widely applied reactive transport model, is a modular reactive package that makes use of the implicit ODE solver LSODA $[259,260]$ to solve kinetic reaction problems. While it does not a priori have any geochemical reactions included, it allows the definition of arbitrary kinetic reactions and thus, in principle, the inclusion of secondary reactions that occur in the aqueous phase.

Detailed overviews of biogeochemical/flow/transport models are available through several process- or application-specific studies in the literature as well as through comprehensive model surveys [18,20,261,262], which list and compare model capabilities. More recent reviews of biodegradation models and/or of biogeochemical models are also available [29,263-268]. In addition, Table 1 gives examples of models that have significant geochemical capabilities and can also include biodegradation reactions of organic compounds. It was compiled from models that

- include a three-dimensional transport simulator;

- have previously been applied to problems involving the fate of organic compounds;

- can solve both equilibrium and kinetically controlled geochemical reactions; and

- allow a flexible definition of reactive processes.

The combination of the latter two attributes assures that users can relatively easily adapt the numerical simulator to a broad range of conceptual hydrogeo- 
Examples of available simulators

\begin{tabular}{llllll}
\hline Model and reference & Model application & Solution method & Saturated/Unsaturated & Advection scheme & Microbial modelling \\
\hline CRUNCH [144,275] & {$[274]$} & SO/GIM & Yes/No & FD/TVD & No \\
PHT3D [271] & {$[273]$} & SO & Yes/No & FD/TVD/MOC & Yes \\
PHAST [270] & {$[276,277]$} & SO & Yes/No & FD & Yes \\
MIN3P [279] & {$[278]$} & GIM & Yes/Yes & FD & No \\
TBC [282] & {$[280,281]$} & SO & Yes/No & FD & Yes \\
HBGC123D [284,285] & {$[283]$} & SO & Yes/Yes & FE & Yes \\
\hline
\end{tabular}

chemical modelling problems. For example, in the PHREEQC-2-based [269] models PHAST [270] and PHT3D [271,272], processes such as microbial activity and NAPL-dissolution can be defined within the reaction database file [273].

\section{Biogeochemical modelling illustrations}

The foregoing modelling section (Section 2) presents a framework for simulating transformations of organic chemicals in groundwater. In this section, we focus on the detailed formulation of models for describing such transformations, providing some examples which show the effects of different assumptions. The SO framework conveniently allows separating classes of processes. Here, we discuss first biogeochemical modelling, before subsequently combining it with physical transport in Sections 8 and 9.

Microbially mediated degradation of dissolved organic compounds is strongly dependent on the redox state. Indeed, typically, we can expect the redox sequence shown in Fig. 1 to be followed, i.e., aerobic degradation occurs first as it is the most energetically favourable, followed by anaerobic degradation under the following sequence: nitrate reducing, manganese reducing, sulfate reducing, iron reducing and, finally, methanogenesis. Reaction rates decrease according to the difference in redox potential (distance between each half of the redox couple). This well-known sequence is discussed fully elsewhere [100]. Note that pe refers to the reduction (upper) part of the diagram.

\subsection{Biodegradation modelling}

Biochemical activity capable of transforming organic compounds into inorganic constituents plays a substantial role in the evolution of groundwater quality in both contaminated and uncontaminated aquifers. The main role of the biological activity within the transformations is to enhance reaction rates (relative to comparable abiotic reactions), accelerating reactions by factors of $10^{9}$ or more [52]. However, only thermodynamically possible reactions can be carried out by the organisms. Thus, the degradation of many contaminants may only occur within a reasonable time frame through the catalysing function of bacteria. Generally, these bacteria are attached to the aquifer matrix with a negligible portion present in the aqueous phase [286]. The biomass, together with extracellular polymer substances, forms, depending on its concentration, a more-or-less uniform coverage of the solid surface. The

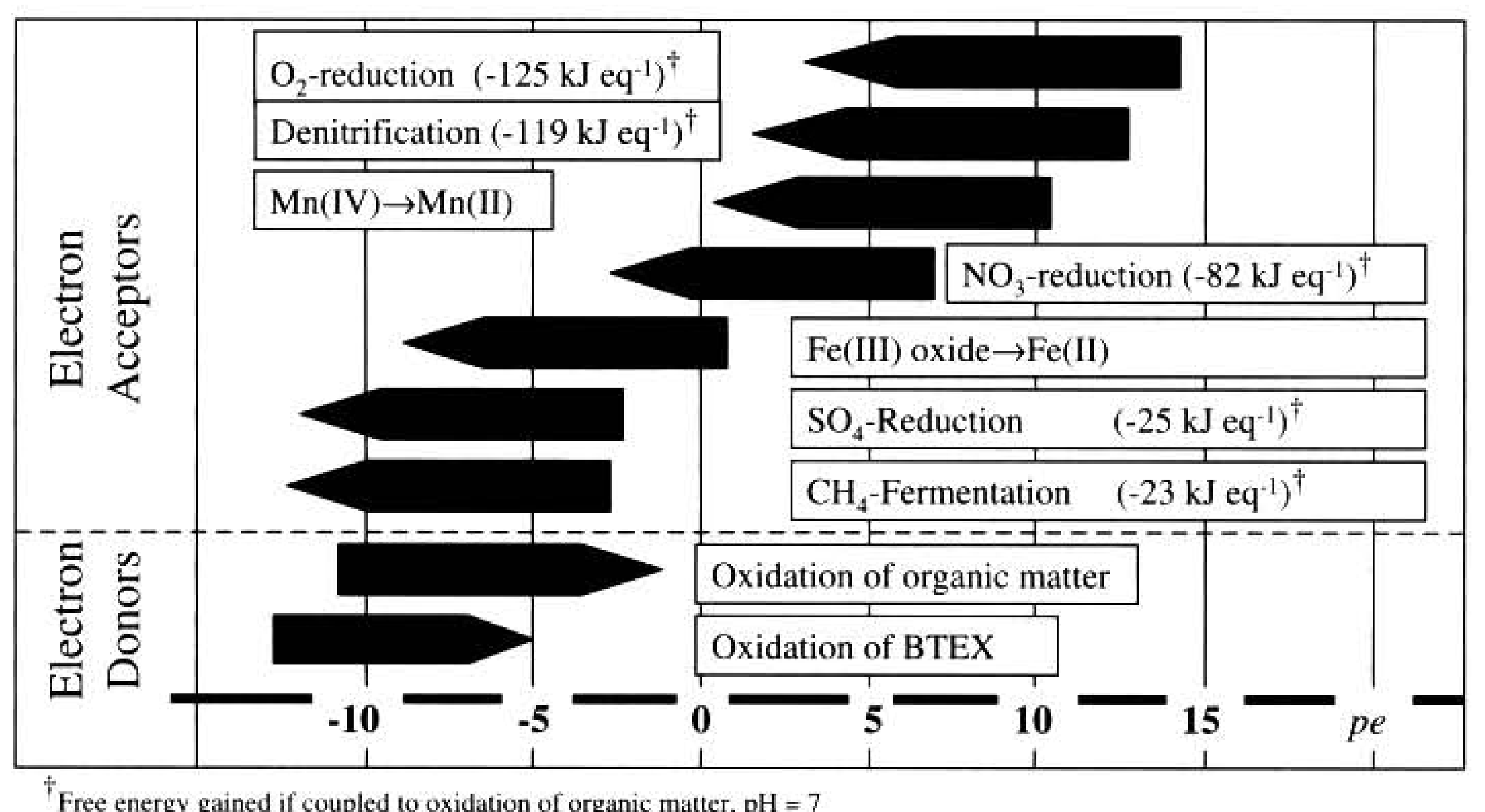

Free energy gained if coupled to oxidation of organic matter, $\mathrm{pH}=7$

Fig. 1. Redox sequence (after [100]) showing organics (below dashes) that donate electrons and species that accept electrons (above dashes). For each redox state, an estimate of the energy gained for oxidation of organic matter is shown ( $\mathrm{pH} 7$ assumed). 
biomass attached to the solid phase typically consists of a rather structured base film with well-defined boundaries and of a surface film as a transition zone to the bulk liquid [287]. Within the surface film advection is the dominating transport mechanism, while within the base film diffusional transport dominates.

Modelling of redox chemistry as affected by microbial degradation reactions involves detailed descriptions of electron transfers within the base film. The electron flow in reactions where organic substances act as electron donors, e.g., petroleum hydrocarbons, can be described by two steps. The first step is the oxidation of an organic substrate which has diffused into the microbial base film. In this step, electrons are transferred to electron carriers such as reduced nicotinamide adenine dinucleotide (NADH) [265,288]. The oxidation reactions for some common organic contaminants are listed in Table 2. In each reaction, an electron transfer occurs to form $\mathrm{NADH}$ on the right-hand side.

The electrons gained in this first step can now be further transferred [288] either to extracellular electron acceptors $\left(\mathrm{O}_{2}, \mathrm{NO}_{3}^{-}\right.$, etc. $)$, or they can be used to form new biomass. Respiration, the transfer of electrons to extracellular electron acceptors, involves the (re)oxidation of NADH. Several such reactions are collected in Table 3 . In a soil solution, reaction products appearing in this table would be subject to further reactions.

Electron-accepting reactions produce energy, which can then be stored as adenosine triphosphate and, together with $\mathrm{NADH}$, reinvested to generate new biomass. Assuming a simplified chemical composition for biomass $\left(\mathrm{C}_{5} \mathrm{H}_{7} \mathrm{O}_{2} \mathrm{~N}\right)$, the reaction in which the electron flow is diverted towards the generation of new biomass is described by [265]

Table 2

Oxidation reactions for selected oxidisable organic compounds/contaminants

\footnotetext{
DOC, i.e., $\mathrm{CH}_{2} \mathrm{O}$

$\mathrm{CH}_{2} \mathrm{O}+2 \mathrm{NAD}^{+}+2 \mathrm{H}_{2} \mathrm{O} \rightarrow 2 \mathrm{NADH}+3 \mathrm{H}^{+}+\mathrm{HCO}_{3}^{-}$

Benzene

$\mathrm{C}_{6} \mathrm{H}_{6}+15 \mathrm{NAD}^{+}+18 \mathrm{H}_{2} \mathrm{O}-15 \mathrm{NADH}+21 \mathrm{H}^{+}+6 \mathrm{HCO}_{3}^{-}$

Toluene

$\mathrm{C}_{7} \mathrm{H}_{8}+18 \mathrm{NAD}^{+}+21 \mathrm{H}_{2} \mathrm{O} \rightarrow 18 \mathrm{NADH}+25 \mathrm{H}^{+}+7 \mathrm{HCO}_{3}^{-}$

Ethylbenzene/xylenes

$\mathrm{C}_{8} \mathrm{H}_{10}+21 \mathrm{NAD}^{+}+24 \mathrm{H}_{2} \mathrm{O} \rightarrow 21 \mathrm{NADH}+29 \mathrm{H}^{+}+8 \mathrm{HCO}_{3}^{-}$

Phenol

$\mathrm{C}_{6} \mathrm{H}_{5} \mathrm{OH}+14 \mathrm{NAD}^{+}+17 \mathrm{H}_{2} \mathrm{O} \rightarrow 14 \mathrm{NADH}+20 \mathrm{H}^{+}+6 \mathrm{HCO}_{3}^{-}$

Naphthalene

$\mathrm{C}_{10} \mathrm{H}_{8}+24 \mathrm{NAD}^{+}+30 \mathrm{H}_{2} \mathrm{O} \rightarrow 24 \mathrm{NADH}+34 \mathrm{H}^{+}+10 \mathrm{HCO}_{3}^{-}$

Phenanthrene

$\mathrm{C}_{14} \mathrm{H}_{10}+33 \mathrm{NAD}^{+}+42 \mathrm{H}_{2} \mathrm{O} \rightarrow 33 \mathrm{NADH}+47 \mathrm{H}^{+}+14 \mathrm{HCO}_{3}^{-}$

Dibenzofuran

$\mathrm{C}_{12} \mathrm{H}_{8} \mathrm{O}+27 \mathrm{NAD}^{+}+35 \mathrm{H}_{2} \mathrm{O} \rightarrow 27 \mathrm{NADH}+39 \mathrm{H}^{+}+12 \mathrm{HCO}_{3}^{-}$

Molasses

$\mathrm{C}_{6} \mathrm{H}_{12} \mathrm{O}_{6}+12 \mathrm{NAD}^{+}+12 \mathrm{H}_{2} \mathrm{O} \rightarrow 12 \mathrm{NADH}+18 \mathrm{H}^{+}+6 \mathrm{HCO}_{3}^{-}$
}

Table 3

Electron-accepting reactions

$$
\begin{array}{r}
10 \mathrm{NADH}+5 \mathrm{H}_{2} \mathrm{CO}_{3}+\mathrm{NH}_{4}^{+}+9 \mathrm{H}^{+} \\
\rightarrow \mathrm{C}_{5} \mathrm{H}_{7} \mathrm{O}_{2} \mathrm{~N}+10 \mathrm{NAD}^{+}+13 \mathrm{H}_{2} \mathrm{O}
\end{array}
$$

The electrons gained in oxidation of organic species (e.g., Table 2) are diverted between the electron-accepting step (according to the reactions listed in Table 3) and biomass generation according to Eq. (44). The ratio of this diversion depends on the microbial efficiency (fraction of oxidised organic carbon that is incorporated into biomass), the determination of which is experimentally based. Depending on both the organic substrate and the electron acceptor, the efficiency can vary significantly. For the electron-accepting reactions which yield the most energy, i.e., oxygen and nitrate reduction (Fig. 1), efficiency can be as high as $50-70 \%$ while it can be as low as $5 \%$ for $\mathrm{CO}_{2}$ fixation [265]. Degradation of toluene and xylene under sulfate-reducing conditions has been investigated [289]. Using ${ }^{14} \mathrm{C}$-labelled substrate, it was found that only about $10 \%$ of the organic carbon was converted to cell material while $90 \%$ of organic carbon was utilised as an energy source and converted to carbon dioxide. Clearly, the stoichiometry of the overall reaction (in which the intermediate $\mathrm{NAD}^{+}$reducing step is formally eliminated) depends on the efficiency of the microorganisms. For a given efficiency, balancing the reaction leads, in the above-mentioned case (oxidation/ mineralisation of dissolved organic carbon (DOC), i.e., $\mathrm{CH}_{2} \mathrm{O}$, under aerobic conditions, $50 \%$ efficiency), to the following reaction

$$
\begin{aligned}
& \mathrm{CH}_{2} \mathrm{O}+0.1 \mathrm{NO}_{3}^{-}+0.3 \mathrm{O}_{2} \\
& \quad \rightarrow 0.5 \mathrm{HCO}_{3}^{-}+0.1 \mathrm{C}_{5} \mathrm{H}_{7} \mathrm{O}_{2} \mathrm{~N}+0.4 \mathrm{H}^{+}+0.2 \mathrm{H}_{2} \mathrm{O}
\end{aligned}
$$

Assuming a lower $(10 \%)$ efficiency, balancing the oxidation/mineralisation of DOC under sulfate-reducing conditions leads to

$$
\begin{aligned}
\mathrm{CH}_{2} \mathrm{O} & +0.02 \mathrm{NH}_{4}^{+}+0.45 \mathrm{SO}_{4}^{2-} \\
\rightarrow & 0.9 \mathrm{HCO}_{3}^{-}+0.02 \mathrm{C}_{5} \mathrm{H}_{7} \mathrm{O}_{2} \mathrm{~N}+0.45 \mathrm{H}_{2} \mathrm{~S} \\
& +0.06 \mathrm{H}_{2} \mathrm{O}+0.02 \mathrm{H}^{+}
\end{aligned}
$$

Table IV of [29] contains the reaction formulas for biodegradation of $\mathrm{CH}_{2} \mathrm{O}$ for the complete redox sequence given in Fig. 1. Those formulas are written for arbitrary proportions of electrons being diverted to microbial growth and energy generation. 
The reactions given in Eqs. (45) and (46) describe the stoichiometry of microbial growth (represented by $\left.\mathrm{C}_{5} \mathrm{H}_{7} \mathrm{O}_{2} \mathrm{~N}\right)$ under different redox conditions. Note that, due to the difference in $\mathrm{C}$ valence between $\mathrm{C}_{5} \mathrm{H}_{7} \mathrm{O}_{2} \mathrm{~N}$ and $\mathrm{HCO}_{3}^{-}$, the conversion of organic carbon into biomass consumes less oxidation capacity [273] than the conversion of biomass into inorganic carbon. However, the decay of bacteria is also consuming oxidation capacity, e.g.,

$$
\mathrm{C}_{5} \mathrm{H}_{7} \mathrm{O}_{2} \mathrm{~N}+5 \mathrm{O}_{2}+3 \mathrm{H}_{2} \mathrm{O} \rightarrow 5 \mathrm{HCO}_{3}^{-}+\mathrm{NH}_{4}^{+}+4 \mathrm{H}^{+}
$$

under aerobic conditions, or, under sulfate-reducing conditions

$$
\begin{aligned}
\mathrm{C}_{5} \mathrm{H}_{7} \mathrm{O}_{2} \mathrm{~N}+3 \mathrm{H}_{2} \mathrm{O}+2.5 \mathrm{SO}_{4}^{2-} \\
\quad \rightarrow 5 \mathrm{HCO}_{3}^{-}+2.5 \mathrm{HS}^{-}+1.5 \mathrm{H}^{+}+\mathrm{NH}_{4}^{+}
\end{aligned}
$$

We consider first the case where microbial growth and decay are balanced, such that the microbial population size is constant. Then, microbial degradation of DOC under aerobic conditions can be described by combining Eqs. (45) and (47) with nitrification (i.e., $\mathrm{NH}_{4}^{+}+2 \mathrm{O}_{2} \rightarrow$ $\mathrm{NO}_{3}^{-}+\mathrm{H}_{2} \mathrm{O}+2 \mathrm{H}^{+}$). The overall reaction becomes

$\mathrm{CH}_{2} \mathrm{O}+\mathrm{O}_{2} \rightarrow \mathrm{HCO}_{3}^{-}+\mathrm{H}^{+}$

This expression is also obtained by combining the first equation in Table 2 with the first equation in Table 3.

Alternatively, again for a constant microbial mass, DOC degradation under sulfate-reducing conditions can be described by combining Eqs. (46) and (48) or by combining the DOC oxidation reaction from Table 2 with the sulfate-reducing reaction in Table 3

$$
\mathrm{CH}_{2} \mathrm{O}+0.5 \mathrm{SO}_{4}^{2-} \rightarrow \mathrm{HCO}_{3}^{-}+0.5 \mathrm{H}_{2} \mathrm{~S}
$$

The above biodegradation reactions are irreversible and proceed at variable rates. Based on the given stoichiometric relationships and appropriate reaction rate parameters, kinetic reaction models as described in Section 2.4.2 can easily be developed. Further, from the stoichiometry of an overall reaction, such as Eq. (50), the stoichiometric coefficients can be used directly to compute the (proportional) consumption or production of the other chemicals involved in this reaction as long as any further, secondary reactions are neglected. Alternatively, the biodegradation reaction could be assumed to be instantaneous, as we have presented in Eq. (21). We recall that, in this case, the reaction rate is limited only by the availability of either the electron acceptor or donor, i.e., the reaction is assumed to proceed at an infinite rate until either of these is depleted [127,128, 290,291].

So far, we have assumed that the biomass concentration remains constant with time (although it can vary spatially) throughout the model domain. Since the dynamics of biomass growth will play an important role in the quantification of the biodegradation reactions, we next discuss rate expressions where changes in biomass concentrations, i.e., microbial growth and decay, are explicitly quantified.

\subsection{Microbial kinetics}

During biomass growth both organic substrate and electron acceptors are consumed at rates quantified according to the models presented in Section 2.4.3. Thus, for a known reaction stoichiometry and knowledge of appropriate rate parameters, the actual rates can be determined. In the following we consider several microbially mediated degradation models. At present, no chemical transport is considered, however. Details of the five cases considered are presented in Table 4 (models used and initial conditions) and Table 5 (parameter values). Note: in these examples no sorption reactions are included.

In case 1 , we consider microbially mediated DOC degradation under aerobic conditions using two different approaches. Case la considers bacterial growth and decay using the the detailed stoichiometry derived from Eqs. (45) and (47), respectively. For comparison, in case lb we again consider bacterial growth and decay but use a simpler model based on the stoichiometry taken from Eq. (49). The latter simplification is made in most biodegradation models.

For this first example, we demonstrate in some detail how the modelling approach presented in Section 2.4.3 is applied. We note that no transport is involved, the aqueous phase volume fraction is taken as constant, no sources are present and that interphase mass transfer does not occur. The transport Eq. (8) becomes

$\frac{\mathrm{d}}{\mathrm{d} t}\left(\theta^{\mathrm{a}} C^{\mathrm{a} a}\right)=\mathscr{R}^{\mathrm{a}}$,

an expression that we now combine with appropriate forms of Eqs. (31) (34).

For case $1 \mathrm{~b}$, the primary chemical species involved are $\mathrm{CH}_{2} \mathrm{O}$ (DOC) and $\mathrm{O}(0)$, as well as the microbial population represented by $\mathrm{C}_{5} \mathrm{H}_{7} \mathrm{O}_{2} \mathrm{~N}$, with concentrations $\mathrm{C}^{\mathrm{CH}_{2} \mathrm{O}}, \mathrm{C}^{\mathrm{O}(0)}$ and $\mathrm{C}^{\mathrm{C}_{5} \mathrm{H}_{7} \mathrm{O}_{2} \mathrm{~N}}$, respectively. The combination of Eqs. (31) and (51) give

$$
\begin{aligned}
\frac{\mathrm{d} C^{\mathrm{CH}_{2} \mathrm{O}}}{\mathrm{d} t}= & -\frac{\mu_{\mathrm{m}}^{\mathrm{CH}_{2} \mathrm{O}} C^{\mathrm{C}_{5} \mathrm{H}_{7} \mathrm{O}_{2} \mathrm{~N}}}{Y^{\mathrm{CH}_{2} \mathrm{O}}} \frac{C^{\mathrm{CH}_{2} \mathrm{O}}}{\left(K_{\mathrm{s}}^{\mathrm{CH}_{2} \mathrm{O}}+C^{\mathrm{CH}_{2} \mathrm{O}}\right)} \\
& \times \frac{C^{\mathrm{O}(0)}}{\left(K_{\mathrm{s}}^{\mathrm{O}(0)}+C^{\mathrm{O}(0)}\right)},
\end{aligned}
$$

where the concentration of $\mathrm{O}(0)$ has been included as a rate-limiting factor while $Y^{\mathrm{CH}_{2} \mathrm{O}}=0.1$ from Eq. (45). The microbial population growth rate is, from Eq. (32)

$\frac{\mathrm{d} C^{\mathrm{C}_{5} \mathrm{H}_{7} \mathrm{O}_{2} \mathrm{~N}}}{\mathrm{~d} t}=Y^{\mathrm{CH}_{2} \mathrm{O}} \frac{\mathrm{d} C^{\mathrm{CH}_{2} \mathrm{O}}}{\mathrm{d} t}-k_{\mathrm{d}} C^{\mathrm{C}_{5} \mathrm{H}_{7} \mathrm{O}_{2} \mathrm{~N}}$. 
Table 4

Initial concentrations of aqueous components, bacterial mass and minerals used in the batch modelling examples

\begin{tabular}{|c|c|c|c|c|c|}
\hline Species & $\begin{array}{l}\text { Cases } \\
\text { la,b }\end{array}$ & $\begin{array}{l}\text { Case } \\
2\end{array}$ & $\begin{array}{l}\text { Case } \\
3\end{array}$ & $\begin{array}{l}\text { Case } \\
4\end{array}$ & $\begin{array}{l}\text { Case } \\
5\end{array}$ \\
\hline $\mathrm{CH}_{2} \mathrm{O}$ & 0.1 & & & & \\
\hline Benzene & & 0.4 & & & \\
\hline Toluene & & 0.3 & 0.3 & 0.3 & 0.2 \\
\hline Ethylbenzene & & 0.1 & & & \\
\hline Xylene & & 0.25 & & & \\
\hline $\mathrm{O}(0)^{\mathrm{b}}$ & 0.2 & & 0.625 & & 0.625 \\
\hline$S(6)$ & & 5 & 0.5 & 0.415 & \\
\hline $\mathrm{N}$ & 0.05 & 0.1 & 0.025 & & 0.2 \\
\hline $\mathrm{Fe}(2)$ & & & & & 0 \\
\hline $\mathrm{Fe}(3)$ & & & & & $2.72 \times 10^{-5}$ \\
\hline $\mathrm{Ca}$ & & & & & 3.23 \\
\hline $\mathrm{Na}$ & 1 & 1 & 1 & 1 & 1 \\
\hline $\mathrm{Cl}$ & 1 & 1 & 1 & 1 & 6.17 \\
\hline $\mathrm{C}(4)$ & & & & & 1.12 \\
\hline Aerobes & $10^{-5}$ & & $10^{-5}$ & & \\
\hline SRB & & $10^{-5}$ & $10^{-5}$ & $10^{-5}$ & \\
\hline $\begin{array}{l}\text { Facultative } \\
\text { aerobes or } \\
\text { iron-reducer }\end{array}$ & & & & & $10^{-5}$ \\
\hline Calcite $\left(\mathrm{CaCO}_{3}\right)$ & & & & & 2 \\
\hline $\begin{array}{l}\text { Goethite } \\
(\mathrm{FeOOH})\end{array}$ & & & & & 4 \\
\hline Siderite $\left(\mathrm{FeCO}_{3}\right)$ & & & & & 0 \\
\hline
\end{tabular}

"Concentrations in mmoll-1.

${ }^{b}$ Notation showing redox state.

Table 5

Parameters used in the batch-type modelling examples

\begin{tabular}{|c|c|c|c|c|c|}
\hline Parameter & $\begin{array}{l}\text { Cases } \\
\text { la,b }\end{array}$ & $\begin{array}{l}\text { Case } \\
2\end{array}$ & $\begin{array}{l}\text { Case } \\
3\end{array}$ & $\begin{array}{l}\text { Case } \\
4\end{array}$ & $\begin{array}{l}\text { Case } \\
5\end{array}$ \\
\hline$\mu_{m}^{\mathrm{CH}}=\left(\mathbf{d}^{-1}\right)$ & 25 & & & & \\
\hline$\mu_{\mathrm{m}}^{\text {benuene sulf }}\left(\mathrm{d}^{-1}\right)$ & & 0.4 & & 5 & \\
\hline$\mu_{\mathrm{m}}^{\text {toluene aerob }}\left(\mathrm{d}^{-1}\right)$ & & & 10 & & 10 \\
\hline$\mu_{\mathrm{m}}^{\text {oiluene sulf. }}\left(\mathrm{d}^{\prime}\right)$ & & 10 & 5 & & \\
\hline$\mu_{\mathrm{m}}^{\text {toluene poeth }}\left(\mathrm{d}^{-1}\right)$ & & & & & 0.2 \\
\hline$\mu_{\mathrm{m}}^{\text {ethylb. sulf }}\left(\mathrm{d}^{-1}\right)$ & & 2 & & & \\
\hline$\mu_{\mathrm{m}}^{\text {xylene.sulf }}\left(\mathrm{d}^{-1}\right)$ & & 1 & & & \\
\hline$k_{\mathrm{d}}\left(\mathrm{d}^{-1}\right)$ & 0.1 & 0.1 & 0.1 & 0.1 & 0.1 \\
\hline$K_{s}^{\text {benzene }}\left(\mathrm{moll}^{-1}\right)$ & & $10^{-5}$ & & & \\
\hline$K_{s}^{\text {toluene }}\left(\mathrm{moll}^{-1}\right)$ & & $10^{5}$ & & $10^{-5}$ & \\
\hline $\mathrm{K}_{3}^{\mathrm{CH}_{2} \mathrm{O}}\left(\mathrm{moll}^{-1}\right)$ & $10^{-5}$ & & & & \\
\hline$K^{\text {ethylbenaene }}\left(\mathrm{moll}^{-1}\right)$ & & $10^{-5}$ & & & \\
\hline$K^{\text {tylene }}\left(\mathrm{moll}^{-1}\right)$ & & $10^{-5}$ & & & \\
\hline$K^{\mathrm{O}(0)}\left(\mathrm{moll}^{-1}\right)$ & $10^{-5}$ & & & $10^{-5}$ & $10^{-5}$ \\
\hline$K_{\text {s sulfate }}\left(\mathrm{moll}^{-1}\right)$ & & $10^{-5}$ & & $10^{-5}$ & \\
\hline$K_{\mathrm{s}}^{\text {gocthise }}\left(\mathrm{moll}^{-1}\right)$ & & & & & $10^{-5}$ \\
\hline$K^{\text {nitrogen }}\left(\mathrm{moll}^{-1}\right)$ & & & $2 \times 10^{-6}$ & & $10^{-5}$ \\
\hline$K_{\text {inh }}^{\text {oxygen }}\left(\mathrm{moll}^{-1}\right)$ & & & $5 \times 10^{-6}$ & & \\
\hline \multirow[t]{3}{*}{$K_{\text {bio }}\left(\operatorname{moll}^{1}\right)$} & & & & $10^{-4}$ & \\
\hline & & & & $10^{-5}$ & \\
\hline & & & & $10^{-6}$ & \\
\hline
\end{tabular}

Because case $1 \mathrm{~b}$ does not model the species produced from microbial decay, there is no expression corresponding to Eq. (33). Eq. (49) shows that bicarbonate
$\left(\mathrm{HCO}_{3}^{-}\right)$and hydrogen ions $\left(\mathrm{H}^{+}\right)$are produced at the exactly the same rate as $\mathrm{CH}_{2} \mathrm{O}$ is degraded - we do not write expressions for these species.

Case la involves the same rate expressions as case $1 \mathrm{~b}$, except that species released by decay of microbial mass are included in the simulation. Thus, the same rate expressions apply as in case $\mathrm{lb}$, with an additional rate expression as given by Eq. (33). The actual species that are produced will depend on the chemical composition of the aqueous phase at the time of release. In general, these are not known a priori, but are calculated by standard equilibration methods as described in Section 2.4.1. In terms of the elements that compose the microbial matter, however, exact rate expressions can be written. For example, each mole of $\mathrm{C}_{5} \mathrm{H}_{7} \mathrm{O}_{2} \mathrm{~N}$ degraded yields a mole of $N$, thus from Eq. (33) we have

$$
\frac{\mathrm{d} C^{\mathrm{N}}}{\mathrm{d} t}=k_{\mathrm{d}} C^{\mathrm{C}_{5} \mathrm{H}_{7} \mathrm{O}_{2} \mathrm{~N}} \text {, }
$$

with similar expressions for $\mathrm{C}, \mathrm{H}$ and $\mathrm{O}$.

For given initial concentrations (Table 4), we can compute, using the geochemical model PHREEQC-2 [269], the temporal development of DOC, oxygen, microbial and inorganic carbon concentrations in a closed batch-type system. We recall that the various reaction rates described above will affect all other species in solution since other (equilibrium) reactions will be initiated. For example, as $\mathrm{N}$ is recycled from microbial degradation, in principle it can speciate to produce nitrate or ammonia. As shown in Fig. 2, in both cases the complete mineralisation of $0.1 \mathrm{mmol}$ of DOC eventually consumes $0.1 \mathrm{mmol}$ of oxygen $\left(\mathrm{O}_{2}\right)$ and produces 0.1 $\mathrm{mmol}$ of inorganic carbon. In both cases, too, during an
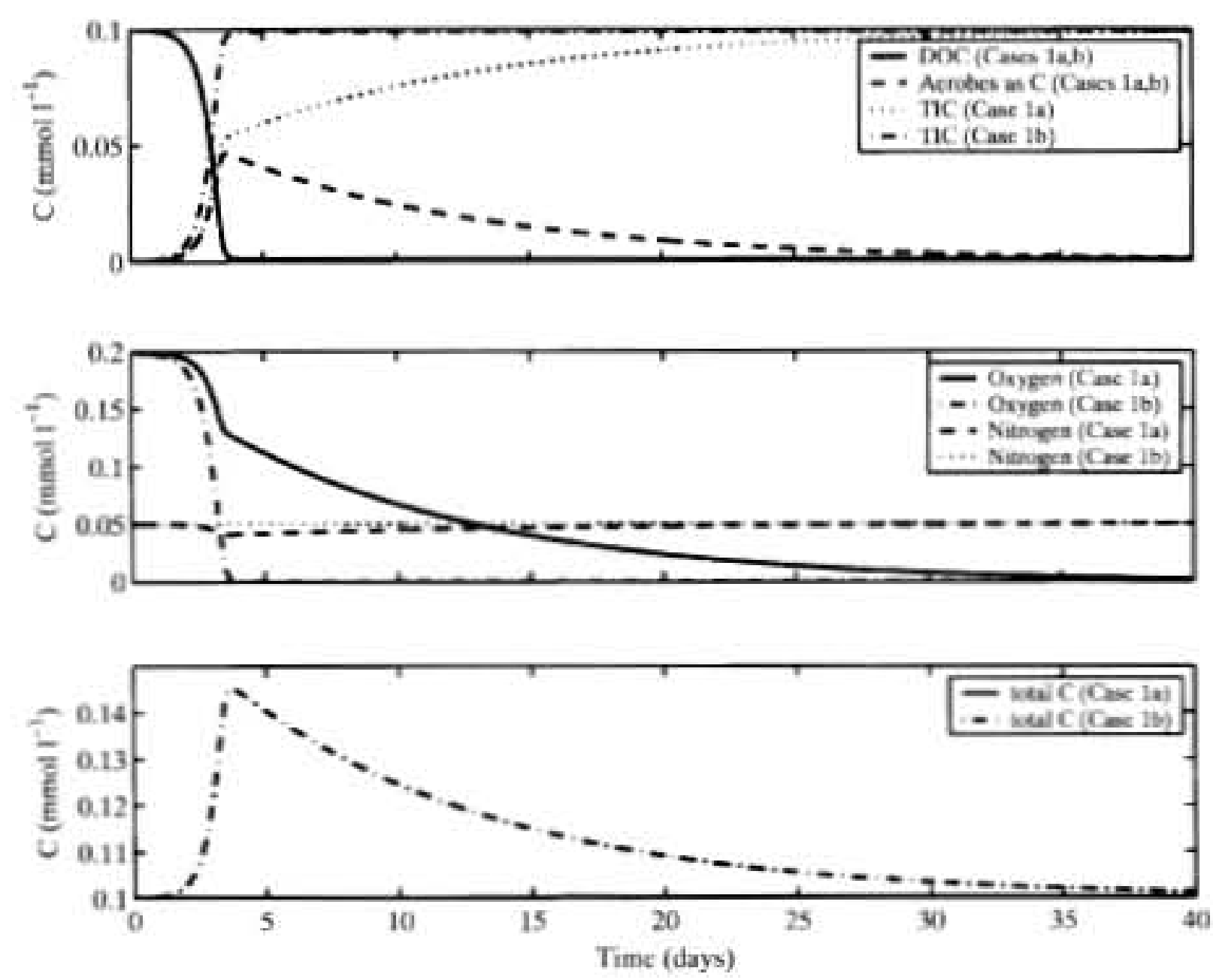

Fig. 2. Modelling example (case 1): Simulation of microbially catalysed mineralisation of DOC under aerobic conditions in a closed batch-system. Case la accounts for the detailed redox reactions and stoichiometry of bacterial growth and decay following Eqs. (45) and (47). In case Ib, a simplified model based on the stoichiometry from Eq. (49) is used. Note that oxygen in the middle plot is $\mathrm{O}(0)$. 
initial lag period microbial concentrations are relatively small and growth does not affect aqueous concentrations of DOC and oxygen. The length of this lag period depends largely on the initial bacterial concentration (Table 4) and on $\mu_{\mathrm{m}}^{\mathrm{CH}_{2} \mathrm{O}}$, the parameter controlling the maximum degradation rate (Table 5). After this lag period concentrations start to change rapidly. In both cases DOC is depleted after 3-4 days and the (net) microbial growth then stops abruptly. At that time, approximately $0.035 \mathrm{mmoll}^{-1}$ of oxygen $\left(\mathrm{O}_{2}\right)$ have been consumed in case la, whereas oxygen is fully depleted in case $1 \mathrm{~b}$. In both cases the microbial mass subsequently decays at the rate given by the final term in Eq. (32). In case la the decay thereby consumes the remaining 0.065 mmoll ${ }^{-1}$ of $\mathrm{O}_{2}$ (Fig. 2) and produces more inorganic carbon. The comparison between the two cases demonstrates that, for conditions where biomass concentrations change rapidly, a significant difference in the dynamics of oxygen consumption is possible. The magnitude of this difference, of course, depends on the parameters (such as rate constants) used.

The nitrogen concentrations in the aqueous phase are shown for both cases in the middle panel of Fig. 2. The model approach used for case 1a considers transfer of nitrogen from the aqueous phase into biomass whereas no nitrogen is removed from the aqueous phase in case lb. During bacterial decay, nitrogen is transferred back into the aqueous phase. Note that the simpler approach used in case $1 \mathrm{lb}$ is not mass conservative with respect to carbon as a result of neglecting the changes of microbial mass in the underlying reaction equations. This can be seen in the lower plot of Fig. 2, where the total carbon concentrations, i.e, the sum of carbon contained within DOC $\left(\mathrm{CH}_{2} \mathrm{O}\right)$, biomass $\left(\mathrm{C}_{5} \mathrm{H}_{7} \mathrm{O}_{2} \mathrm{~N}\right)$ and inorganic carbon $\left(\mathrm{HCO}_{3}^{-}\right.$, etc.) is plotted versus time. Note that the third panel shows the concentration for case la as 0.1 mmoll ${ }^{-1}$.

In reality, contamination rarely consists of a single organic compound but of a mixture of compounds with differing physicochemical properties. Thus, several models have been proposed to account for the simultaneous uptake of multiple substrates, e.g., benzene, toluene, ethylbenzene and xylenes (BTEX), by the same bacterial group. One model [262], which has been adopted in other applications [263,282,293-296], suggests modelling the rate of growth of a microbial population as the sum of growth rates due to different dissolved organic compounds, as was mentioned in Section 2.4.3. The uptake rates $\mu_{\mathrm{m}}^{t}$ will normally differ for different substrates. In this way, it is possible to model degradation of different electron donors at different rates so that benzene, for example, degrades more slowly than toluene.

Case 2 extends the model approach used in case 1a and demonstrates the joint uptake of four different BTEX compounds by one microbial group under sul-
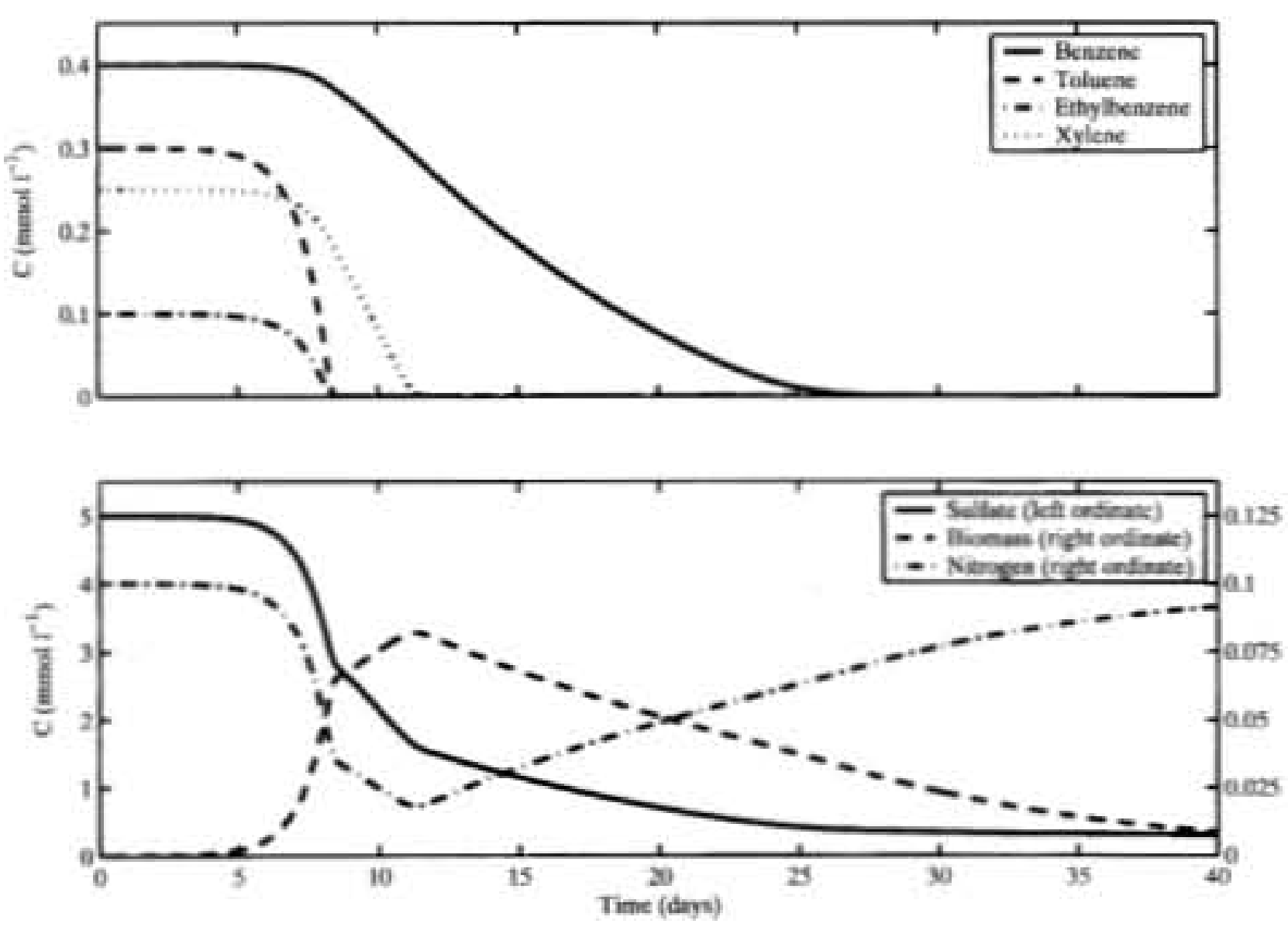

Fig. 3. Modelling example (case 2): Simulation of BTEX mineralisation under sulfate-reducing conditions.

fate-reducing conditions. Different initial amounts of organic compounds were assumed to be present (see Table 4). As can be seen in Fig. 3, for the chosen parameters (Table 5), toluene and ethylbenzene degrade first, followed by xylene while degradation of benzene takes significantly longer. The rate of sulfate consumption decreases once toluene and ethylbenzene are depleted and slows down even further when only benzene is left to degrade. As in the previous case, we considered nitrogen uptake into biomass but, unlike there, nitrogen was not depleted at any point in time and thus did not limit the removal rate of the organic compounds.

\subsection{Multiple bacterial groups and growth inhibition}

In active remediation schemes, contaminant degradation might be dominated by one particular biogeochemical process, e.g., anaerobic biodegradation, involving only one bacterial group [297]. However, under natural conditions, a range of terminal electron acceptor processes (TEAPs) would be expected. Where contaminants degrade naturally, the number of microbial populations involved might vary in space and time as electron acceptors become locally depleted (Fig. 1). That is, microbial groups will typically be associated with a particular electron acceptor, e.g., iron- or sulfatereducing bacteria. Generally, microbial groups associated with more thermodynamically favorable electron acceptors will out-perform those using less favorable electron acceptors.

We mentioned in Section 2.4.3 that inhibition terms might be used to describe mathematically the sequential use of electron acceptors. For example, aerobic condition would inhibit the growth of sulfate-reducing bacteria. This can be modelled by multiplying the growth rate expression, Eq. (36), for these bacteria by 


$$
I_{\text {inh }}^{\text {oxygen }}=\frac{K_{\text {inh }}^{\text {oxygen }}}{K_{\text {inh }}^{\text {oxygen }}+C^{\text {oxygen }}},
$$

where $C^{\text {oxygen }}$ is the aqueous oxygen concentration. Note that in the modelling results presented here we took $C^{\text {oxygen }}$ as the concentration of $\mathrm{O}(0)$ (i.e., atoms of oxygen) rather than concentration of the molecules $\mathrm{O}_{2}$. $K_{\text {inh }}^{\text {oxygen }}$ needs to be much smaller than typical oxygen concentrations under aerobic conditions. The Monodtype inhibition term $I_{\text {inh }}^{\text {oxygen }}$ will then remain very small so long as oxygen is present in significant amounts but reaches its maximum value of unity (growth not inhibited) when oxygen is depleted. Note that the mathematical form of the inhibition term is similar to that used in models that directly describe the contaminant destruction rates without explicitly considering the microbial population changes (e.g., [298]). Inhibition terms of this form have also been applied for biogeochemical transformations such as mineralisation of organic matter in aquatic sediments [299].

The sequential consumption of oxygen and sulfate for the mineralisation of toluene is demonstrated in the third simulation example (case 3, Fig. 4). Toluene is only mineralised partially by the oxygen that is initially present in the system. For the period between the third and the seventh days the example demonstrates the effect of nitrogen limitation on the microbial population growth and thus on the toluene degradation rate. During this period the growth rate is limited to the magnitude of the decay rate as nitrogen is only available from decaying bacteria. The microbial population is thus constant in this period. After a further lag period resulting from the small initial concentrations of SRB (sulfate-reducing bacteria), toluene is further reduced during growth of SRB until sulfate is also depleted. The inclusion of multiple inhibition terms of this form into a growth equation can then be used for modelling a predefined
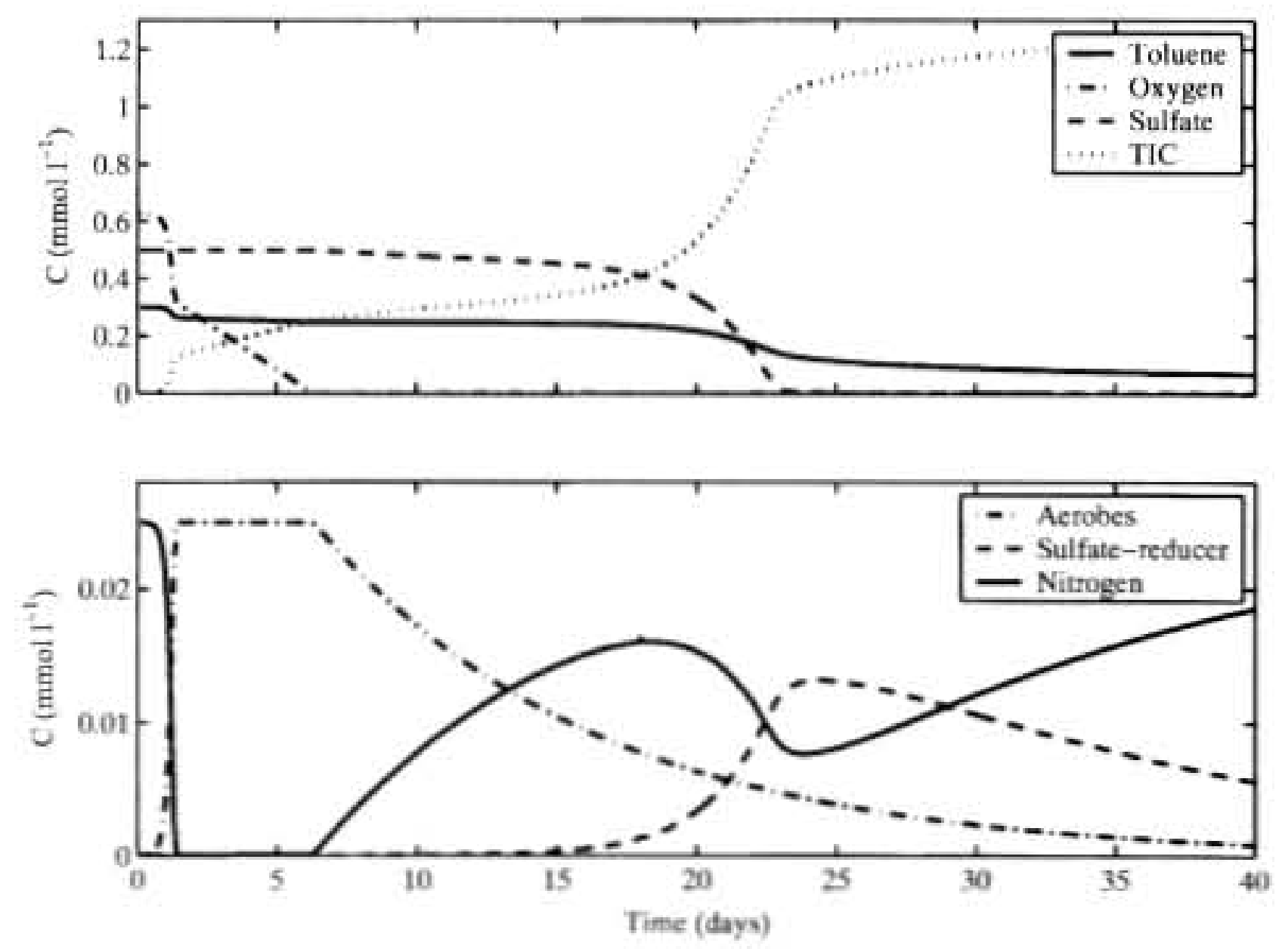

Fig. 4. Modelling example (case 3): Simulation of toluene mineralisation by sequential reduction of oxygen and sulfate. Note that oxygen in the top plot is $\mathrm{O}(0)$.
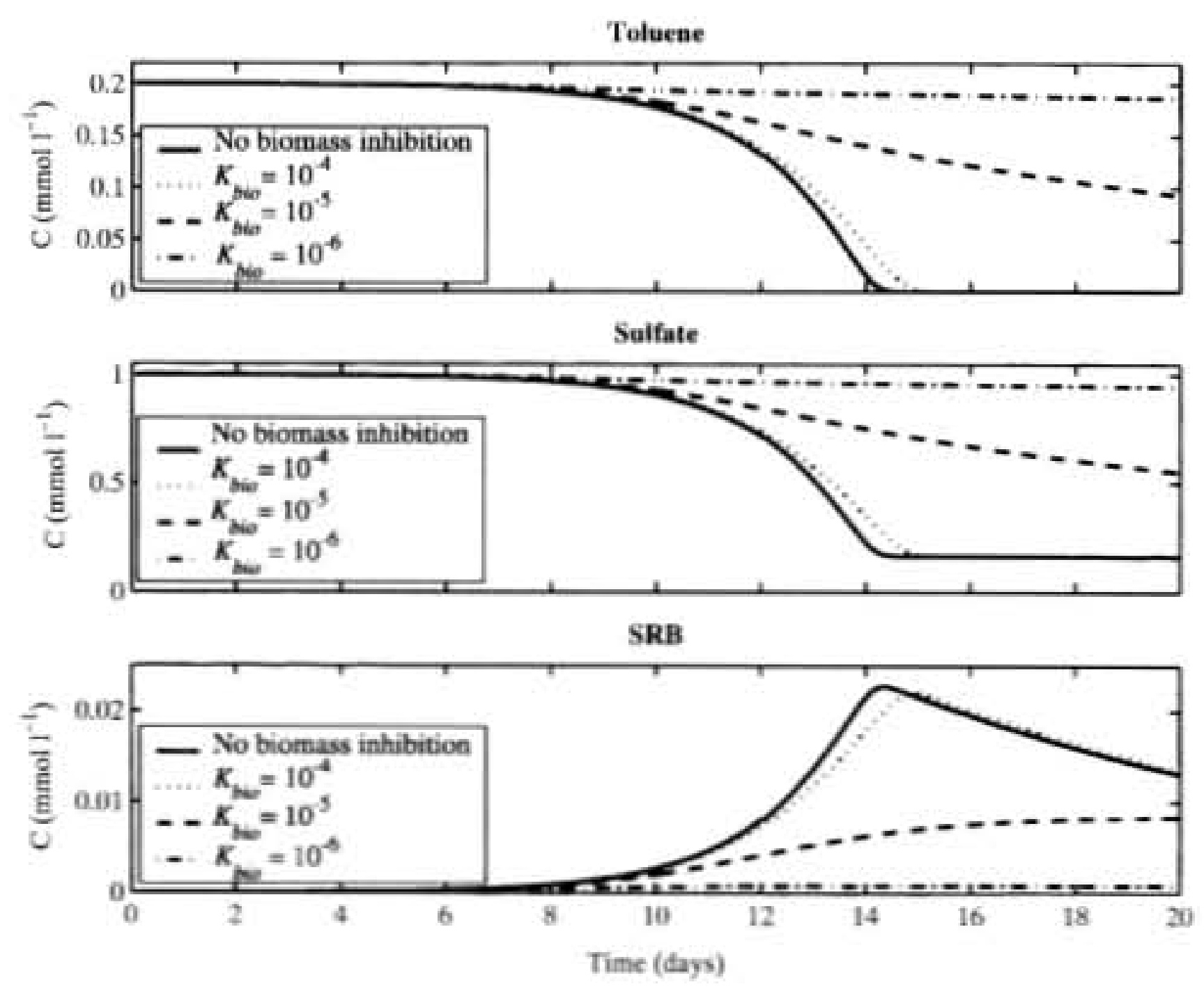

Fig. 5. Modelling example (case 4): Simulation of toluene mineralisation under sulfate-reducing conditions using three different biomass inhibition constants $K_{\text {boo }}\left(\mathrm{moll}^{-1}\right)$.

redox sequence, e.g., growth of SRB can be inhibited by the presence of oxygen, nitrate and $\mathrm{Fe}(3)$ minerals.

Another mechanism that, under some circumstances, is thought to affect microbial growth is the diffusive transport of reactants into biofilms. In order to circumvent solving pore-scale diffusive transport equations, a simple formulation for growth inhibition by excessive biomass accumulation has been proposed [292]. Once again, an inhibition term is used of the form given in Eq. (55), except that the parameter $K_{\text {inh }}^{\prime}$ is renamed $K_{\text {bio }}$ and the microbial concentration used. In the case where a microbial concentration becomes much larger than $K_{\text {bio }}$, the growth term conceptually represents a situation where the real biofilm thickness becomes irrelevant as the metabolic activity occurs predominantly in the upper layers of a biofilm that is more exposed to the nutrient-bearing aqueous phase. Because only the surface layer is receiving nutrients, the specific growth rate for the entire microbial mass reduces. Other, similar approaches are also available [15].

The simulations shown in Fig. 5 demonstrate the influence of $K_{\text {bio }}$ on the maximum bacterial concentrations. For $K_{\text {bio }}=10^{-4} \mathrm{moll}^{-1}$ the resulting simulated biomass concentrations are very similar to the uninhibited case, while a $K_{\text {bio }}$ of $10^{-6} \mathrm{moll}^{-1}$ leads to a very strong inhibition and almost negligible contaminant removal within the simulation time. This simple example involves only one TEAP and the difference between uptake of toluene and sulfate is a constant (stoichiometric) factor.

\subsection{Geochemical response}

So far, we have discussed biodegradation of selected organic substrates with a focus on the main (or pri- 
mary) reactants. For many practical cases, however, limiting the reactive system to these species is insufficient to describe degradation. This is mainly because (a) additional information about the fate of the reaction end products is desired and, perhaps more importantly, (b) the primary reactants are simultaneously involved in other reactions that proceed independently (but at a comparable time scale) or in response to the biodegradation reactions. The former point is of particular interest for applying natural attenuation as a remediation scheme. There, the geochemical changes resulting from the biodegradation reactions are used to demonstrate the occurrence of attenuation processes [8]. Where the contaminants (e.g., BTEX) are oxidised, this typically includes changes in alkalinity, total inorganic carbon (TIC) and of reduced forms of electron acceptors such as sulfide or ferrous iron. These and other species might undergo further reactions, e.g., they can form mineral precipitates such as siderite $\left(\mathrm{FeCO}_{3}\right)$, iron sulfide $(\mathrm{FeS})$ or pyrite $\left(\mathrm{FeS}_{2}\right)$. The question whether these (secondary) reactions proceed and, if so, at what rate, is more difficult to solve than the more simple cases presented above. The occurrence and rate of these reactions depend on the $\mathrm{pH}$ of the groundwater, which can in turn change during biodegradation of organic contaminants. In these cases, geochemical models based on thermodynamic principles are essential tools for predicting of the fate of aqueous species and minerals.

We illustrate these interactions with another example (case 5), where we take a closer look at the fate of the reaction products. Again, we simulated the degradation of toluene. For simplicity, we assume that the degradation itself is the rate-limiting step and reactions of inorganic chemicals and minerals can be approximated as equilibrium reactions. Here, oxygen and the mineral goethite, $\mathrm{FeOOH}$, serve as electron acceptors and are used sequentially by the same facultative microbial group. The most significant geochemical changes occurring during the first, aerobic biodegradation stage are, besides the consumption of toluene and oxygen (Fig. 6), the increase in TIC concentration and the decrease in $\mathrm{pH}$. The latter is somewhat buffered through the presence of calcite $\left(\mathrm{CaCO}_{3}\right)$, resulting in a release of calcium into the aqueous solution. Once oxygen is depleted completely, the electron acceptor consumption switches to goethite. Iron reduction of toluene is a hydrogen-consuming process, so the $\mathrm{pH}$ increases with ongoing mineralisation of toluene. As the model includes the possibility of siderite precipitation, the $\mathrm{Fe}^{2+}$ concentration in the aqueous phase remains low. TIC is partially removed from the aqueous phase by precipitation of siderite and calcite, the latter also decreasing the calcium concentrations in the aqueous solution. For the maximum uptake rates assumed in this simulation, the rate of microbial decay is greater than the
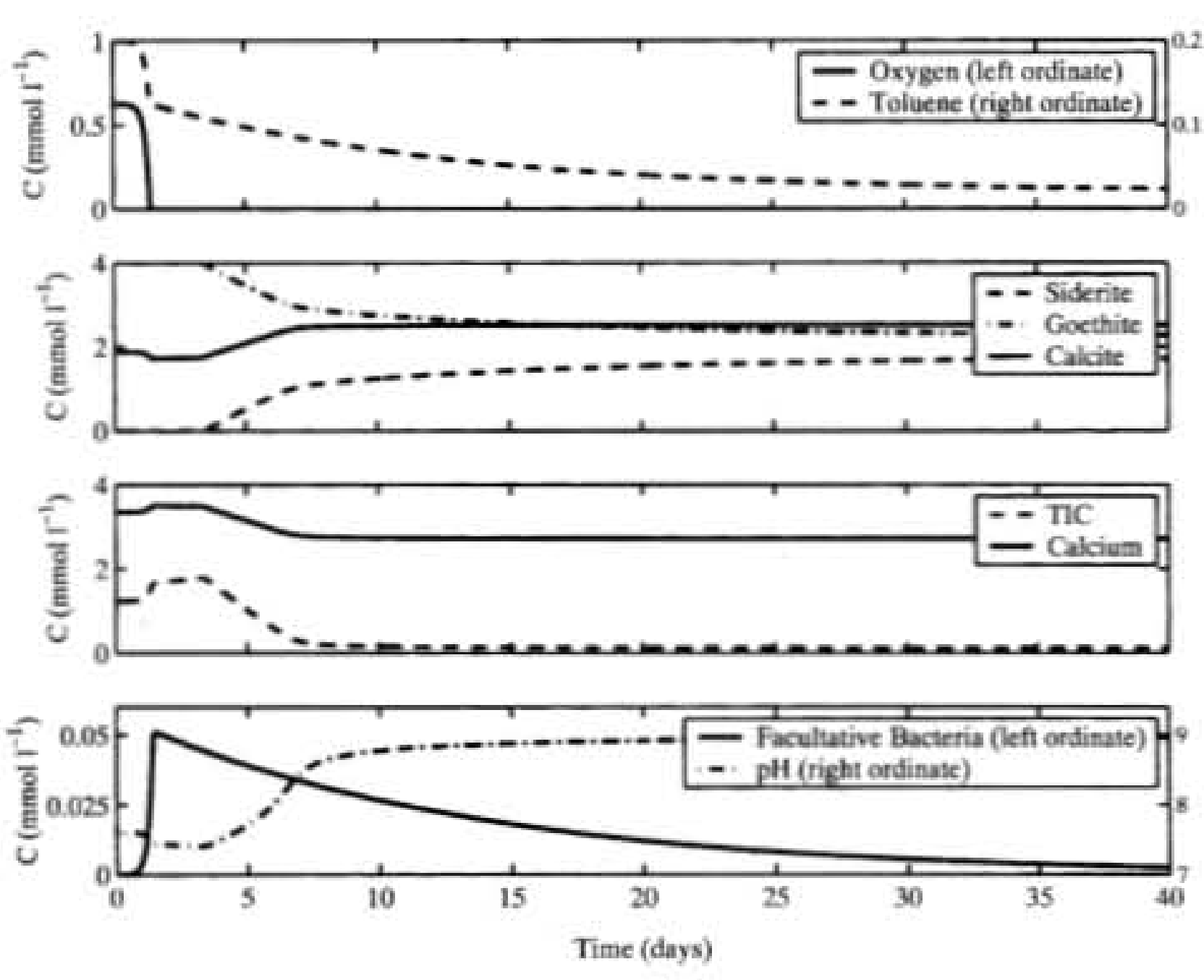

Fig. 6. Modelling example (case 5): Simulation of toluene mineralisation and its geochemical response under sequential aerobic/ironreducing conditions. Note that oxygen in the top plot is $\mathrm{O}(0)$.

growth rate (during iron reduction), so the total bacterial mass decreases.

\section{Application: modelling biogeochemistry in a landfill plume}

Landfills typically contain a mixture of organic and inorganic pollutants and generate leachate for which natural attenuation is the favoured remediation strategy [300]. Successful natural attenuation is documented pollutant mass reduction, a difficult task given constraints imposed by the plume complexity and limited hydrogeochemical data collection [301]. Thus, modelling the fate of organic compounds in groundwater systems that are heterogeneous physically and biogeochemically is vital to any natural attenuation feasibility study [302].

Here, we illustrate how a model that can simulate transport and biogeochemical processes was used to determine the redox zonation in groundwater downstream from a landfill. The landfill has been described elsewhere [300] and a comparison between model results and field observations has been performed recently [303]. Such a model can be used to determine the spatial zonation of redox environments. These range from aerobic respiration at the plume fringes to denitrification, iron reduction, sulfate reduction and, finally, methanogenesis close to the landfill border, i.e., the full sequence of TEAPs will be displayed. For landfill leachate plumes with a mixture of oxidisable organic wastes, degradation of DOC generally determines the spatial distribution of redox environments. Other specific organic chemicals are present in much lower concentrations and therefore do not contribute as much to reduction capacity. However, these low concentration chemicals are possibly of much more interest because 
they can be detrimental to water resources. Some of these are more easily (perhaps only) degraded in anaerobic environments whereas others degrade preferentially in aerobic environments. It is thus important to quantify the spatial and temporal evolution of redox zonation as well as the residence time in each zone.

The modelling objectives were to simulate the degradation of DOC in this aquifer, the effect of degradation on the creation of a sequence of redox environments and the coupling of organic degradation to the geochemical system.

Fig. 7 shows a cross-section through the main part of the observed DOC plume at the Vejen landfill. The aquifer is sandy with pore water velocities of 50-150 $\mathrm{m} \mathrm{yr}^{-1}$. The plume was shaped by the leachate input and low-permeability units beneath and at the border of the landfill [303]. Furthermore, uncontaminated groundwater from below the landfill mixes with the DOC plume along the cross-section.

As mentioned in Section 5, the success of any reactive transport model depends on reliably simulating the flow field together with knowledge of the dispersion parameters, such that correct mixing of reactive contaminants ensues. Information on movement and spreading of non-reactive tracers is therefore very useful. For the Vejen landfill, different hydrogeological interpretations resulted in very different fits to the observed chloride (C1) plume [267]. However, the simulations still did not match many of the fine details of the observed $\mathrm{Cl}$ plume, leading to uncertainties in the physical transport modelling that are transferred to the reactive transport simulations.

More detail on the model used in the current example is available elsewhere [268]. It is essentially identical to the approach discussed in Section 7.3. The model assumes the presence of multiple bacterial groups with their own capabilities for using one specific TEAP, i.e., $\mathrm{O}_{2}$-reducing, $\mathrm{NO}_{3}^{-}$-reducing, $\mathrm{Fe}(3)$-reducing, $\mathrm{SO}_{4}^{2-}$ reducing and $\mathrm{CH}_{4}$-producing biomasses. The sequential

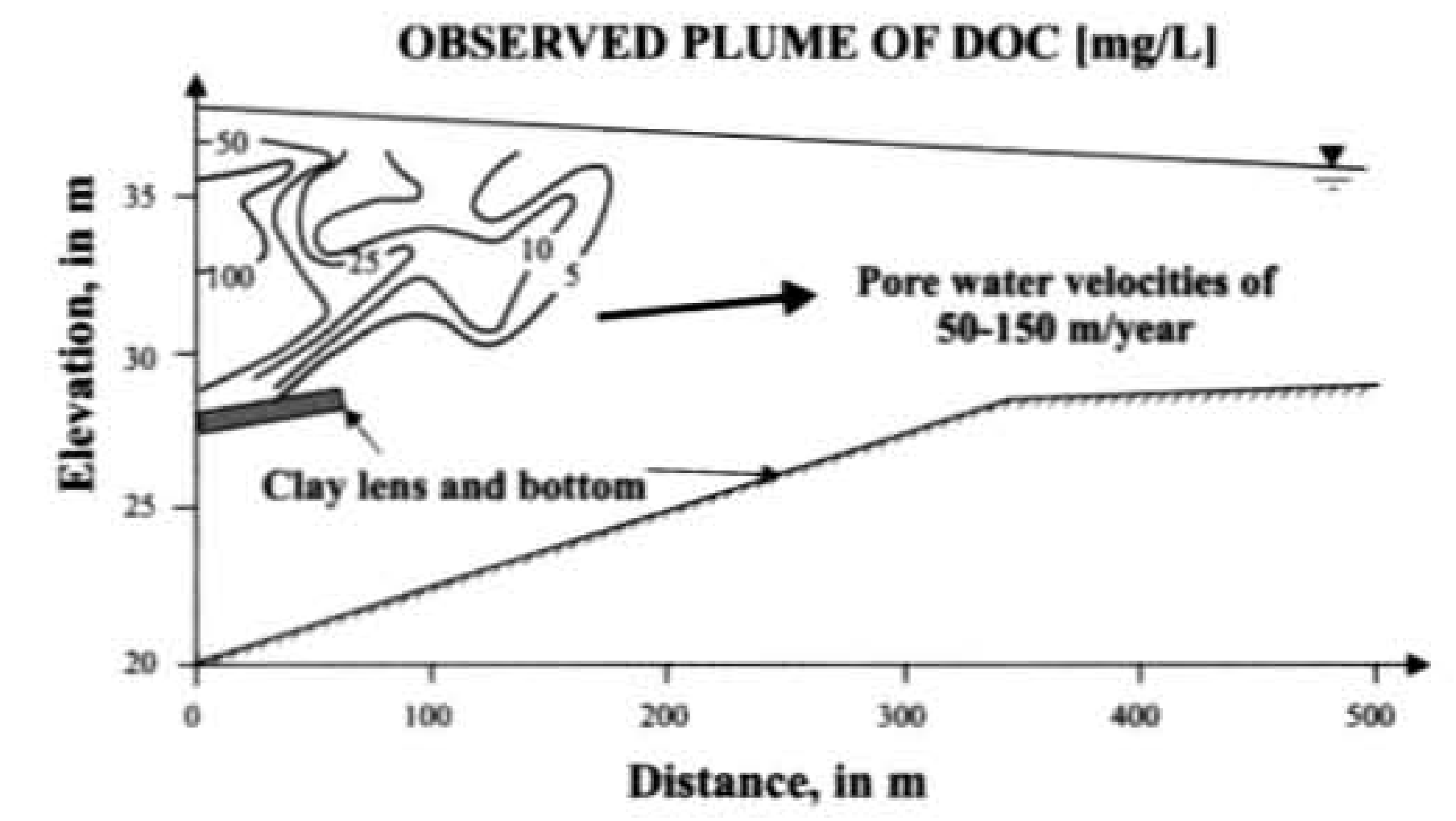

Fig. 7. Observed distribution of DOC downstream of the Vejen landfill (adapted from [303]). use of TEAPs is simulated using two types of inhibition functions to specify the conditions under which bacterial groups are active. This is done by specifying TEAP concentrations for each bacterial group. For example, for $\mathrm{SO}_{4}^{2-}$ reduction, all other possible TEAPs are assigned switch value concentrations. For higher redoxpotential species $-\mathrm{O}_{2}, \mathrm{NO}_{3}^{-}$and $\mathrm{Fe}(\mathrm{OH})_{3}$ - boundary switch values need to be specified for each electron acceptor. For $\mathrm{SO}_{4}^{2-}$ itself, a boundary switch value is needed as well. Only if the $\mathrm{SO}_{4}^{2-}$ concentration is higher than its own TEAP switch value concentration and all other higher redox-potential species have concentrations less than their switch values, will the inhibition function have a value of unity. Otherwise it is zero and the bacterial group is not active (Section 2.4.3). In modelling terms, different microbial populations can thus be "active" at the same time, although electron acceptors are consumed strictly in sequence. Alternatively, a gradual change from using one electron acceptor to the next would result where the rate is a gradual function of concentration, e.g., as modelled by Eq. (55). In the results presented here, this gradual approach was used specifically to model the effect of inhibition due to $\mathrm{pH}$ changes. An optimal $\mathrm{pH}$ is specified for each bacterial group. Any deviation from this optimum results in a decrease in the calculated rate [268].

We will present two simulations conducted to calibrate some of the process parameters. Most of the parameters in the biodegradation model are unknown and many of them are interdependent, e.g., the initial concentration of the microbial population and the maximum growth rate both will determine the biomass concentration at any given time. To fit a given biomass, starting with a high initial biomass would require lowering the maximum growth rate and vice versa. Moreover, even for this fairly well-characterised site, the biogeochemical data are not enough to permit calibration of all parameters. It is, therefore, important to define targets for the modelling/calibration. These were to reproduce the observed zonation of the main TEAPs and, based on the calibrated biodegradation parameters, to estimate the effective rate of degradation in the various redox zones. These measures of biodegradation are important for documenting natural attenuation of other chemical compounds as well, since the zonation defines the coverage of an aquifer where a certain type of biodegradation is likely to dominate. Together with knowledge of the effective degradation rate, one can ascertain the relative importance of redox zones in reducing mass of contaminant species.

The following two simulations (S1 and S3) represent a simulation time of 13 years, the time period from onset of possible leaching from the landfill to the time when measurements of the plumes were carried out. By this time, the plumes had reached a quasi steady state. The simulations assume (a) a steady, albeit non-uniform 
source at the landfill boundary of all components and (b) a steady-state flow field.

The distributions of $\mathrm{O}_{2}, \mathrm{NO}_{3}^{-}, \mathrm{Fe}(\mathrm{OH})_{3}, \mathrm{SO}_{4}^{2-}$ and $\mathrm{CH}_{4}$ are shown in Fig. 8 for simulation S1. The distribution of $\mathrm{Fe}^{2+}$ is also included, because re-oxidation of $\mathrm{Fe}^{2+}$ occurs at the fringes of the $\mathrm{Fe}(3)$-reduction zone. The distribution of the increase in biomass concentrations for the various TEAPs are shown in Fig. 9, together with the simulated DOC (i.e., $\mathrm{CH}_{2} \mathrm{O}$ ) plume. The actual rate parameters used to produce $\mathrm{S} 1$ are not important, as the discussion will focus on how relative changes in rate and switch value parameters affect the redox zonation.

The distribution of $\mathrm{O}_{2}$-reducing biomass shows that $\mathrm{O}_{2}$ is used as a TEAP near the water table for the first $180 \mathrm{~m}$, where infiltrating $\mathrm{O}_{2}$ mixes with DOC. A close inspection of the $\mathrm{Fe}(\mathrm{OH})_{3}$ concentrations at the boundary of the $\mathrm{Fe}(3)$-reducing zone shows that reoxidation of $\mathrm{Fe}^{2+}$ occurs in a thin layer (difficult to see in figure). The consumption of $\mathrm{O}_{2}$ when it mixes with DOC and the re-oxidation of $\mathrm{Fe}^{2+}$ explains the limited vertical extent of $\mathrm{O}_{2}$. The simulated distribution of $\mathrm{O}_{2}$ largely depends on the transverse dispersivity, as discussed in Section 5. Nitrate also infiltrates the water table and has a similar distribution to $\mathrm{O}_{2}$. Both $\mathrm{O}_{2}$ and $\mathrm{NO}_{3}^{-}$were initially present in the aquifer. This initial aquifer oxi- dation capacity can still be seen in the low permeability, slightly upward-sloping clay lens beneath the landfill, which retains high concentrations of both species. $\mathrm{Fe}(\mathrm{OH})_{3}$ is almost depleted in a zone stretching about $250 \mathrm{~m}$ out from the landfill. The reduction of $\mathrm{SO}_{4}^{2-}$ is limited by the presence of $\mathrm{Fe}(\mathrm{OH})_{3}$. The concentration of $\mathrm{Fe}(\mathrm{OH})_{3}$ must be less than $2 \times 10^{-8}$ molar (switchvalue) before $\mathrm{SO}_{4}^{2-}$-reduction is initiated. The $\mathrm{Fe}(\mathrm{OH})_{3}$ concentration is below this switch value in two zones, as shown by the distribution of the increase in $\mathrm{SO}_{4}^{2-}$ reducing biomass. Growth of the $\mathrm{CH}_{4}$-producing biomass is suppressed by the presence of $\mathrm{Fe}(\mathrm{OH})_{3}$ in the same manner. The $\mathrm{CH}_{4}$ plume is due to transport of leachate into the aquifer from the landfill.

In simulation $\mathrm{S} 3$, the maximum growth rate of the $\mathrm{Fe}(\mathrm{OH})_{3}$-reducing biomass was increased by a factor of 5 while the switch value for $\mathrm{SO}_{4}^{2-}$-reduction is increased such that the $\mathrm{CH}_{4}$-producing biomass starts degrading at $\mathrm{SO}_{4}^{2-}$ concentrations that are a factor of 10 higher. Predicted distributions of $\mathrm{O}_{2}, \mathrm{NO}_{3}^{-}, \mathrm{Fe}(\mathrm{OH})_{3}$, and $\mathrm{CH}_{4}$ are shown in Fig. 10. The distributions of the biomass concentration increase for the TEAPs are shown in Fig. 11, together with the simulated DOC plume. In this case, $\mathrm{Fe}(\mathrm{OH})_{3}$ is totally depleted within the first $180 \mathrm{~m}$. The $\mathrm{NO}_{3}^{-}$concentrations are slightly higher, and the vertical extent of this zone has increased. This is coupled
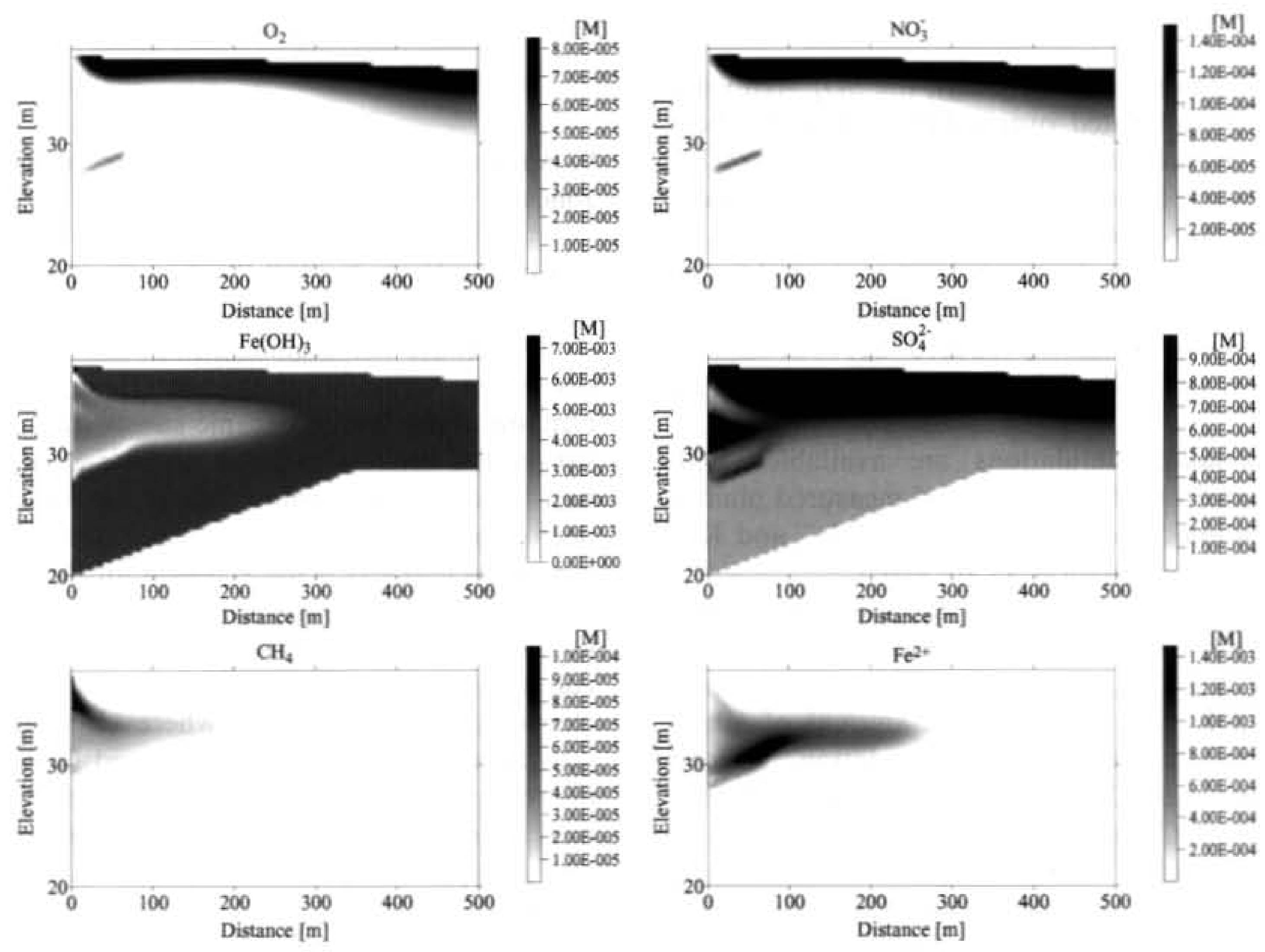

Fig. 8. Distribution of redox species, simulation S1. 

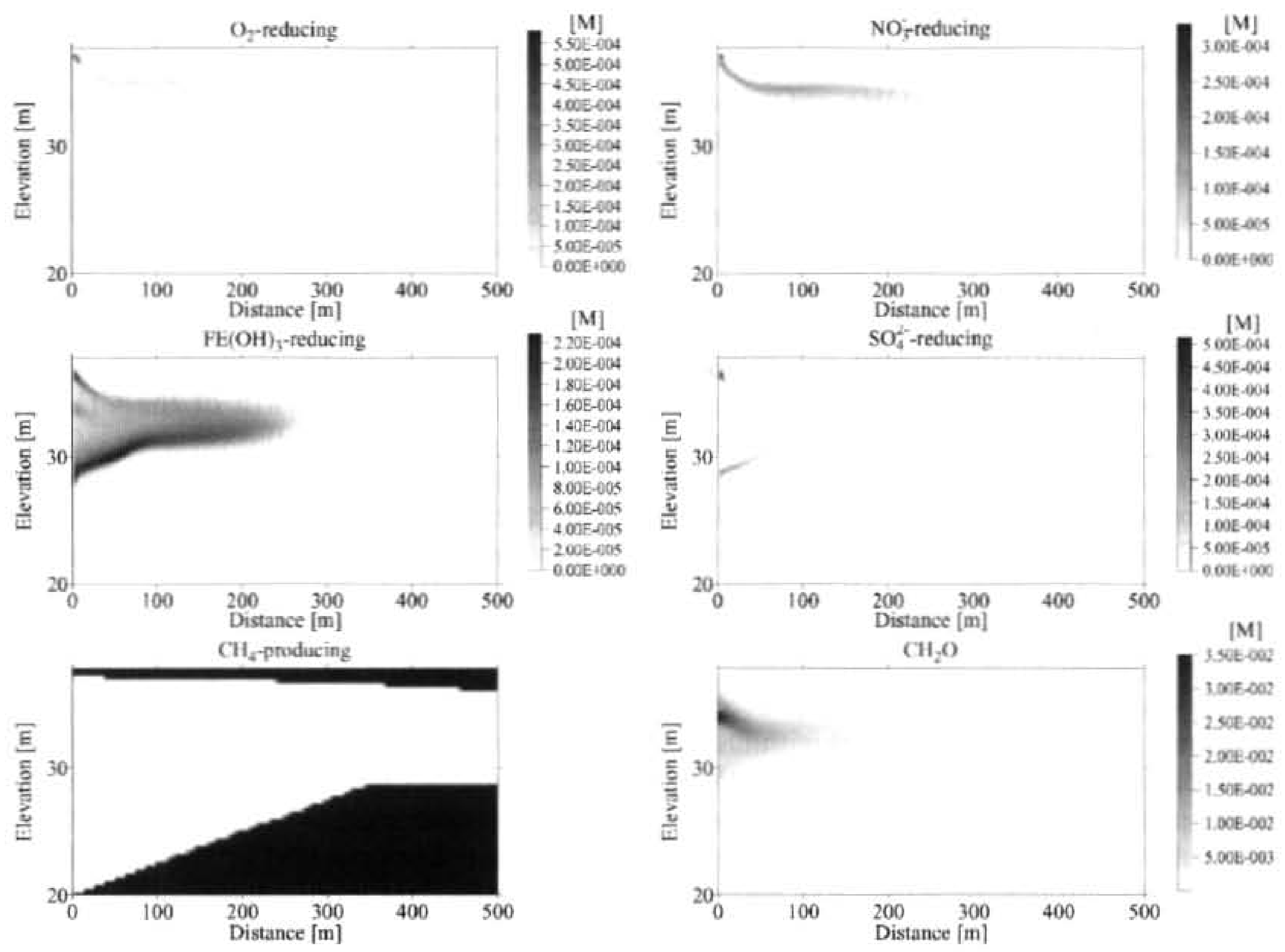

Fig. 9. Distribution of $\mathrm{CH}_{2} \mathrm{O}$ and increases in biomass concentrations, simulation $\mathrm{S} 1$.

with a decrease in the size of the DOC plume because of increased consumption of DOC with $\mathrm{Fe}(\mathrm{OH})_{3}$ as the TEAP.

Due to the depletion of $\mathrm{Fe}(\mathrm{OH})_{3}$, the $\mathrm{SO}_{4}^{2-}$-reducing biomass is now activated over a larger area. In these areas, $\mathrm{SO}_{4}^{2-}$ is reduced and $\mathrm{HS}^{-}$is produced. This changes the $\mathrm{Fe}^{2+}$ plume because of precipitation of $\mathrm{FeS}$, due to the $\mathrm{HS}^{-}$production. The peak concentration of $\mathrm{Fe}^{2+}$ has moved further down-gradient compared to the location of the same peak in $\mathrm{S} 1$. The $\mathrm{CH}_{4}$ plume is larger because the plume is now produced by both landfill leachate and microbially driven degradation within the aquifer.

Further detailed simulations are available [303], where a comparison of simulated and measured plumes of TEAPs, cationic species $\left(\mathrm{Ca}^{2+}, \mathrm{Mg}^{2+}, \mathrm{Na}^{+}\right.$and $\left.\mathrm{K}^{+}\right)$ and $\mathrm{pH}$ based on simulation $\mathrm{S} 3$ are given.

Fig. 12 shows more detail of the simulated DOC plume from S3, which can be compared with the observed plume in Fig. 7. The simulation and observation agree reasonably well. To show the amount of attenuation that has taken place by degradation, Fig. 13 shows the simulated DOC plume as if no degradation had taken place. Clearly, the DOC plume is longer in the non-reactive case, and the aquifer is affected by DOC more than $500 \mathrm{~m}$ downstream. Elsewhere [303], equivalent or effective DOC half-lives were calculated for the various redox zones. These ranged from 100 days to 1-2 days, going from the methanogenic to the aerobic zone.

\section{Application: modelling the creation of in situ reactive zones}

For the Vejen landfill (Section 8), the fate of the organic substances was the main interest in the modelling study because the organic compounds themselves represent the actual (health) risk. The quantitative description of the fate of organic substances can also be of substantial interest in cases where the degradation of non-toxic organic compounds is used within an engineered in situ remediation system to create a favourable (i.e., reducing) geochemical milieu for the attenuation of contaminants. Two emerging and increasingly applied applications where the engineered formation of reducing zones is applied are (a) the enhanced remediation of chlorinated hydrocarbons, where electron donors for substances such as TCE are injected [304,305] and (b) the removal of heavy metals [306]. In the latter case, the goal is to induce a sulfate-reducing environment such that precipitation (i.e., immobilisation) of metal sulfides occurs.

For natural attenuation, the main role of numerical modelling is typically the detailed analysis of observa- 


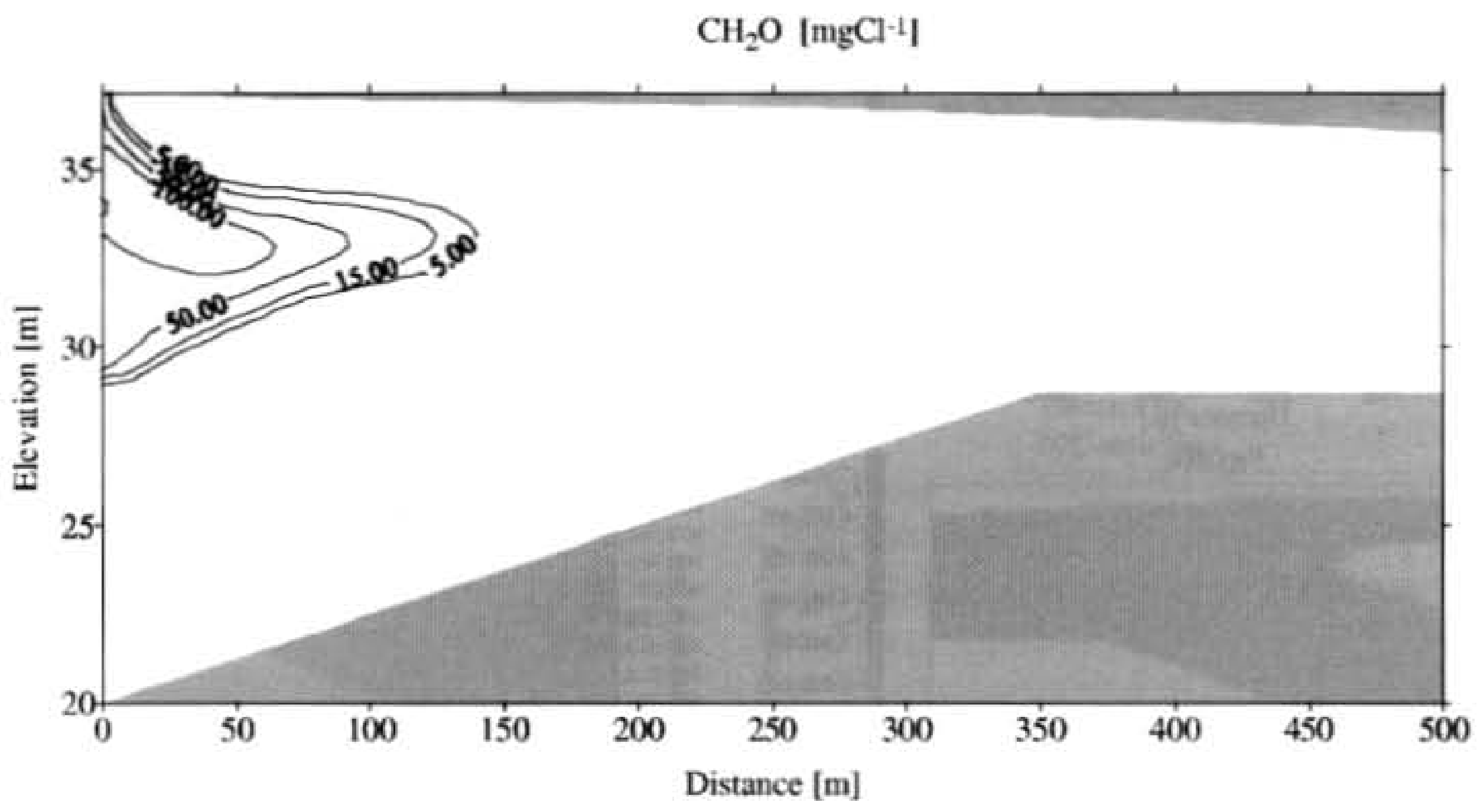

Fig. 12. Simulated distribution of $\mathrm{CH}_{2} \mathrm{O}$, simulation $\mathrm{S} 3$.

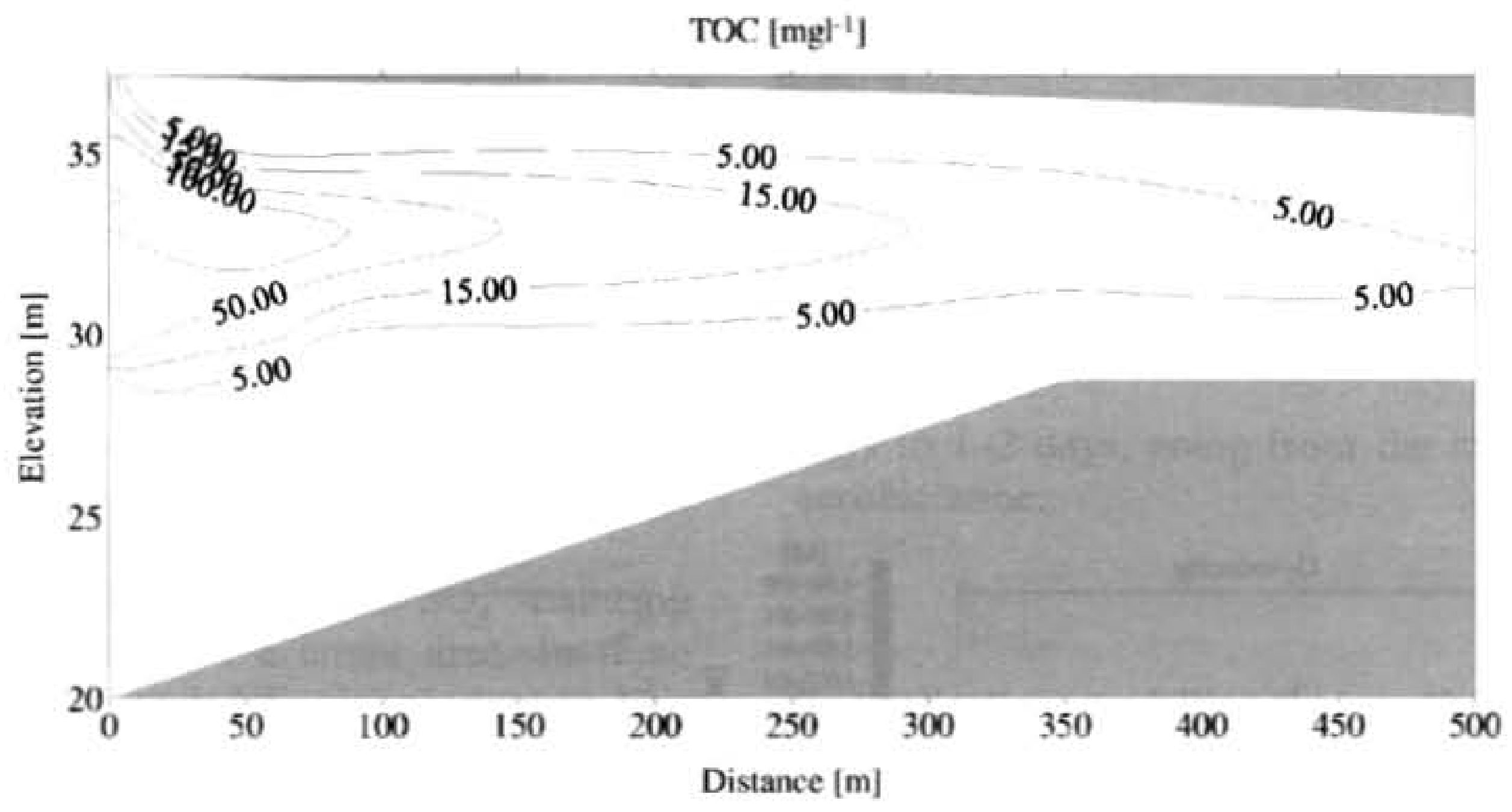

Fig. 13. Simulated distribution of $\mathrm{CH}_{2} \mathrm{O}$ assuming no degradation.

tions whereas, for engineered systems, the emphasis shifts towards predictive modelling and the exploitation of models as design tools [307], e.g., in order to optimise remediation schemes. The second field-scale modelling application presented here describes an application of the latter type.

In this example, we model the geochemical changes that occur in a metal-contaminated aquifer in response to the injection of diluted molasses $\left(\mathrm{C}_{6} \mathrm{H}_{12} \mathrm{O}_{6}\right)$. Although the focus of this paper is on organic contaminants in groundwater, a category that that would not normally include molasses, the modelling approaches involved are similar. The modelling was motivated by a recent field investigation and accompanying laboratory experimentation. The overall integrated field/laboratory/modelling project is too large to report in detail here, so we focus on its modelling aspects.
The molasses is added in dissolved form through pulsed injection into a row (or curtain) of wells perpendicular to the main groundwater flow direction. Given that the aquifer's physical properties are fixed, the main parameters, i.e., design variables for efficiently creating and maintaining a reducing zone are the distance between wells, injection rates, length of injection periods, length of period between injections and substrate concentration. As in the previous case, physical, chemical and biological processes interact in a complex manner. The processes underlying the conceptual and numerical model of the problem are

- advective-dispersive transport of molasses, organic degradation products and inorganic chemicals;

- sorption of molasses; 
- microbially mediated, kinetically controlled oxidation of molasses under sulfate-reducing and methanogenic conditions as well as sulfide production;

- aqueous complexation reactions among inorganic chemicals (LEA);

- reductive dissolution of metal oxides; and

- kinetically controlled precipitation of metal-sulfides.

Prediction of metal mobility and, thus, the efficiency of the in situ remediation scheme, requires accurate prediction of the aquifer's redox state and $\mathrm{pH}$. Modelling the physical processes affecting metal transport and mobility is a vast research area by itself and so, in the present example, we focus on modelling of the hydrochemical changes resulting from the injection of the degradable organic compound. From this base we predict metal transport/mobility. The numerical model PHT3D (Table 1) was used for the subsequently described simulations. In PHT3D, the kinetic reactions included in the simulations, such as microbial growth and decay, are added to the (standard) PHREEQC-2 database that otherwise contains all relevant equilibrium reactions. As demonstrated in Section 7 for a range of batch-type problems, a consistent degradation model was developed from the governing reactions and their stoichiometry, as described below.

\subsection{Degradation model}

Mineralisation reactions of organic compounds typically either produce or consume $\mathrm{H}^{+}$, depending on the TEAP. In the case presented here, however, the full mineralisation reaction (i.e., the dominant TEAPsulfate reduction - coupled to the oxidation of molasses) does not indicate changes in $\mathrm{pH}$

$$
\mathrm{C}_{6} \mathrm{H}_{12} \mathrm{O}_{6}+3 \mathrm{SO}_{4}^{2-} \rightarrow 6 \mathrm{HCO}_{3}^{-}+3 \mathrm{H}_{2} \mathrm{~S}
$$

However, laboratory column testing provided measurements that exhibited a strong decrease in $\mathrm{pH}$ near the injection source, indicating buildup of acidic reaction intermediates. A similar, although less pronounced, tendency was observed during a trial injection at the field site. In order to reproduce these observations and their potential impact on the efficiency of the remediation scheme, the production of organic acid intermediates was represented in a refined degradation model by including acetate as a breakdown product

$$
\mathrm{C}_{6} \mathrm{H}_{12} \mathrm{O}_{6} \rightarrow 3 \mathrm{C}_{2} \mathrm{H}_{3} \mathrm{O}_{2}^{-}+3 \mathrm{H}^{+}
$$

and the subsequent mineralisation of acetate as a second step

$$
\mathrm{C}_{2} \mathrm{H}_{3} \mathrm{O}_{2}^{-}+\mathrm{SO}_{4}^{2-}+\mathrm{H}^{+} \rightarrow 2 \mathrm{HCO}_{3}^{-}+\mathrm{H}_{2} \mathrm{~S}
$$

The combination of Eqs. (57) and (58) gives Eq. (56).
During molasses injection cycles, bacterial mass will increase, while, once the injection is paused, bacterial mass will decrease, in which case bacterial decay continues to promote reduction in the aquifer. In order to investigate these dynamic changes in bacterial mass, explicit simulation of bacterial growth and decay was included in the degradation model. Two parallel degradation pathways were included: (a) direct, complete mineralisation of molasses, as given in Eq. (56) and (b) the two-step transformation involving acetate and its subsequent degradation, Eqs. (57) and (58). Thus, for this latter case, carbon (from molasses) is diverted between $\mathrm{HCO}_{3}^{-}$(or other inorganic $\mathrm{CO}_{2}$ species), acetate and microbial mass (with an estimated efficiency of $20 \%$ ). As part of a model calibration, the ratio between $\mathrm{HCO}_{3}^{-}$production and acetate formation was adjusted such that the observed temporal development of the $\mathrm{pH}$ during the trial injection was replicated. The key parameters of the degradation model, the maximum uptake rates for molasses and acetate, were fitted based on observed data of the temporal changes for sulfate, sulfide and alkalinity during the field trial. The relative rates of these reactions affect to what extent acetate will accumulate. In the model approach used in the simulations presented here, i.e., where bacterial growth and decay is explicitly modelled, the accumulation depends on the ratio (here 5.5) of the maximum uptake rates for molasses and acetate.

A range of simulation scenarios was set up to investigate the influence of crucial design parameters so as to find a robust, safe design for the remediation scheme. While not applied here, optimisation tools using methods such as gradient methods [308], simulated annealing $[309,310]$ or genetic algorithms [311,312] amongst other methods [313] might ultimately be coupled to the process model to obtain the most efficient solution for a given remediation design.

\subsection{Model simulations}

In the particular remediation scenario discussed here, a line of wells is located transverse to the main flow direction in the aquifer. Molasses-enriched water is injected for short periods (five days), alternating with 35day long periods without injection. In addition, active wells alternate with their neighbours such that in fact each individual well operates only five out of 80 days. In this scheme, mixing between injected water and background water results from both longitudinal $(0.1 \mathrm{~m})$ and transverse $(0.01 \mathrm{~m})$ dispersivity as well as through chromatographic effects caused by differential sorption between molasses (retardation factor of 1.2) and other reactants (no retardation). The effects of this pulsed injection and the propagation of the resulting geochemical changes downstream can be seen in Figs. 14 and 15 . 


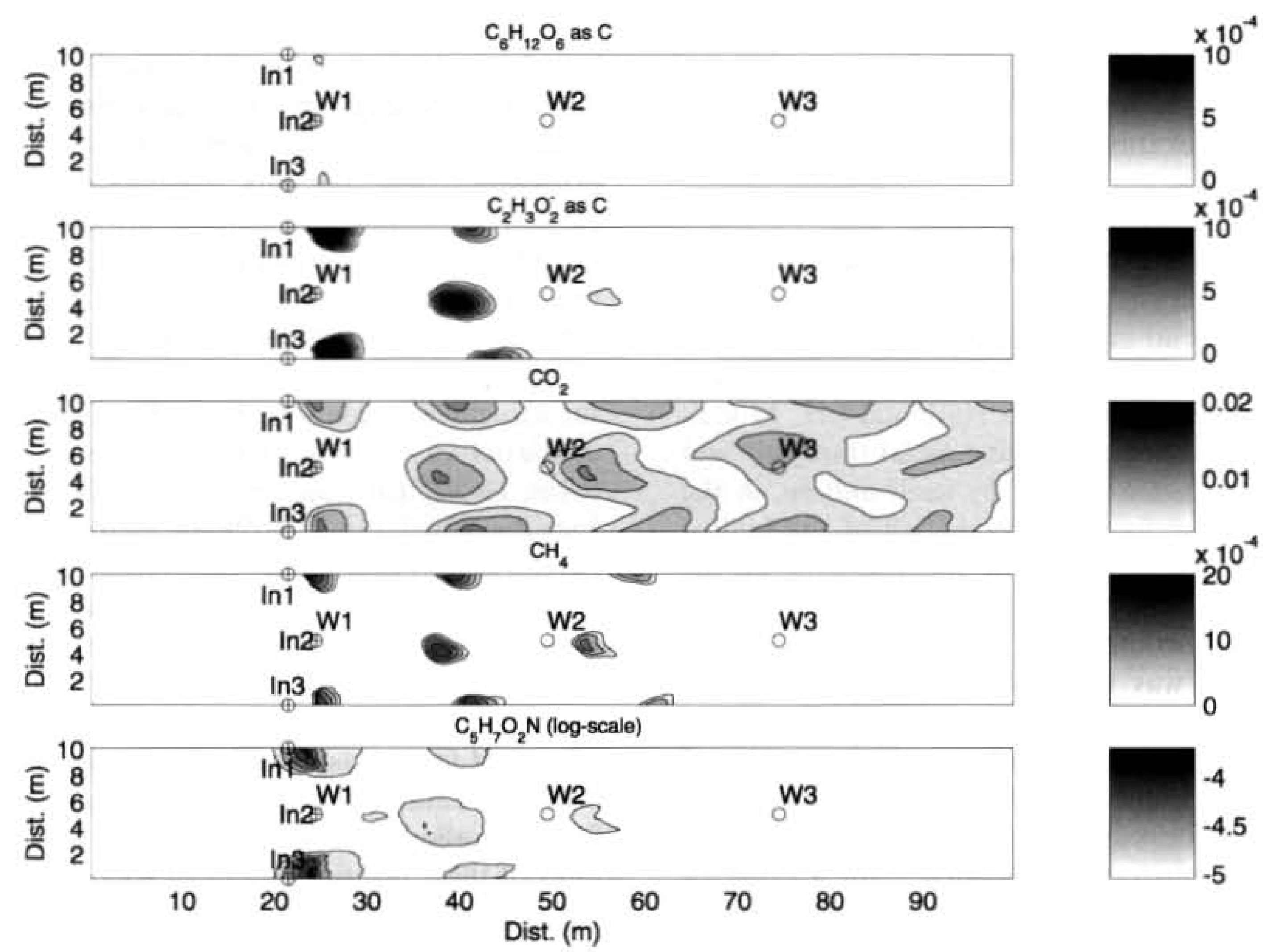

Fig. 14. Concentration contours of selected aqueous organic components and bacteria one year after start of the first injection. All concentrations are given in $\mathrm{moll}^{-1}$.

Hematite $\left(\mathrm{Fe}_{2} \mathrm{O}_{3}\right)$ and sulfate are consumed as a result of the oxidation of acetate whereas sulfide, carbon dioxide and methane are produced. The $\mathrm{pH}$-lowering effect that occurs near the injection wells (top plot of Fig. 15) during transformation of molasses to acetate is evident in Fig. 14 (second plot). However, further downstream of the injection zone the $\mathrm{pH}$ recovers to approximately the background value. This can also be seen in Fig. 16 where the temporal development of molasses and acetate concentrations as well as the $\mathrm{pH}$ is shown in comparison for three selected locations (W1: injection well, W2: $25-\mathrm{m}$ downstream of an injection well and W3: 50-m downstream of an injection well), as also indicated in Figs. 14 and 15. The remediating effect of the in situ reducing zone can be seen in the contour plots for dissolved $\mathrm{Zn}$ and for $\mathrm{ZnS}$. The former is largely removed from the aqueous phase through the precipitation of $\mathrm{ZnS}$ (bottom plot).

\subsection{Carbon budget}

The geochemical modelling approach used for the simulations conserves, to within numerical errors, mass of all chemical elements. It also tracks their spatial and temporal partitioning between aqueous, mineral and biophases (i.e., bacterial mass). As an example, Fig. 17 shows the carbon budget within the modelled domain. Before the start of the molasses injection, all carbon is present as carbon dioxide, i.e., in dissolved form and in only one valence state. The cyclic injection of molasses leads to a stepwise, monotonic increase in the total mass of carbon. Within each cycle, the mass of molasses is completely transformed whereas acetate accumulates for a few injection cycles then reaches a dynamic equilibrium between newly formed and degraded biomass. The simulations for the presented scenario show that bacterial mass stores only a relatively small fraction of carbon and thus is not capable of contributing significantly to sulfate-reducing activity in periods without molasses injection. Siderite $\left(\mathrm{FeCO}_{3}\right)$ was included in the reaction database for the simulation but it did not form. The dominant form of carbon remains carbon dioxide, although some methane forms. Results from other simulations (not shown here) indicate that for a lower mixing efficiency between background water and injected water, the amount of carbon converted to methane increases, accompanied by a reduction in the amount carbon dioxide. This means that a lower fraction of the total mass of injected molasses is used for sulfate reduction and thus for the formation of metal-immobilising sulfides. Again, this result underlines the important role of physical flow and mixing processes in the fate of organic chemicals in aquifers. 


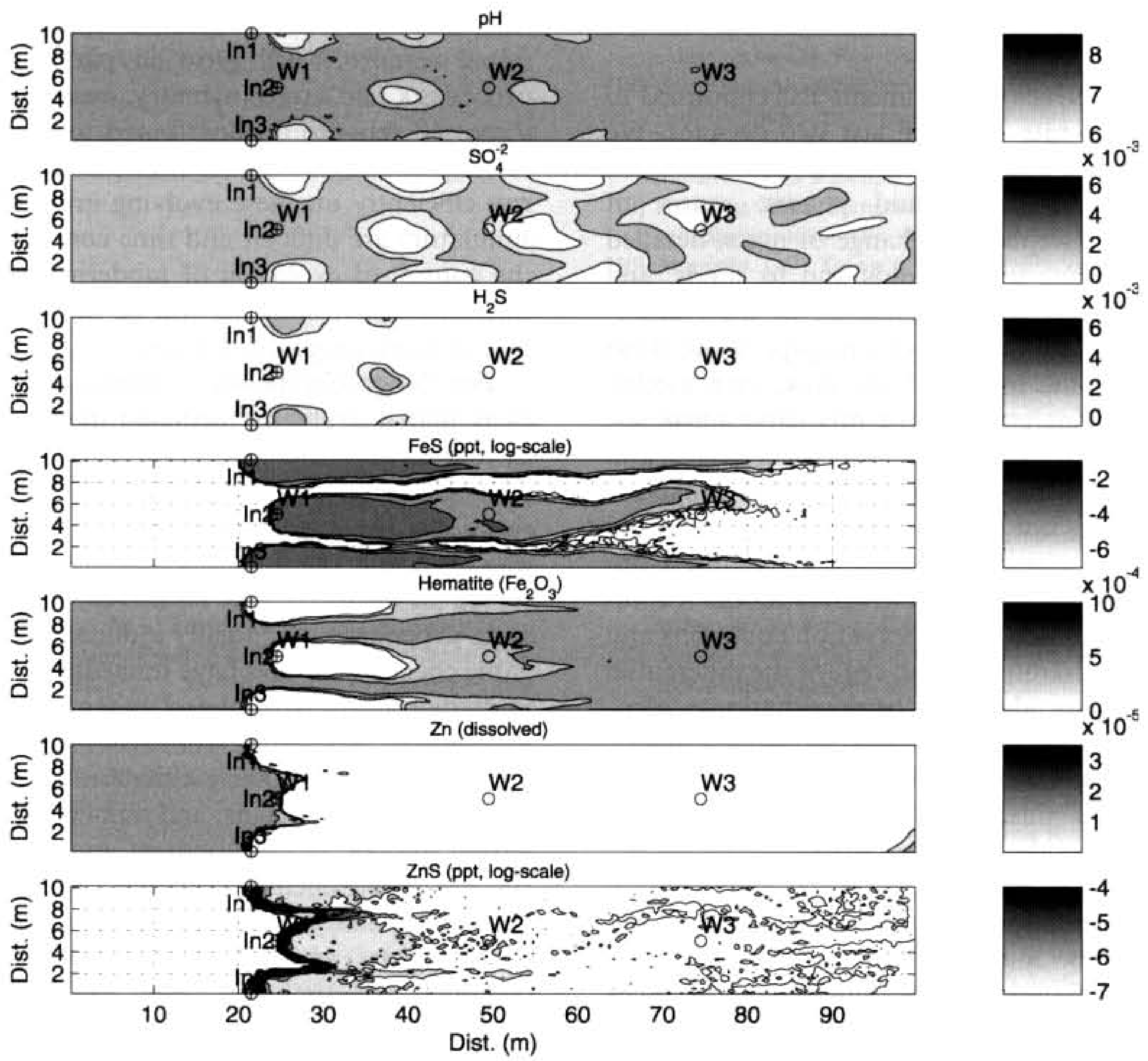

Fig. 15. Concentration contours of selected aqueous inorganic components and minerals one year after start of the first injection. All concentrations are given in $\mathrm{moll}^{-1}$.
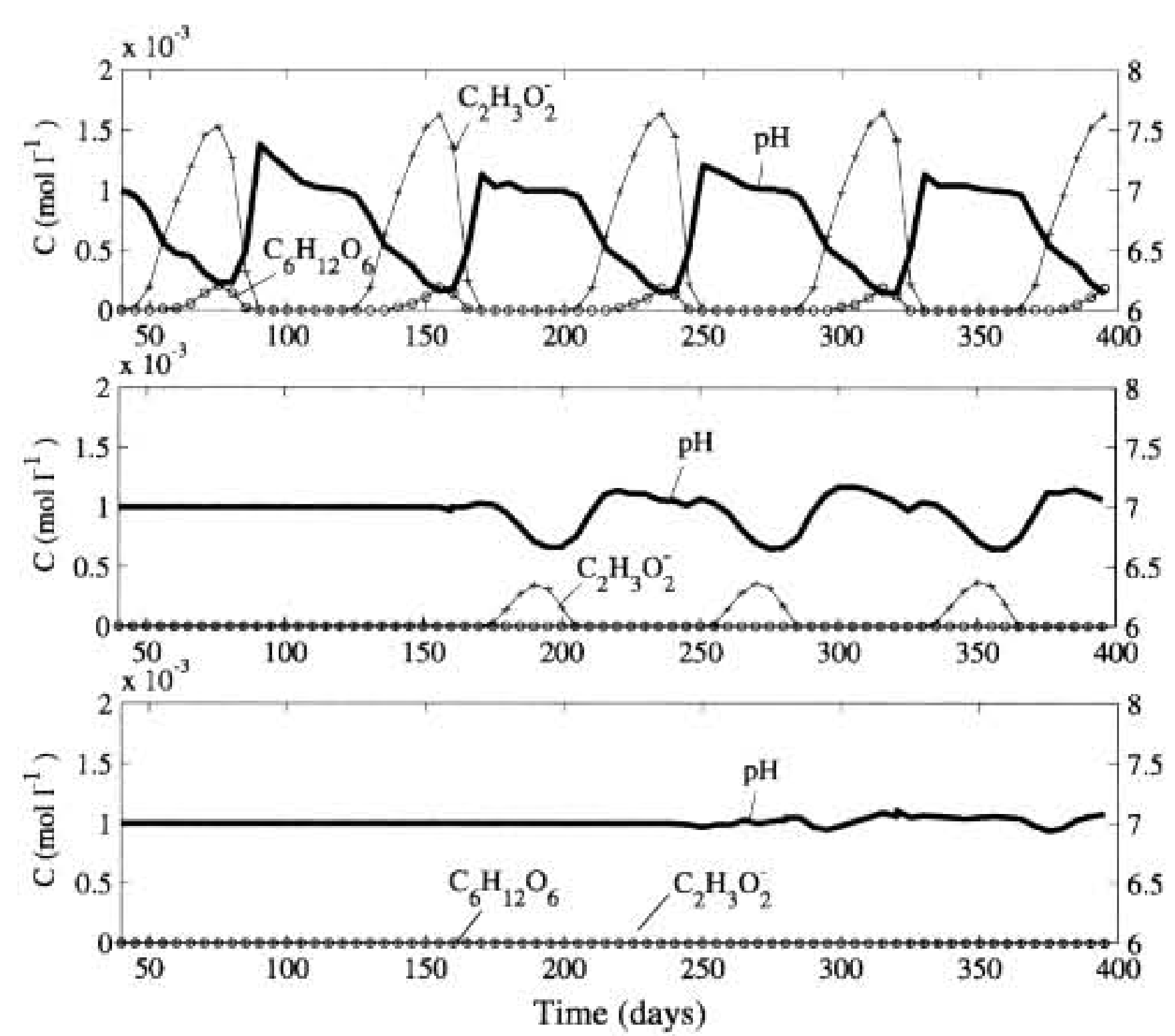

Fig. 16. Organic compound concentrations (left ordinate) and $\mathrm{pH}$ (right ordinate) at observation points WI (top), W2 (middle) and W3 (bottom).
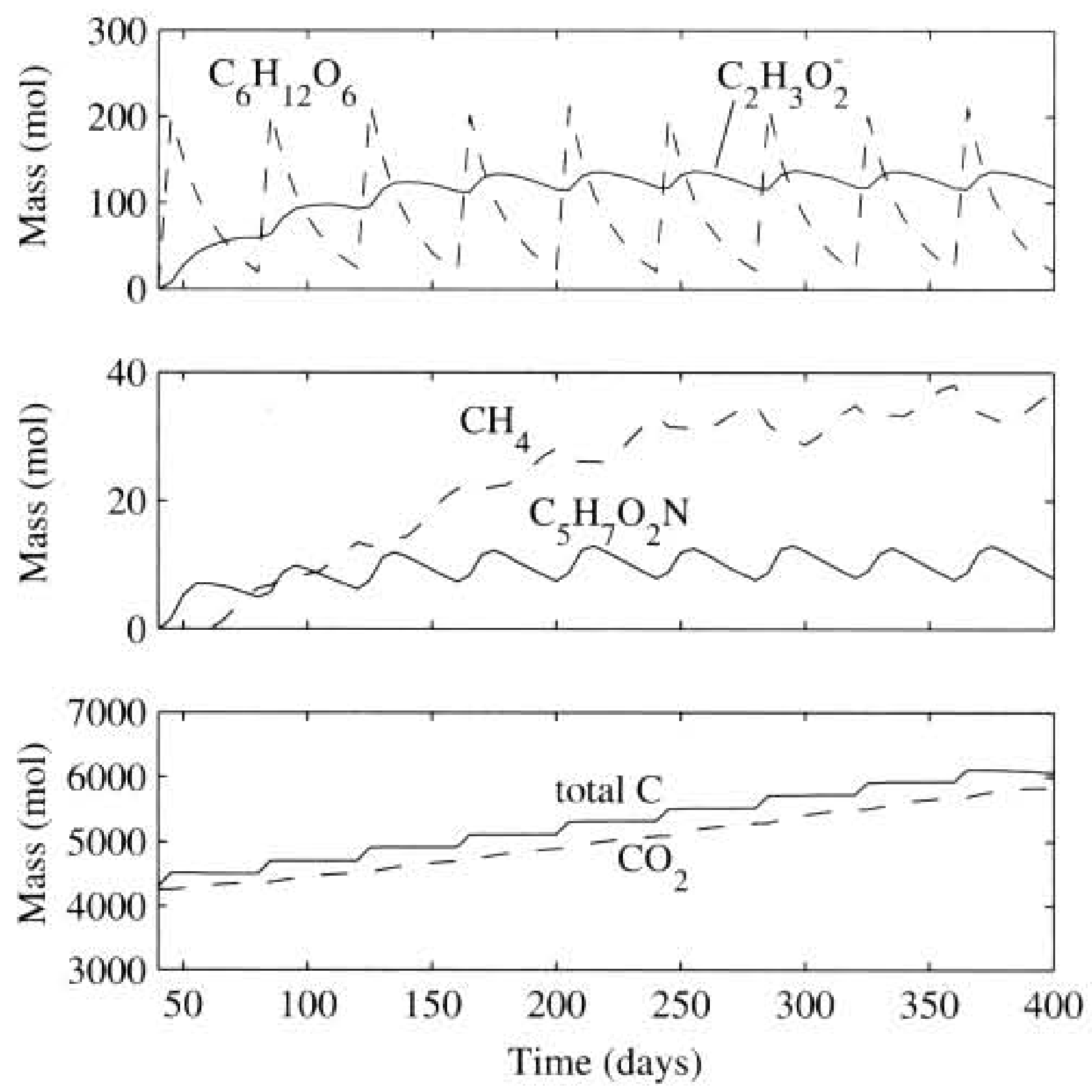

Fig. 17. Carbon budget for the first year after start of the first injection (molasses: $\mathrm{C}_{6} \mathrm{H}_{12} \mathrm{O}_{6}$, acetate: $\mathrm{C}_{2} \mathrm{H}_{3} \mathrm{O}_{2}^{-}$, biomass: $\mathrm{C}_{5} \mathrm{H}_{7} \mathrm{O}_{2} \mathrm{~N}$ ). 


\section{Concluding remarks}

Modelling subsurface environments has continued to develop at a rapid rate over the last two decades. We now can simulate multi-dimensional, heterogeneous systems involving multiple fluid phases, scores of chemical species, interphase exchange of mass, detailed geochemical reactions within fluids and to solids, and biologically mediated transformations. In the foreseeable future, modelling applications incorporating these processes will become routine. Even now, such modelling is being used increasingly for predictive purposes, for evaluating risks to human and ecological health, and for designing environmental restoration approaches. However, the field is not yet characterised by robust and reliable models of complex subsurface systems. Conceptually, the modelling process involves model formulation of appropriate sets of conservation equations and closure relations; discretisation to reduce the differential equation models to algebraic approximations; algorithms to solve the resultant discrete forms of a model; and non-linear and linear algebraic solution methods. Each of these areas must mature in order to model the target problems considered in this work.

Multiple aspects of model formulation deserve additional study. These aspects include conservation and closure relations for multiple fluid phase systems, interphase mass exchange models, and biological models for complex, multi-species, multi-organism systems typical of natural subsurface systems. To give just one example, biologically enhanced dissolution, including the effect of natural and applied surfactants, will affect source-term modelling, as will spatial distributions and temporal changes in NAPL physical properties. Furthermore, even in cases where current models are adequate, issues of scale are almost always a concern. Models are often developed based upon controlled laboratory conditions involving homogeneous systems, while the natural systems of interest are orders of magnitude larger in scale, heterogeneous and sparsely characterised. Such a situation presents a significant challenge as both the parameters and the form of model closure relations are subject to change. Clearly, this challenge affects aspects of data collection, data reliability, a need to combine multiple scales and types of data, inverse problem solution methods and optimal knowledge processing - all active and important areas of research.

While computational resources continue to evolve at a rapid rate, we believe both numerical solution methods and computational advances will play important roles-in advancing the resolution and reliability of geochemical models. On the numerical side, continued maturation of methods will be crucial to estimate and control errors through dynamic adaptation in the order of the numerical approximation scheme and discretisation. On the computational side, the availability of computational resources will grow in part because of faster processors and larger memory, but also because of an increased reliance on distributed memory parallel processing. It will be important to produce simulators that run efficiently on these evolving architectures. Because simulators are difficult and time consuming to produce, the continued evolution of modern software tools and simulation environments will be necessary to speed the rate of modelling advancements.

For biogeochemically complex environments, it is clear that microbially mediated degradation modelling is, to a certain extent, somewhat semi-empirical. This is particularly so with regard to scaling of biochemical reactions, the interplay of these with relevant physical processes and the apparent reaction rates that are observed or deduced. An improved basis for modelling scale-dependent microbially induced degradation of organic chemicals would have immediate practical benefits in predictions of natural and enhanced attenuation, risk assessment, and so on.

More generally, active collaborations among experimentalists, theoreticians, and numerical modelers would hasten the rate of development and application of subsurface biogeochemical models. Such groups should cross disciplinary boundaries and include chemists, microbiologists, engineers, geologists, mathematicians, computer scientists and others that can contribute to these challenging problems. Each of these classes of researchers has an active and important role to play. A process of routine model-data comparison and detailed mechanistic evaluation will be needed to improve current models.

In the past 20 years much progress has been made in the development of models and their application to a variety of oxidisable organic contamination problems. This period has also seen major gains in readily available computational power, the availability of numerous, well-tested packages for flow, transport and reaction, and a growing need to integrate biological, chemical and physical processes affecting the fate of oxidisable organics in the subsurface. While acknowledging this progress, these remarks are intended to bring attention to the significant challenges that can now be addressed. The future is bright, but much hard work remains.

\section{Acknowledgements}

DAB and HP are grateful for the support of the Scottish Higher Education Funding Council, particularly the Research Development Grant scheme. Simulations in Section 9 were supported by Rio Tinto Technology. The efforts of CTM were supported in part by National Institute of Environmental Health Sciences Grant 2 P42 ES05948 and computational resources in 
part by an allocation from the North Carolina Supercomputing Center. O.A. Cirpka, M.W. Farthing, M. Hilpert, R.P. Johnston, J.F. Kanney, C.E. Kees, L.F. Kees, J.A. Pedit and several anonymous referees made valuable comments on drafts of this manuscript.

\section{References}

[1] Cole GM. Assessment and remediation of petroleum contaminated sites. Boca Raton, FL: Lewis Publishers, Inc; 1994.

[2] Matsuda T, Yagi T, Kawanishi M, Matsui S, Takebe H. Molecular analysis of mutations induced by 2-chloroacetaldehyde, the ultimate carcinogenic form of vinyl chloride, in human cells using shuttle vectors. Carcinogenesis 1995;16(10):2389-94.

[3] US Environmental Protection Agency. Cleaning up the nation's waste sites: Markets and technology trends. Technical Report EPA 542-R-96-005, PB96-178041, EPA, Washington, DC, 1997.

[4] Filz GM, Widdowson MA, Little JC. Barrier-controlled monitored natural attenuation. Environ Sci Technol 2001;35(15):322530.

[5] Roberts PV, Hopkins GD, Mackay DM, Semprini L. A field evaluation of in situ biodegradation of chlorinated ethenes: Part 1. Methodology and field site characterization. Ground Water 1990;28(4):591-604.

[6] Semprini L, Roberts PV, Hopkins GD, McCarty PL. A field evaluation of in situ biodegradation of chlorinated ethenes: Part 2. Results of biostimulation and biotransformation experiments. Ground Water 1990:28(5):715-27.

[7] Semprini L, Hopkins GD, Roberts PV, Grbic-Galic D, McCarty PL. A field evaluation of in situ biodegradation of chlorinated ethenes: Part 3. Studies of competitive inhibition. Ground Water $1991 ; 29(2): 239-50$.

[8] Wiedemeier TH, Wilson JT, Kampbell DH, Miller RN, Hansen JE. Technical protocol for implementing intrinsic remediation with long-term monitoring for natural attenuation of fuel contaminant dissolved in groundwater. Technical report, Air Force Center for Technical Excellence, Technology Transfer Division 1 and 2, Brooks A.F.B., San Antonio, TX, 1995.

[9] US Environmental Protection Agency. Use of monitored natural attenuation at Superfund, RCRA corrective action, and underground storage tank sites. Technical Report Directive 9200.4-17, Office of Solid Waste and Emergency Response, Washington, DC, 1997.

[10] US Environmental Protection Agency. Technical protocol for evaluating natural attenuation of chlorinated solvents in ground water. Technical Report EPA/600/R-98/128, Washington, DC, 1998.

[11] Baveye P, Vandevivere P, Hoyle BL, DeLeo PC, de Lozada DS. Environmental impact and mechanisms of the biological clogging of saturated soils and aquifer materials. Critical Rev Environ Sci Technol 1998;28(2):123-91.

[12] Clement TP, Hooker BS, Skeen RS. Macroscopic models for predicting changes in saturated porous media properties caused by microbial growth. Ground Water 1996;34(5):934 42.

[13] Taylor SW, Jaffé PR. Substrate and biomass transport in a porous medium. Water Resour Res 1990;26(9):2181-94.

[14] Kildsgaard J, Engesgaard P. Numerical analysis of biological clogging in two-dimensional sand box experiments. J Contam Hydrol 2001;50(3-4):261-85.

[15] Zysset A, Stauffer F, Dracos T. Modeling of chemically reactive groundwater transport. Water Resour Res 1994:30(7):2217-28.

[16] Zysset A, Stauffer F, Dracos T. Modeling of reactive groundwater transport governed by biodegradation. Water Resour Res $1994 ; 30(8): 2423-34$.
[17] Barry DA. Supercomputers and their use in modeling subsurface solute transport. Rev Geophys 1990;38(3):277-95.

[18] Barry DA. Modeling contaminant transport in subsurface: Theory and computer programs. In: Ghadiri H, Rose $\mathrm{CW}$, editors. Modeling chemical transport in soil: natural and applied contaminants. Boca Raton, FL: Lewis Publishers; 1992. p. 105-44.

[19] Brusseau ML. Transport of reactive contaminants in heterogeneous porous media. Rev Geophys 1994;32(3):285-313.

[20] Mangold DC, Tsang C. A summary of subsurface hydrological and hydrochemical models. Rev Geophys 1991:29(1):5179.

[21] Parker JC. Multiphase flow and transport in porous media. Rev Geophys 1989;27(3):311-28.

[22] Morrison SJ, Tripathi VS, Spangler RR. Coupled reaction/ transport modeling of a chemical barrier for controlling Uranium (VI) Contamination in ground water. J Contam Hydrol 1995; 17(4):347-63.

[23] Tripathi VS, Yeh GT. A performance comparison of scalar, vector, and concurrent vector computers including supercomputers for modeling transport of reactive contaminants in groundwater. Water Resour Res 1993;29(6):1819-23.

[24] Yeh GT, Tripathi VS. Correction to A critical evaluation of recent developments in hydrogeochemical transport models of reactive multichemical components'. Water Resour Res 1989; 25(5): 1066.

[25] Yeh GT, Tripathi VS. A critical evaluation of recent developments in hydrogeochemical transport models of reactive multichemical components. Water Resour Res 1989:25(1):93-108.

[26] Bruaset AM, Langtangen HP. A comprehensive set of tools for solving partial differential equations: Diffpack. In: Daeblen M, Tveito A, editors. Numerical methods and software tools in industrial mathematics. Boston, MA: Birkhauser; 1997. p. 61-90.

[27] Smith B, Bjorstad P, Gropp W. Domain decomposition: parallel multilevel methods for elliptic partial differential equations. New York: Cambridge University Press; 1996.

[28] Steefel CI, Van Cappellen P. Reactive transport modeling of natural systems. J Hydrol 1998;209(1-4):1-7.

[29] Islam J, Singhal N, O'Sullivan M. Modeling biogeochemical processes in leachate-contaminated soils: a review. Transport Porous Media 2001;43(3):407-40.

[30] Christakos G. Random field models in the earth sciences, San Diego, CA: Academic Press; 1992.

[31] Gelhar LW. Stochastic subsurface hydrology. Englewood Cliffs, NJ: Prentice Hall; 1993.

[32] Rabideau AJ, Miller CT. Two-dimensional modeling of aquifer remediation influenced by sorption nonequilibrium and hydraulic conductivity heterogeneity. Water Resour Res 1994;30(5):145770 .

[33] Skaggs TH, Barry DA. Sensitivity methods for time-continuous, spatially discrete groundwater contaminant transport models. Water Resour Res 1996;32(8):2409-20.

[34] Miller CT, Christakos G, Imhoff PT, McBride JF, Pedit JA, Trangenstein JA. Multiphase flow and transport modeling in heterogeneous porous media: Challenges and approaches. Adv Water Resour 1998;21(2):77-120.

[35] Darcy H. Les Fontaines Publiques de la Ville de Dijon. Paris: Dalmont; 1856.

[36] Shearer M, Trangenstein JA. Loss of real characteristics for models of three-phase flow in a poқous medium. Transport Porous Media 1989;4(5):499-525.

[37] Sleep BE, Sykes JF. Numerical simulation of three-phase multidimensional flow in porous media. In: Gambolati G, Rinaldo A, Brebbia CA, Gray WG, Pinder GF, editors. Proceedings of the Eighth International Conference on Computational Methods in Water Resources Computational methods in subsurface hydrology, Southampton: Computational Mechanics Publications; 1990. p. $211-6$. 
[38] White MD, Oostrom M, Lenhard RJ. Modeling fluid flow and transport in variably saturated porous media with the STOMP simulator. 1. Nonvolatile three-phase model description. Adv Water Resour 1995;18(6):353-64.

[39] Willson CS, Kees CE, Miller CT. Investigation of three-fluidphase flow in porous media. American Geophysical Union Fall Meeting, vol. 79(45) of EOS Transactions. 1998. p. F294.

[40] van Dijke MU, Sorbie KS, McDougall SR. Saturation-dependencies of three-phase relative permeabilities in mixed-wet and fractionally-wet systems. Adv Water Resour 2001;24(3-4):36584.

[41] Steffy DA, Barry DA, Johnston CD. Influence of antecedent moisture content on residual LNAPL saturation. J Soil Contaminat 1997;6(2):113-47.

[42] Steffy DA, Johnston CD, Barry DA. Monitoring residual gasoline movement associated with a fluctuating water table. Geotechnical Special Publication Number 71. In: Evans JC, editor. In situ remediation of the geoenvironment. Reston, VA: American Society of Civil Engineers; 1997. p. 227-42.

[43] Steffy DA, Johnston CD, Barry DA. A field study of the vertical immiscible displacement of LNAPL associated with a fluctuating water table. In: Kovar K, Krásný J, editors. Groundwater quality: remediation and protection, number 225. Wallingford, United Kingdom: International Association of Hydrological Sciences, IAHS publication; 1995. p. 49-57.

[44] Steffy DA, Johnston CD, Barry DA. Numerical simulations and long-column tests of LNAPL displacement and trapping by a fluctuating water table. J Soil Contaminat 1998;7(3):325-56.

[45] Bear J. Dynamics of fluids in porous media. New York: Dover Publ. Inc; 1972.

[46] de Marsily G. Quantitative hydrogeology: groundwater hydrology for engineers. San Diego, CA: Academic Press; 1986.

[47] Miller CT, Gleyzer SN, Imhoff PT. Numerical modeling of NAPL dissolution fingering in porous media. In: Selim $\mathrm{HM}, \mathrm{Ma} \mathrm{L}$, editors. Physical nonequilibrium in soils: Modeling and application. Ann Arbor, MI: Ann Arbor Press; 1998.

[48] Bear J. Hydraulics of groundwater. New York: McGraw-Hill; 1979.

[49] Bear J. Verruijt A. Modeling groundwater flow and pollution. Dordrecht, The Netherlands: D. Reidel Publishing Company; 1987.

[50] Park JH, Zhao XD, Voice TC. Biodegradation of non-desorbable naphthalene in soils. Environ Sci Technol 2001:35(13):2734 40 .

[51] Garrels RM, Christ CL. Solutions, minerals, and equilibria. New York: Harper and Row; 1965.

[52] Schwarzenbach RP, Gschwend PM, Imboden DM. Environmental organic chemistry. New York: John Wiley \& Sons; 1993.

[53] Powers SE, Abriola LM, Weber Jr WJ. Development of phenomenological models for NAPL dissolution processes. Subsurface Restoration Conference-3rd International Conference on Ground Water Quality Research. 1992. p. 1-5.

[54] Imhoff PT, Jaffé PR, Pinder GF. An experimental study of complete dissolution of a nonaqueous phase liquid in saturated porous media. Water Resour Res 1994;30(2):307-20.

[55] Powers SE, Abriola LM, Dunkin JS, Weber jr WJ. Phenomenological models for transient NAPL-water mass-transfer processes. J Contam Hydrol 1994;16(1):1-33.

[56] Imhoff PT, Arthur MH, Miller CT. Complete dissolution of trichloroethylene in saturated porous media. Environ Sci Technol 1998;32(16):2417-24.

[57] Miller CT, Poirier-McNeill MM, Mayer AS. Dissolution of trapped nonaqueous phase liquids: Mass transfer characteristics. Water Resour Res 1990;26(11):2783-96.

[58] Grimberg SJ, Miller CT, Aitken MD. Surfactant-enhanced dissolution of phenanthrene into water for laminar flow conditions. Environ Sci Technol 1996;30(10):2967-74.
[59] Brown CL, Pope GA, Abriola LM, Sepehrnoori K. Simulation of surfactant enhanced aquifer remediation. Water Resour Res 1994;30(11):2959-77.

[60] Imhoff PT, Miller CT. Dissolution fingering during the solubilization of nonaqueous phase liquids in saturated porous media 1. Model predictions. Water Resour Res 1996;32(7):191928.

[61] Imhoff PT, Thyrum GP, Miller CT. Dissolution fingering during the solubilization of nonaqueous phase liquids in saturated porous media 2. Experimental observations. Water Resour Res 1996;32(7):1929-42.

[62] Farrell J, Reinhard M. Desorption of halogenated organics from model solids sediments and soil under unsaturated conditions. 1 . Isotherms. Environ Sci Technol 1994;28(1):53-62.

[63] Karickhoff SW, Brown DS, Scott TA. Sorption of hydrophobic pollutants on natural sediments. Water Res 1979;13(2):241-8.

[64] Weber Jr WJ. Physicochemical processes for water quality control. New York: John Wiley \& Sons; 1972.

[65] Grathwohl P, Reinhard M. Desorption of trichloroethylene in aquifer material: Rate limitation at the grain scale. Environ Sci Technol 1993;27(12):2360-6.

[66] Freundlich H. Of the adsorption of gases. Section II. Kinetics and energetics of gas adsorption. J Am Chem Soc 1931:195-201.

[67] Barry DA, Bajracharya K. Optimised Muskingum-Cunge solution method for solute transport with equilibrium Freundlich reactions. J Contam Hydrol 1995;18(3):221-38.

[68] Kinninburgh DG. General purpose adsorption isotherms. Environ Sci Technol 1986;20(9):895-903.

[69] Pedit JA, Miller CT. Heterogeneous sorption processes in subsurface systems. 1. Model formulations and applications. Environ Sci Technol 1994;28(12):2094-104.

[70] Miller CT, Weber Jr WJ. Modeling organic contaminant partitioning in ground water systems. Ground Water 1984;22(5):584 92.

[71] Miller CT, Weber Jr WJ. Sorption of hydrophobic organic pollutants in saturated soil systems. J Contam Hydrol 1986;1:24361 .

[72] Weber Jr WJ, Miller CT. Modeling the sorption of hydrophobic contaminants by aquifer materials - I: Rates and equilibria. Water Res 1988;22(4):457-64.

[73] Miller CT, Weber Jr WJ. Modeling the sorption of hydrophobic contaminants by aquifer materials-II: Column reactor systems. Water Res 1988;22(4):465-74.

[74] Miller CT, Pedit JA, Staes EG, Gilbertsen RH. Modeling organic contaminant sorption impacts on aquifer restoration. Technical Report Report Number 246, Water Resources Research Institute of North Carolina, Raleigh, NC, 1989.

[75] Fábrega JR, Jafvert CT, Li H, Lee LS. Modeling competitive cation exchange of aromatic amines in water-saturated soils. Environ Sci Technol 2001;35(13):2727-33.

[76] Miller CT, Pedit JA, Levert AM, Rabideau AJ. Investigation of multicomponent sorption and desorption rates in saturated groundwater systems. Technical Report 263, The United States Geological Survey and the Water Resources Research Institute of North Carolina, Raleigh, NC, 1992.

[77] Bajracharya K, Barry DA, Vigneswaran S, Das Gupta A. Heavy metal adsorption in soil: Comparison of bisolute adsorption models and laboratory experiments. In: Singh VP, Kumar B, editors. Proceedings of the International Conference on Hydrology and Water Resources, New Delhi, India, December 1993. number 3. Water Science and Technology Library, vol. 16 in Water-Quality Hydrology. Dordrecht, The Netherlands: Kluwer Academic Publishers; 1996. p. 19-26.

[78] Weber Jr WJ, McGinley PM, Katz LE. A distributed reactivity model for sorption by soils and sediments. 1. Conceptual basis and equilibrium assessments. Environ Sci Technol 1992;26(10): 1955-62. 
[79] Rav-Acha Ch, Rebhun M. Binding of organic solutes to dissolved humic substances and its effects on adsorption and transport in the aquatic environment. Water Res 1992;26(12):1645-54.

[80] Rav-Acha C, Duchovni I, Kanarek A, Izakson N, Rebhun M. Retardation factors and breakthrough times of organic micropollutants in groundwater recharged with effluents. Water Sci Technol 1996;33(10-11):391-9.

[81] Karickhoff SW. Organic pollutant sorption in aquatic systems. J Hydraul Eng 1984;110(6):707-35.

[82] Karickhoff SW. Semi-empirical estimation of adsorption of hydrophobic pollutants on natural sediments and soils. Chemosphere 1981;10(8):833-46.

[83] Rivett MO, Feenstra S, Cherry JA. A controlled field experiment on groundwater contamination by a multicomponent DNAPL: Creation of the emplaced-source and overview of dissolved plume development. J Contam Hydrol 2001;49(1-2):111-49.

[84] Curtis GP, Reinhard M, Roberts PV. Sorption of hydrophobic organic compounds by sediments. In: Davis JA, Hayes KF, editors. Geochemical processes at mineral surfaces ACS Symposium Series 323. Washington, DC: American Chemical Society; 1986. p. 191-216.

[85] Weber Jr WJ, McGinley PM, Katz LE. Sorption phenomena in subsurface systems: Concepts, models and effects on contaminant fate and transport. Water Res 1991;25(5):499-528.

[86] Valsaraj KT, Kommalapati RR, Robertson ED, Constant WD. Partition constants and adsorption desorption hysteresis for volatile organic compounds on soil from a Louisiana superfund site. Environ Monitor Assess 1999;58(2):225-41.

[87] McCarty PL, Reinhard M, Rittman BE. Trace organics in groundwater. Environ Sci Technol 1981;15(1):40-51.

[88] Bajracharya K, Barry DA. Mixing cell models for nonlinear equilibrium single species adsorption and transport. J Contam Hydrol 1993;12(3):227-43.

[89] Bajracharya K, Barry DA. Mixing cell models for nonlinear nonequilibrium single species adsorption and transport. Water Resour Res 1992;29(5):1405-13.

[90] Bajracharya K, Barry DA. Analysis of one-dimensional multispecies transport experiments in laboratory soil columns. Environ Int 1995;21(5):687-91.

[91] Cameron DR, Klute A. Convective-dispersive solute transport with a combined equilibrium and kinetic adsorption model. Water Resour Res 1977;13(1):183-8.

[92] Selim HM, Davidson JM, Mansell RS. Evaluation of a two-site adsorption-desorption model for describing solute transport in soils. In: Proceedings of the 1976 Summer Computer Simulation Conference. La Jolla, CA: Simulation Councils, Inc; 1976. p. 444-8.

[93] Crittenden JC, Hutzler NJ, Geyer DG, Oravitz JL, Friedman G. Transport of organic compounds with saturated groundwater flow: Model development and parameter sensitivity. Water Resour Res 1986;22(3):271-84.

[94] Cunningham JA, Werth CJ, Reinhard M, Roberts PV. Effects of grain-scale mass transfer on the transport of volatile organics through sediments. 1. Model development. Water Resour Res 1997;33(12):2713-26.

[95] Werth CJ, Cunningham JA, Roberts PV, Reinhard M. Effects of grain-scale mass transfer on the transport of volatile organics through sediments. 2. Column results. Water Resour Res 1997;33(12):2727-40.

[96] Farrell J, Reinhard M. Desorption of halogenated organics from model solids, sediments, and soil under unsaturated conditions. 2. Kinetics. Environ Sci Technol 1994;28(1):63-72.

[97] Pedit JA, Miller CT. Heterogeneous sorption processes in subsurface systems. 2. Diffusion modeling approaches. Environ Sci Technol 1995;29(7):1766-72.

[98] Kirkner DJ, Theis TL, Jennings AA. Multicomponent solute transport with sorption and soluble complexation. Adv Water Resour 1984;7(3):120-5.
[99] Miller CW, Benson LV. Simulation of solute transport in a chemically reactive heterogeneous system: Model development and application. Water Resour Res 1983;19(2):381-91.

[100] Stumm W, Morgan JJ. Aquatic chemistry: chemical equilibria and rates in natural waters. 3rd ed. New York: Wiley-Interscience, John Wiley \& Sons; 1995.

[101] Lichtner PC. Time-space continuum description of fluid/rock interaction in permeable media. Water Resour Res 1992; 28(12):3135-55.

[102] Liang LY, Korte N, Gu BH, Puls R, Reeter C. Geochemical and microbial reactions affecting the long-term performance of in situ iron barriers. Adv Environ Res 2000;4(4):273 86.

[103] Furumai H, Rittmann BE. Evaluation of multiple-species biofilm and floc processes using a simplified aggregate model. Water Sci Technol 1994;29(10-11):439-46.

[104] Valocchi AJ. Validity of the local equilibrium assumption for modeling sorbing solute transport through homogeneous soils, Water Resour Res 1985;21(6):808-20.

[105] Bahr JM, Rubin J. Direct comparison of kinetic and local equilibrium formulations for solute transport affected by surface reactions. Water Resour Res 1987;23(3):438-52.

[106] Miller CT, Rabideau AJ. Development of split-operator, PetrovGalerkin methods to simulate transport and diffusion problems. Water Resour Res 1993;29(7):2227-40.

[107] Boucher DF, Alves GE. Dimensionless numbers for fluid mechanics, mass transfer and chemical reaction. Chem Eng Prog 1959;55(9):55-64.

[108] Barry DA, Li L. Physical basis of nonequilibrium solute transport in soil. In: Fifteenth International Congress of Soil Science Transactions, vol. 2a. Acapulco, Mexico: International Society of Soil Science and Mexican Society of Soil Science; 1994. p. 86-105.

[109] Kirkner DJ, Jennings AA, Theis TL. Multisolute mass transport with chemical interaction kinetics. J Hydrol 1985;76(1-2):107-17.

[110] Saaltink MW, Ayora C, Carrera J. A mathematical formulation for reactive transport that eliminates mineral concentrations. Water Resour Res 1998;34(7):1649-56.

[111] Sposito G. Chemical equilibria and kinetics in soils. New York: Oxford University Press; 1994.

[112] Sposito G. The chemistry of soils. New York: Oxford University Press; 1989.

[113] Tan KH. Principles of soil chemistry. New York: Marcel Dekker; 1982.

[114] Bethke CM. Geochemical reaction modeling: concepts and applications. New York: Oxford University Press; 1996.

[115] Davies CW. Ion association. London: Butterworths; 1962.

[116] Evangelou VP. Environmental soil and water chemistry: principles and applications. New York: Wiley-Interscience, John Wiley \& Sons; 1998.

[117] Steefel CI, MacQuarrie KTB. Approaches to modeling of reactive transport in porous media. In: Lichtner PC, Steefel CI, Oelkers $\mathrm{EH}$, editors. Reactive transport in pqrous media, volume 34 of reviews in mineralogy. Washington, DC: Mineralogical Society of America; 1996. p. 83-129 (Chapter 2).

[118] Parkhurst DL, Thorstenson DC, Plummer LN. PHREEQE-A computer program for geochemical calculations. Technical report, US Geological Survey techniques of Water-Resources Investigations Report, 1980.

[119] Brown PL, Haworth A, Sharland SM, Tweed CJ. HARPHRQ: A geochemical speciation code based on PHREEQE. Technical Report Report NSSR. 188, Harwall Laboratory, Didcot UK, 1991.

[120] Wolery TJ. Calculation of chemical equilibrium between aqueous solution and minerals: The EQ3/6 software package. Technical Report URCL-52658, Lawrence Livermore National Laboratory, 1979.

[121] Wolery TJ. EQ3NR, A computer program for geochemical aqueous speciation-solubility calculations: Theoretical manual, 
user's guide, and related documentation (version 7.0). Technical Report UCRL-MA-110662 PT III. Lawrence Livermore National Laboratory, 1992.

[122] Allison JD, Brown DS. Novo-Gradac KJ. MINTEQA2/PRODEF2, A geochemical assessment model for environmental systems: Version 3.0 User's Manual, EPA/600/3-91/021. Technical report. US Environmental Protection Agency, Athens, GA, 1991.

[123] Nordstrom DK, Plummer LN, Wigley TML, Wolery TJ, Ball JW, Jenne EA, et al. A comparison of computerized chemical models for equilibrium calculations in aqueous systems. In: Jenne EA. editor. Chemical modeling in aqueous systems: speciation, sorption, solubility, and kinetics Symposium Series No 93. Washington, DC: American Chemical Society; 1979.

[124] Brown LF. Ebinger MH. Modeling precipitation from concentrated solutions with the EQ3/6 chemical speciation codes. Comput Chem 1998;22(5):419-27.

[125] Wernberg T. Multicomponent groundwater transport with chemical equilibrium and kinetics: Model development and evaluation. Hydrol Sci J 1988;43(2):299-317.

[126] Liu CW, Narasimhan TN. Redox-controlled multiple-species reactive chemical transport, 1. Model development. Water Resour Res 1989:25(5):869-82.

[127] Borden RC. Bedient PB. Transport of dissolved hydrocarbons influenced by oxygen-limited biodegradation 1. Theoretical development. Water Resour Res 1986;22(13):1973-82.

[128] Borden RC, Bedient PB, Lee MD, Ward CH, Wilson JT. Transport of dissolved hydrocarbons influenced by oxygenlimited biodegradation. 2. Field application. Water Resour Res 1986:22(13): 1983-90.

[129] Marquis SA. Bioplume II: A powerful tool for bioremediation design in alluvial and periglacial paleodepositional settings. In: Proceedings of The Eighth National Outdoor Action Conference and Exposition. Dublin, $\mathrm{OH}$ : Ground Water Publishing Company: 1994. p. 175-90.

[130] Michaelis L, Menten ML. Die Kinetik der Invertinwirkung. Biochemische Zeitschrift 1931:49:333-69.

[131] Parlange J-Y, Starr JL, Barry DA, Braddock RD. Some approximate solutions of the transport equation with irreversible reactions. Soil Sci 1984:137(6):434 42.

[132] Barry DA, Parlange J-Y, Starr JL. Interpolation method for solving the transport equation in soil columns with irreversible kinetics. Soil Sci 1986;142(5):296-307.

[133] Monod J. The growth of bacterial cultures. Ann Rev Microbiol 1949;3:371-94.

[134] Semprini L, McCarty PL. Comparison between model simulations and field results for in situ biorestoration of chlorinated aliphatics: Part 1. Biostimulation of methanotrophic bacteria. Ground Water 1991:29(3):365-74.

[135] Semprini L, Mccarty PL. Comparison between model simulations and field results for in situ biorestoration of chlorinated aliphatics: Part 2. Cometabolic transformations. Ground Water 1992:30(1): $37-44$.

[136] Bae W, Rittmann BE. A structured model of dual-limitation kinetics, Biotechnol Bioeng 1996:49(6):683-9.

[137] Bae W. Rittmann BE. Responses of intracellular cofactors to single and dual substrate limitations. Biotechnol Bioeng 1996:49(6):690-9.

[138] Guha S, Jaffé PR, Peters CA. Bioavailability of mixtures of PAHs partitioned into the micellar phase of a nonionic surfactant. Environ Sci Technol 1998:32(15):2317-24.

[139] Soda S, Heinzle E. Fujita M. Modeling and simulation of competition between two microorganisms for a single inhibitory substrate in a biofilm reactor. Biotechnol Bioeng 1999;66(4):258 64.

[140] Spiegel MR. Mathematical handbook of formulas and tables. Schaum's Outline Series. New York: McGraw-Hill Book Company: 1968 .
[141] Abrams RH, Loague K. A compartmentalized solute transport model for redox zones in contaminated aquifers. 1. Theory and development. Water Resour Res 2000;36(8):2001 13.

[142] Holstad A. Modelling subsurface coupled chemical reactions and fluid flow over long time periods. Numer Algorithms 1998;19(14):95-110.

[143] Holstad A. A mathematical and numerical model for reactive fluid flow systems. Computat Geosci 2000;4(2):103-39.

[144] Steefel CI, Yabusaki SB. OS3D/GIMRT. Software for multicomponent-multidimensional reactive transport, User manual and programmers guide. PNL-11166. Technical report, Pacific Northwest National Laboratory, 1996.

[145] Barry DA, Bajracharya K, Miller CT. Alternative split-operator approach for solving chemical reaction/groundwater transport models. Adv Water Resour 1996;19(5):261-75.

[146] Herzer J, Kinzelbach W. Coupling of transport and chemical processes in numerical transport models. Geoderma 1989:44(2 3):115-27.

[147] Barry DA, Bajracharya K. Crapper M. Prommer H, Cunningham CJ. Comparison of split-operator methods for solving coupled chemical non-equilibrium reaction/groundwater transport models. Math Comput Simulat 2000:53(1-2):113-27.

[148] Valocchi AJ, Malmstead M. Accuracy of operator splitting for advection-dispersion-reaction problems. Water Resour Res 1992;28(5):1471-6.

[149] Zysset A. Modellierung des chemischen Zustandes in Grundwasser-Infiltrations-Systemen. Institut f. Hydromechanik und Wasserwirtschaft, ETH Zürich, PhD Thesis, 1993.

[150] Kaluarachchi JJ, Morshed J. Critical assessment of the operatorsplitting technique in solving the advection-dispersion reaction equation. 1. First-order reaction. Adv Water Resour 1995;18(2): 89-100.

[151] Morshed J, Kaluarachchi JJ. Critical assessment of the operatorsplitting technique in solving the advection-dispersion reaction equation. 2. Monod kinetics and coupled transport. Adv Water Resour 1995;18(2):101-10.

[152] Barry DA, Miller CT, Culligan-Hensley PJ. Temporal discretisation errors in non-iterative split-operator approaches to solving chemical reaction/groundwater transport models. J Contam Hydrol 1996;22(1/2):1-17.

[153] Barry DA, Miller CT, Culligan-Hensley PJ, Bajracharya K. Analysis of split operator methods for nonlinear and multispecies groundwater chemical transport models. Math Comput Simulat $1997 ; 43(3-6): 331-41$.

[154] Garcia-Delgardo RA. Koussis AD. Ground-water solute transport with hydrogeochemical reactions. Ground Water 1997:35(2): 243-9.

[155] Chilakapati A, Yabusaki S, Szecsody J, MacEvoy W. Groundwater flow, multicomponent transport and biogeochemistry: Development and application of a coupled process model. J Contam Hydrol 2000;43(3-4):303-25.

[156] Khan LA, Liu PLF. An operator splitting algorithm for coupled one-dimensional advection-diffusion-reaction equations. Comput Meth Appl Mech Eng 1995;127(1-4):181-201.

[157] Ramanujam G. Koussis AD. Comparison of two splitting algorithms for 2-D modelling of advection-dominated solute transport in groundwater. Adv Water Resour 1991;14(4):18391.

[158] Zhang W, DiGiano FA, Miller CT. Using sequential splitting operator methods to solve a bacterial regrowth model. 2000 Joint Conference in Water Resources Engineering and Water Resources Planning \& Management 2000.

[159] Barry DA, Miller CT, Bajracharya K. An improved split-operator algorithm for solving coupled solute transport and reaction equations. EOS transactions. American Geophysical Union, American Geophysical Union Fall Meeting. vol. 75. 1994. 
[160] Barry DA, Miller CT, Culligan PJ, Bajracharya K. Split operator methods for reactive chemical transport in groundwater. In: Proceedings of the International Conference on Modelling and Simulation 1995: MODSIM95 New South Wales, 1995. Modelling and Simulation Society of Australia, Inc.

[161] Kanney JF, Miller CT, Barry DA. Comparison of fully coupled approaches for approximating nonlinear transport and reaction problems. Adv Water Resour, in press.

[162] Miller CT, Kanney JF; Barry DA. Modeling reactive transport processes in porous media systems. Fifth SIAM Conference on Mathematical and Computational Issues in the Geosciences. Society for Industrial and Applied Mathematics; 1999.

[163] Kanney JF. Computer Code: SORT: Split operator reactive transport, 1997.

[164] König C. Operator split for three dimensional mass transport equation. In: Peters A, Wittum G, Herrling B, Meissner U, Brebbia CA. Gray WG, Pinder GF, editors. Computational methods in water resources X volume, vol. I. Dordrecht, The Netherlands: Kluwer Academic Publishers; 1994. p. 309-16.

[165] Kanney JF, Miller CT. OOBR: A object-oriented batch reaction module for split operator reactive transport codes. Technical Report Research notes report: RN-OOBR, University of North Carolina, Chapel Hill, North Carolina, 1997.

[166] Rabideau AJ, Miller CT. Evaluation of a split-operator PetrovGalerkin model for simulating multicomponent transport and transformations processes in porous media systems. In: EOS Transactions, vol. 71(43). American Geophysical Union; 1990. p. 1336.

[167] Strang G. On the construction and comparison of difference schemes. SIAM J Numer Anal 1968;5(3):506-17.

[168] Kinzelbach W, Schäfer W, Herzer J. Numerical modeling of natural and enhanced denitrification processes in aquifers. Water Resour Res 1991;27(6):1123-35.

[169] Kanney JF, Miller CT, Kelley CT. Convergence of iterative splitoperator approaches for approximating nonlinear reactive transport problems, Adv Water Resour, in review.

[170] Mitchell AR. Recent developments in the finite element method. In: Noye J, Fletcher CAJ, editors. Computational techniques and applications, CTAC-83. Amsterdam: Elsevier/North-Holland; 1984. p. 2-14.

[171] Leonard BP. Universal limiter for transient interpolation modeling of the advective transport equations: The ULTIMATE conservative difference scheme. In: NASA Technical Memorandum 100916 (ICOMP-88-11). Cleveland, OH: NASA-Lewis Research Center; 1988.

[172] Neuman SP. Adaptive Eulerian-Lagrangian finite element method for advection dispersion. Int J Numer Meth Eng 1984; 20(2):321-37.

[173] Zheng C, Bennett GD. Applied contaminant transport modeling. 2nd ed. New York: John Wiley and Sons; 2002.

[174] Wheeler MF, Peszynska M. Computational engineering and science methodologies for modeling and simulation of subsurface applications. Adv Water Resour 2002;25.

[175] Huyakorn PS. Pinder GF. Computational methods in subsurface flow. Orlando, FL: Academic Press; 1983.

[176] Voss CI. SUTRA - A finite element simulation model for saturated-unsaturated, fluid-density-dependent ground water flow with energy transport or chemical reactive single-species solute transport. In: Water-Resources Investigations Report 84-4369. Reston, VA: US Geological Survey; 1984.

[177] Kipp KL. HST3D: A computer code for simulation of heat and solute transport in three-dimensional ground-water flow systems. In: Water-Resources Investigations Report 86-4095. Denver, CO: US Geological Survey; 1987.

[178] Sun N-Z. Mathematical modeling of groundwater pollution. New York: Springer-Verlag: 1996.
[179] Prickett TA. Naymik TG, Lonnquist CG. A "random-walk" solute transport model for selected groundwater quality evaluations. Technical Report Bulletin 65, State of Illinois Water Survey Division, Champaign, IL, 1981.

[180] Uffink GJM. A random-walk method for simulation of macrodispersion in a stratified aquifer. Proceedings of the Hamburg Symposium of IUGG I8th General Assembly. Publication 65. IAHS, 1985.

[181] Kinzelbach W. Groundwater modeling: an introduction with sample programs in BASIC. Amsterdam. The Netherlands: Elsevier Scientific Publishers; 1986.

[182] Tompson AF, Gelhar LW. Numerical simulation of solute transport in three-dimensional, randomly heterogeneous porous media. Water Resour Res 1990;26(10):2541-62.

[183] Bosma WJP, van der Zee SEATM, van Duijn CJ. Plume development of a nonlinearly adsorbing solute in heterogeneous porous formations. Water Resour Res 1996:32(6):1569 84.

[184] LaBolle EM, Fogg GE, Tompson AFB. Random-walk simulation of transport in heterogeneous porous media: Local mass-conservation problem and implementation methods. Water Resour Res 1996;32(3):583-93.

[185] Sun N-Z. A finite cell method for simulating the mass transport process in porous media. Water Resour Res 1999;35(12):3649 62.

[186] Yeh GT. A Lagrangian-Eulerian method with zoomable hidden fine-mesh approach to solving advection-dominated advectiondispersion equations. Water Resour Res 1990;28(11):113344.

[187] Zheng C, Wang P. MT3DMS: A modular three-dimensional multispeces transport model for simulation of advection, dispersion, and chemical reactions of contaminants in groundwater systems. Technical report, Waterways Experiment Station, US Army Corps of Engineers, Vicksburg. MS, 1998.

[188] Zheng C. MT3D. A modular three-dimensional transport model for simulation of advection, dispersion and chemical reactions of contaminant in groundwater systems. Technical report, Environmental Protection Agency, Ada, OK. 1990.

[189] Konikow LF, Bredehoeft JD. Computer model of two-dimensional solute transport and dispersion in ground water. In: Water-Resources Investigations Book, vol. 7. Reston, VA: US Geological Survey; 1978 [Chapter C2].

[190] Konikow LF, Goode DJ, Hornberger GZ. A three-dimensional method-of-characteristics solute-transport model (MOC3D). In: Water-Resources Investigations Report 96-4267. Reston, VA: US Geological Survey; 1996.

[191] Douglas J, Russell TF. Numerical methods for convection dominated diffusion problems based on combining the method of characteristics with finite element or finite difference procedures. SIAM J Numer Anal 1982;19(5):871-85.

[192] Cheng RT, Casulli V, Milford SN. Eulerian-Lagrangian solution of the convective-dispersion equation in natural coordiantes. Water Resour Res 1984;20(7):944-52.

[193] Celia MA, Russell TF, Herrera I, Ewing RE. An EulerianLagrangian localized adjoint method for the advection-dispersion equation. Adv Water Resour 1990;13(4):187-206.

[194] Zheng C. Extension of the method of characteristics for simulation of solute transport in 3 dimensions. Ground Water 1993; 31(3):456-65.

[195] Bentley LR, Pinder GF. Eulerian-Lagrangian solution of the vertically averaged groundwater transport equation. Water Resour Res 1992;28(11):3011-20.

[196] Roache PJ. A flux-based modified method of characteristics. Int J Numer Meth Fluids 1992:15(11):1259-75.

[197] Healy RW, Russell TF. A finite-volume Eulerian-Lagrangian localized adjoint method for solution of the advection-dispersion equation. Water Resour Res 1993:29(7):2399-413. 
[198] Binning P, Celia MA. A finite volume Eulerian-Lagrangian localized adjoint method for solution of the contaminant transport equations in two-dimensional multiphase flow systems. Water Resour Res 1996;32(1):103-14.

[199] Cheng HP, Cheng JR, Yeh GT. A particle tracking technique for the Lagrangian-Eulerian finite element method in multi-dimensions. Int J Numer Meth Eng 1996;39(7):1115-36.

[200] Bensabat J, Zhou Q, Bear J. An adaptive pathline-based particle tracking algorithm for the Eulerian-Lagrangian method. Adv Water Resour 2000;23(4):383-97.

[201] Heberton CI, Russell TF, Konikow LF, Hornberger GZ. A threedimensional finite-volume Eulerian-Lagrangian localized adjoint method (ELLAM) for solute-transport modeling. In: WaterResources Investigations Report 00-4087. Reston, VA: US Geological Survey; 2000.

[202] van Leer B. Toward the ultimate conservative difference scheme. IV. A new approach to numerical convection. J Comput Phys 1977;23(3):276-99.

[203] Leonard BP. A stable and accurate convective modeling procedure based on quadratic upstream interpolation. Comput Meth Appl Mech Eng 1979;19(1):59-89.

[204] Harten A. High resolution schemes for hyperbolic conservation laws. J Comput Phys 1983;49(3):357-93.

[205] Goodman JB, LeVeque RJ. A geometric approach to high resolution TVD schemes. SIAM J Numer Anal 1988;25(2):268-84.

[206] Putti M, Yeh WW-G, Mulder WA. A triangular finite volume approach with high-resolution upwind terms for the solution of groundwater transport equations. Water Resour Res 1990;26(12): 2865-80.

[207] Leonard BP, Niknafs HS. Cost-effective accurate coarse-grid method for highly convective multidimensional unsteady flows. NASA Conference Publication 3078. 1990. p. 227-40.

[208] Leonard BP, Niknafs H. Sharp monotonic resolution of discontinuities without clipping of narrow extrema. Comput Fluids 1991;19(1):141-54.

[209] Cox RA, Nishikawa T. A new total variation diminishing scheme for the solution of advective-dominant solute transport. Water Resour Res 1991;27(10):2645-54.

[210] Cox RA, Nishikawa T. Correction to A new total variation diminishing scheme for the solution of advective-dominant solute transport' by Ronald A. Cox and Tracy Nishikawa. Water Resour Res 1991;27(12):3279.

[211] Leonard BP, Lock AP, Macvean MK. The NIRVANA scheme applied to one-dimensional advection. Int J Numer Meth Heat Fluid Flow 1995;5(4):341-77.

[212] Thuburn J. TVD schemes, positive schemes, and the universal limiter. Monthly Weather Rev 1997;125(8):1990-5.

[213] Pietrzak J. The use of TVD limiters for forward-in-time upstreambiased advection schemes in ocean modeling. Monthly Weather Rev 1998;126(3):812-30.

[214] Oldenburg CM, Pruess K. Simulation of propagating fronts in geothermal reservoirs with the implicit Leonard total variation diminishing scheme. Geothermics 2000;29(1):1-25.

[215] Farthing MW, Miller CT. A comparison of high-resolution, finitevolume, adaptive-stencil schemes for simulating advective-dispersive transport. Adv Water Resour 2001;24(1):29-48.

[216] Putti M, Mulder WA, Yeh WW. A time-accurate multigrid algorithm for the solution of the transport equations. In: Gambolati G, Rinaldo A, Brebbia CA, Gray WG, Pinder GF, editors. Proceedings of the Eighth International Conference on Computational Methods in Water, Resources Computational Methods in Subsurface Hydrology. Southampton: Computational Mechanics Publications; 1990. p. 441-8.

[217] Beckie R, Wood EF, Aldama AA. Mixed finite element simulation of saturated groundwater flow using a multigrid accelerated domain decomposition technique. Water Resour Res 1993;29(9): $3145-57$.
[218] Briggs WL, Henson VE, McCormick SF, A multigrid tutorial. Philadelphia: Society for Industrial and Applied Mathematics; 2000.

[219] Diskin B. Efficient multigrid methods for solving upwind-biased discretizations of the convection equation. Appl Math Comput 2001;123(3):343-79.

[220] Bastian P, Helmig R. Efficient fully-coupled solution techniques for two-phase flow in porous media-Parallel multigrid solution and large scale computations. Adv Water Resour 1999;23(3):199 216.

[221] Gupta MM, Zhang J. High accuracy multigrid solution of the 3D convection-diffusion equation. Appl Math Comput 2000;113(2 3):249-74.

[222] Wolfsberg AV, Freyberg DL. Efficient simulation of single species and multispecies transport in groundwater with local adaptive grid refinement. Water Resour Res 1994;30(11):2979-91.

[223] Dawson CN, Dupont TF. Explicit/implicit, conservative domain decomposition procedures for parabolic problems based on blockcentered finite differences. SIAM J Numer Anal 1994;31(4):104561.

[224] Guarnaccia J, Herrera I, Pinder GF. Solution of flow and transport problems using a collocation discretization of a domain decomposition algorithm. In: Peters A, Wittum G, Herrling B, Meissner U, Brebbia CA, Gray WG, Pinder GF, editors. Computational methods in water resources X, vol. 1. The Netherlands: Kluwer Academic; 1994. p. 265-72.

[225] Chen Z, Ewing RE, Lazarov R. Domain decomposition algorithms for mixed methods for second-order elliptic problems. Math Comput 1996;65(214):467-90.

[226] Gelhar LW, Axness CL. Three-dimensional stochastic analysis of macrodispersion in aquifers. Water Resour Res 1983;19(1):16180.

[227] Dagan G. Solute transport in heterogeneous porous formations. J Fluid Mech 1984;145:151-77.

[228] Sposito G, Barry DA. On the Dagan model of solute transport in groundwater: foundational aspects. Water Resour Res 1987; 23(10):1867-75.

[229] Molz FJ, Widdowson MA. Internal inconsistencies in dispersiondominated models that incorporate chemical and microbial kinetics. Water Resour Res 1988;24(4):615-9.

[230] MacQuarrie KT, Sudicky EA. Simulation of biodegradable organic contaminants in groundwater. 2. Plume behavior in uniform and random flow fields. Water Resour Res 1990; 26(2):223-39.

[231] Kemblowski MW, Chang C-M, Kamil I. A mean behavior model of aerobic biodegradation in heterogeneous formation. Stochas Hydrol Hydraul 1997;1 (3):255-66.

[232] Cirpka OA, Frind EO, Helmig R. Numerical simulation of biodegradation controlled by transverse mixing. J Contam Hydrol 1999;40(2):159-82.

[233] Miralles-Wilhelm F, Gelhar LW, Kapoor V. Stohcastic analysis of oxygen-limited biodegradation in three-dimensionally heterogeneous aquifers. Water Resour Res 1997;33(6):1251-63.

[234] Kapoor V, Gelhar LW, Miralles-Wilhelm F. Bimolecular secondorder reactions in spatially varying flows: Segregation induced scale-dependent transformation rates. Water Resour Res 1997;33(4):527-36.

[235] Miralles-Wilhelm F, Gelhar LW. Stochastic analysis of oxygenlimited biodegradation in heterogeneous aquifers with transient microbial dynamics. J Contam Hydrol 2000;42(1):69-97.

[236] Molz FJ, Widdowson MA, Benefield LD. Simulation of microbial growth dynamics coupled to nutrient and oxygen transport in porous media. Water Resour Res 1986;22(8):1207-16.

[237] Widdowson MA, Molz FJ, Benefield LD. A numerical transport model for oxygen- and nitrate-based respiration linked to substrate and nutrient availability in porous media. Water Resour Res 1988;24(9):1553-65. 
[238] Celia MA, Kindred JS, Herrera I. Contaminant transport and biodegradation. 1. A numerical model for reactive transport in porous media. Water Resour Res 1989;25(6):1141-8.

[239] MacQuarrie KT, Sudicky EA, Frind EO. Simulation of biodegradable organic contaminants in groundwater. 1. Numerical formulation in principal directions. Water Resour Res 1990; 26(2):207-22.

[240] Chen ZQ, McTernan WF. Multi-substrate, multi-option groundwater transport model. J Contam Hydrol 1992;11(3-4):215-44.

[241] Chen YM, Abriola LM, Alvarez PJJ, Anid PJ, Vogel TM. Modeling transport and biodegradation of benzene and toluene in sandy aquifer material: Comparisons with experimental measurements. Water Resour Res 1992;28(7):1833- 47.

[242] Rifai HS, Newell CJ, Miller R, Taffinder S, Rounsaville M. Simulation of natural attenuation with multiple electron acceptors. In: Hinchee RE, Wilson JT, Downey DC, editors. Intrinsic bioremediation. Columbus, OH: Battelle Press; 1995. p. 53-8.

[243] Clement TP. RT3D - A modular computer code for simulating reactive multi-species transport in 3-dimensional groundwater aquifers. Technical Report PNNL-SA-28967, Battelle Pacific Northwest National Laboratory Research Report, Richlands, Washington, September 1997.

[244] Waddill DW, Widdowson MA. Three-dimensional model for subsurface transport and biodegradation. ASCE J Environ Eng 1998;124(4):336-44.

[245] Papadopulos SS and Associates. Inc. MT3D99. 1999. Available from: http://www.sspa.com/products/Mt3d99.htm.

[246] Molson JWH. Numerical Simulation of Hydrocarbon Fuel Dissolution and Biodegradation in Groundwater. PhD Thesis, Department of Earth Sciences, University of Waterloo, 2000.

[247] Malone DR, Kao C-M, Borden RC. Dissolution and biorestoration of nonaqueous phase hydrocarbons: Model development and laboratory evaluation. Water Resour Res 1993;29(7):2203-13.

[248] Appelo CAJ, Willemsen A. Geochemical calculations and observations on salt water intrusions. I. A combined geochemical/ mixing cell model. J Hydrol 1987;94(3-4):313-30.

[249] Yeh G-T, Tripathi VS. A model for simulating transport of reactive multispecies components: Model development and demonstration. Water Resour Res 1991;27(12):3075-94.

[250] Engesgaard P, Kipp KL. A geochemical transport model for redox-controlled movement of mineral fronts in groundwater flow systems: A case of nitrate removal by oxidation of pyrite. Water Resour Res 1992;28(10):2829-43.

[251] Walter AL, Frind EO, Blowes DW, Ptacek CJ, Molson JW. Modeling of multicomponent reactive transport in groundwater. 1. Model development and evaluation. Water Resour Res 1994;30(11):3137-48.

[252] Parkhurst DL. User's guide to PHREEQC - A computer program for speciation, reaction-path, advective-transport, and inverse geochemical calculations. Technical Report Water-Resources Investigations Report 95-4227. US Geological Survey, 1995. p. 143.

[253] Guerin M, Zheng C. GMT3D - Coupling multicomponent, threedimensional transport with geochemistry. In: Poeter EP, Zheng C. Hill MC, editors. MODFLOW98 International Conference, Proceedings Colorado School of Mines. Colorado: Golden; 1998.

[254] Schäfer W. Numerische Modellierung mikrobiell beeinflusster Stofftransportvorgänge im Wasser. München, Wien: Oldenbourg Verlag: 1992.

[255] Brun A, Engesgaard P, Frind EO, A coupled microbiologygeochemistry transport model for saturated groundwater flow. In: Dracos TH, Stauffer F, editors. Transport and reactive processes in aquifers. Rotterdam: A.A. Balkema; 1994. p. 457-62.

[256] McNab WW, Narasimhan TN. Modeling reactive transport of organic compounds in groundwater using a partial redox disequilibrium approach. Water Resour Res 1994;30(9):261935.
[257] Lensing HJ, Vogt M, Herrling B. Modeling of biologically mediated redox processes in the subsurface. J Hydrol 1994;159(14):125-43.

[258] Schäfer W, Therrien R. Simulating transport and removal of xylene during remediation of a sandy aquifer. J Contam Hydrol 1995;19(19):205-36.

[259] Hindmarsh AC. ODEPACK: A systematized collection of ODE solvers. In: Stepleman R, editor. Scientific computing. Amsterdam: North-Holland; 1983, p. 55-64.

[260] Petzold L. Automatic selection of methods for solving stiff and nonstiff systems of ordinary differential equations. SIAM J Sci Stat Comput 1983;4(1):136-48.

[261] Yates MV, Yates SR. Modeling microbial fate in the subsurface environment. CRC Critic Rev Environ Control 1987;17(4):307-44.

[262] Moskowitz PD, Pardi R, Dephillips MP, Meinhold AF. Computer-models used to support cleanup decision-making at hazardous and radioactive-waste sites. Risk Anal 1992;12(4):591621.

[263] Essaid HI, Bekins BA, Godsy EM, Warren E, Baedecker MJ, Cozzarelli IM. Simulation of aerobic and anaerobic biodegradation processes at a crude oil spill site. Water Resour Res 1995;31(12):3309-27.

[264] de Blanc PC, McKinney GE. Modeling subsurface biodegradation of non-aqueous phase liquids. In: Corapcioglu MY, editor. Advances in porous media, vol. 3. Amsterdam: Elsevier; 1996. p. 1-86 [Chapter 1].

[265] Rittmann BW, VanBriesen JM. Microbiological processes in reactive modeling. In: Lichtner PC, Steefel CI, Oelkers EH, editors. Reactive transport in porous media, Reviews in Mineralogy, vol. 34. Washington, DC: Mineralogical Society of America; 1996. p. 311-34 [Chapter 7].

[266] Hunter KS, Wang Y, Van Cappellen P. Kinetic modeling of microbially-driven redox chemistry of subsurface environments: Coupling transport, microbial metabolism and geochemistry. J Hydrol 1998;209(1-4):53-80.

[267] Brun A. Reactive transport modeling of coupled inorganic and organic processes in groundwater. Department of Hydrodynamics and Water Resources, Technical University of Denmark, Lyngby, 1997. Series Paper 65 (PhD Thesis).

[268] Brun A, Engesgaard P. Modelling of transport and biogeochemical processes in pollution plumes: Literature review and model development. J Hydrol 2002;256(3-4):211-27.

[269] Parkhurst DL, Appelo CAJ. User's guide to PHREEQC (version 2) - A computer program for speciation, batch-reaction, onedimensional transport, and inverse geochemical calculations. In: Technical Report Water-Resources Investigations Report 994259. US Geological Survey; 1999. p. 312.

[270] Parkhurst DL, Engesgaard P, Kipp KL. Coupling the geochemical model PHREEQC with a 3D multi-component solute transport model. In: Fifth Annual V.M. Goldschmidt Conference Penn State University, University Park, Pennsylvania USA, 24-26 May 1995. Geochemical Society.

[271] Prommer H. PHT3D A Reactive Multicomponent Transport Model for Saturated Porous Media. User's Manual Version 1.0. Technical report, Contaminated Land Assessment and Remediation Research Centre, The University of Edinburgh, Edinburgh UK, 2001.

[272] Prommer H, Barry DA, Davis GB. Numerical modelling for design and evaluation of groundwater remediation schemes. Ecol Modell 2000;128(2-3):181-95.

[273] Prommer H, Barry DA, Davis GB. Influence of transient groundwater flow on physical and reactive processes during biodegradation of a hydrocarbon plume. J Contam Hydrol, in press.

[274] Steefel CI. New directions in hydrogeochemical transport modeling: Incorporating multiple kinetic and equilibrium reaction pathways. In: Bentley LR, Sykes JF, Brebbia CA, Gray WG, 
Pinder GF, editors. Computational methods in water resources XIII. Rotterdam: A.A. Balkema; 2000. p. 331-8.

[275] Steefel CI. GIMRT, Version 1.2: Software for modeling multicomponent, multidimensional reactive transport. Users guide. Technical Report UCRL-MA-143182, Lawrence Livermore National Laboratory, Livermore, California, 2001.

[276] Stollenwerk KG. Molybdate transport in a chemically complex aquifer: Field measurements compared with solute-transport model predictions. Water Resour Res 1998:34(10):2727-40.

[277] Basberg L. Field and numerical investigations of landfill leachate in the Gardermoen glaciofluvial aquifer, Norway. PhD Thesis, Department of Geology and Mineral Resources Engineering. Faculty of Applied Earth Sciences, The Norwegian University of Science and Technology, 1999.

[278] Mayer KU, Benner SG, Frind EO, Thornton SF, Lerner DN. Reactive transport modeling of processes controlling the distribution and natural attenuation of phenolic compounds in a deep sandstone aquifer. J Contam Hydrol 2001:53(3-4):341-68.

[279] Mayer KU. A numerical model for multicomponent reactive transport in variably saturated porous media, $\mathrm{PhD}$ Thesis, Department of Earth Sciences, University of Waterloo, 1999.

[280] Schäfer D, Schäfer W, Kinzelbach W. Simulation of processes related to biodegradation of aquifers -2 . Model application to a column study on organic carbon degradation. J Contam Hydrol 1998;31(1-2):187-209.

[281] Schäfer W. Predicting natural attenuation of xylene in groundwater using a numerical model. J Contam Hydrol 2001;52(14):57-83.

[282] Schäfer D, Schäfer W, Kinzelbach W. Simulation of processes related to biodegradation of aquifers-1. Structure of the 3D transport model. J Contam Hydrol 1998;31(1-2):167-86.

[283] Yeh G-T, Salvage KM, Gwo JP, Zachara JM, Szecsody JE. HydroBioGeoChem: A coupled model of hydrologic transport and mixed biogeochemical kinetic/equilibrium reactions in saturated-unsaturated media. Technical Report ORNLTM-13668. Oak Ridge, TN: Oak Ridge National Laboratory: 1998.

[284] Salvage KM. Reactive Contaminant Transport in Variably Saturated Porous Media: Biogeochemical Model Development, Verification, and Application. PhD Thesis, Department of Civil and Environmental Engineering, The Pennsylvania State University, University Park, PA 16802, 1998.

[285] Salvage KM, Yeh GT. Development and application of a numerical model of kinetic and equilibrium microbiological and geochemical reactions BIOKEMOD. J Hydrol 1998;209(1-4):2752.

[286] Rittmann BE. The significance of biofilms in porous media. Water Resour Res 1993;29(7):2195-202.

[287] Characklis WG, Marshall KC, editors. Biofilms. Wiley series in Ecological and Applied Microbiology. New York: John Wiley \& Sons, Inc; 1990.

[288] Brock TD, Madigan MT, Martinko JM, Parker J. Biology of microorganisms. 7th ed. Englewood Cliffs, NJ: Prentice Hall International; 1994

[289] Edwards EA, Wills LE, Reinhard M, Grbic-Galic D. Anaerobic degradation of toluene and xylene by aquifer microorganisms under sulfate-reducing conditions. Appl Environ Microbiol 1992:58(3):794-800.

[290] Rifai HS, Bedient PB, Borden RC, Haasbeek JF. BIOPLUME II, Computer model of two-dimensional contaminant transport under the influence of oxygen limited biodegradation in ground water. In: Technical report. Houston, TX: Rice University; 1987.

[291] Rifai HS, Bedient PB, Wilson JT, Miller KM, Armstrong JM. Biodegradation modeling at aviation fuel spill site. ASCE J Environ Eng 1988;114(5):1007-29.

[292] Kindred JS, Celia MA. Contaminant transport and biodegradation. 2. Conceptual model and test simulation. Water Resour Res 1989:25(6):1149-60.
[293] Prommer H, Barry DA, Davis GB. A one-dimensional reactive multi-component transport model for biodegradation of petroleum hydrocarbons in groundwater. Environ Modell Software 1999; 14(2-3):213-23.

[294] Prommer H, Barry DA, Davis GB. Groundwater remediation assessment using biogeochemical transport modelling. In: Forde MC, editor. Polluted + marginal land-98, Proceedings of Fifth International Conference on Re-Use of Contaminated Land and Landfills. Brunel University, London, United Kingdom. Edinburgh: Engineering Technics Press; 1998. p. 177-90.

[295] Prommer H, Davis GB, Barry DA. Biogeochemical transport modelling of natural and enhanced remediation processes in aquifers. Land Contaminat Reclamat 2000;8(3):217-23.

[296] Johnson SJ, Woolhouse KJ, Prommer H. Barry DA, Christofi N. Contribution of anaerobic microbial activity to natural attenuation of the ' $\mathrm{B}$ ' in BTEX. In: Yong RN, Thomas HR, editors. Geoenvironmental engineering, geoenvironmental impact management. London: Thomas Telford Publishing; 2001. p. 300-6.

[297] Coates JD, Chakraborty R, Lack JG, O'Connor SM, Cole KA, Bender KS, et al. Anaerobic benzene oxidation coupled to nitrate reduction in pure culture by two strains of dechloromonas. Nature 2001;411(6841):1039-43.

[298] Lu G, Clement TC, Zheng C, Wiedemeier TH. Natural attenuation of BTEX compounds: Model development and field-scale application. Ground Water 1999;37(5):707-17.

[299] Van Cappellen P, Gaillard J-F, Rabouille C. Biogeochemical transformations in sediments: Kinetic models of early diagenesis. In: Wollast R, Mackenzie FT, Chou L, editors. Interactions of C, N, P and S-Biogeochemical cycles and global change. Berlin: Springer-Verlag: 1993. p. 401-45.

[300] Christensen TH, Bjerg PL, Kjeldsen P. Natural remediation: A feasible approach to remediation of ground water pollution at landfills? Ground Water Monitor Remediat 2000;20(1):69-77.

[301] Dobbins DC, Aelion CM. Pfaender F. Subsurface, terrestrial microbial ecology and biodegradation of organic chemicals - A review. Critic Rev Environ Control 1992;22(1-2):67-136.

[302] Bekins B, Rittmann BE, MacDonald JA. Natural attenuation strategy for groundwater cleanup focuses on demonstrating cause and effect. EOS, Trans, Am Geophys Union 2001;82(5):53-8.

[303] Brun A, Engesgaard P, Christensen TH, Rosbjerg D. Modelling of transport and biogeochemical processes in pollution plumes: Vejen landfill, Denmark. J Hydrol 2002;256(3-4):228-47.

[304] Nyer E, Lenzo F, Burdick J. In situ reactive zones: Dehalogenation of chlorinated hydrocarbons. Ground Water Monitor Rev 1998;18(2):68-72.

[305] Ellis DE, Lutz EJ, Odom JM, Buchanan RJ, Bartlett CL, Lee MD, et al. Bioaugmentation for accelerated in situ anaerobic bioremediation. Environ Sci Technol 2000;34(11):2254 60 .

[306] Nyer EK, Suthersan S. In situ reactive zones. Ground Water Monitor Rev 1996;16(3):70-5.

[307] Cirpka OA, Kitanidis PK. Travel-time based model of bioremediation using circulation wells. Ground Water 2001;39(3):422-32.

[308] Bajracharya K, Barry DA. MCMFIT: Efficient optimal fitting of a generalized nonlinear advection-dispersion model to experimental data. Comput Geosci 1995;21(1):61-76.

[309] Li L, Barry DA, Morris J, Stagnitti F. CXTANNEAL: An improved program for estimating solute transport parameters. Environ Modell Software 1999;14(6):607-11.

[310] Marryott RA, Dougherty DE, Stollar RL. Optimal groundwater management. 2. Application of simulated annealing to a fieldscale contamination site. Water Resour Res 1993;29(4):847-60.

[311] McKinney DC, Gates GB, Lin MD. Groundwater resource management models: A comparison of genetic algorithms and nonlinear programming. In: Peters A, Wittum G, Herrling B, Meissner U, Brebbia CA, Gray WG. Pinder GF, editors. Computational methods in water resources X, vol. 2. Dordrecht, The Netherlands: Kluwer Academic Publishers; 1994. p. 859-66. 
[312] McKinney DC, Lin M-D. Genetic algorithm solution of groundwater management models. Water Resour Res 1994;30(6):1897906.
[313] Minsker BS, Shoemaker CA. Dynamic optimal control of in situ bioremediation of ground water. ASCE J Water Resour Plann Mgmt 1998;124(3):149-61. 